\title{
The use and effectiveness of analytical review in auditing : a field study
}

Citation for published version (APA):

Eimers, P. W. A. (2002). The use and effectiveness of analytical review in auditing : a field study.

[Doctoral Thesis, Maastricht University]. Universiteit Maastricht. https://doi.org/10.26481/dis.20020913pe

Document status and date:

Published: 01/01/2002

DOI:

10.26481/dis.20020913pe

Document Version:

Publisher's PDF, also known as Version of record

\section{Please check the document version of this publication:}

- A submitted manuscript is the version of the article upon submission and before peer-review. There can be important differences between the submitted version and the official published version of record.

People interested in the research are advised to contact the author for the final version of the publication, or visit the DOI to the publisher's website.

- The final author version and the galley proof are versions of the publication after peer review.

- The final published version features the final layout of the paper including the volume, issue and page numbers.

Link to publication

\footnotetext{
General rights rights.

- You may freely distribute the URL identifying the publication in the public portal. please follow below link for the End User Agreement:

www.umlib.nl/taverne-license

Take down policy

If you believe that this document breaches copyright please contact us at:

repository@maastrichtuniversity.nl

providing details and we will investigate your claim.
}

Copyright and moral rights for the publications made accessible in the public portal are retained by the authors and/or other copyright owners and it is a condition of accessing publications that users recognise and abide by the legal requirements associated with these

- Users may download and print one copy of any publication from the public portal for the purpose of private study or research.

- You may not further distribute the material or use it for any profit-making activity or commercial gain

If the publication is distributed under the terms of Article $25 \mathrm{fa}$ of the Dutch Copyright Act, indicated by the "Taverne" license above, 


\title{
THE USE AND EFFECTIVENESS OF ANALYTICAL REVIEW
}

\section{IN AUditing}

\author{
A field study
}


Peter W.A. Eimers, Doorn 2002

ISBN 90-9016037-X

Druk: Datawyse/Universitaire Pers Maastricht 


\title{
The USE AND EFFectiveness of ANALYTICAL REVIEW IN AUDITING
}

\author{
A field study
}

\section{PROEFSCHRIFT}

ter verkrijging van de graad van doctor aan de Universiteit Maastricht, op gezag van de Rector Magnificus, Prof.dr. A.C. Nieuwenhuijzen Kruseman volgens het besluit van het College van Decanen, in het openbaar te verdedigen op vrijdag 13 september 2002 om 14.00 uur

door

PIETER WILLEM ARIE EIMERS 


\section{PROMOTORES:}

Prof. Dr. S.J. Maijoor

Prof. Dr. T.J. Mock

Prof. J.C.A. Gortemaker RA (Erasmus Universiteit Rotterdam)

\section{BEOORDELINGSCOMMISSIE:}

Prof. Dr. E.H.J.Vaassen (voorzitter)

Prof. Dr. W.F.J. Buijink (Katholieke Universiteit Brabant)

Prof. Dr. R.J.M. Dassen RA

Prof. Dr. Ph. Wallage RA (Universiteit van Amsterdam) 


\section{ACKNOWLEDGEMENTS}

People say "A man's life can only be all-inclusive when having finalized three topics: (1) beget a child, (2) raise a tree, and (3) write a book". With the completion of this thesis, the trilogy that started 10 years ago has been finalized. The first two elements of this trilogy were completed some time ago. With pleasure, I can now observe that the third element has been completed. All in all, the completion time of writing this thesis has totaled 7 years, with frequent periods of working on other (client) projects. Many times, the combination of working as a practitioner in a challenging client environment, working on the research project, and having a family life necessitated significant flexibility and time management from my family and myself. Without doubt, the completion time could have been shortened, but this would have affected family and career for sure.

Many persons were very important during this research project. These persons can be categorized as 'coaches', 'facilitators', and 'supporters'.

With respect to the coaches, Steven Maijoor was the person who continuously expressed his trust in this project and continued to emphasize that this type of research has the great opportunity of adding value to theory as well as practice. He was a stimulating coach with an ongoing focus on the methodological aspects of the research. The absence of any formal research appointment with the Maastricht Accounting and Auditing Research and Education Center made our relationship special.

I thank Ted Mock for his affirmative and methodological way of commenting on the many draft versions of the thesis. I especially thank him for his invitation to set up a literature study in 1996 for two months at the University of Southern California, Los Angeles. Sabine and I are still looking back with nostalgia about the campus life at USC, far away from the daily client environment.

I thank Hans Gortemaker for his valuable contributions with respect to the professional standards and his key role in the involvement of PricewaterhouseCoopers in the Netherlands while collecting the field data. In particular, his involvement was of great importance for the acceptance of this lengthy project along with my client work.

I thank Eddy Vaassen, Willem Buijink, Roger Dassen and Philip Wallage for their comments when reviewing the final manuscript. 
With respect to the facilitators, PricewaterhouseCoopers made it possible that I could spend substantial efforts in both professional and intellectual development during a long period and with uncertain outcomes. In this respect, 'employer of choice' was operationalized even before PwC included thesis projects as part of its employment strategy.

Many colleagues were involved during this research project. First of all, Jaap van Wijck, the former Business Unit Leader of the Maastricht Office, had the courage to include a research clause in my employment contract when I entered the firm in 1992. Special thanks also to Peter Tieleman, who challenged me to deliver always the best quality in all aspects of life.

Many thanks to all colleagues who were engaged in the data collection process. Specially, the 149 PwC practitioners who completed the audit file questionnaire. Without all of you, this book could have never been completed!

Miranda Oplaat entered the data in a database. Melis Visser collated the final manuscript. As always, he signaled errors that nobody had identified before!

Research friends at Universiteit Maastricht functioned as a belp desk concerning statistical issues. I specifically mention Roger Meuwissen, Caren Schelleman and Frank Moers.

Finally, I would thank all my supporters. Your warm support and human conversions on the matters that actually kept me busy encouraged me to insist on continuing this project and deliver the current output! My daughter Jasmijn is acknowledged for her encouraging remarks, one of which was "daddy, go upstairs now, and finalize your book!"

The greatest acknowledgement is without doubt to my wife Sabine, who had to live with a husband with a strong, but uncertain and moving goal. I admit, you won our bet on who became the first 'doc' in the family. Your support meant more for me than a man can ever express!

Peter W.A. Eimers

Doorn, summer 2002 


\section{Contents}

1 INTRODUCTION

$\begin{array}{lll}1.1 & \text { THE RELEVANCE OF ANALYTICAL REVIEW } & 10\end{array}$

1.2 ANALYTICAL REVIEW, EFFICIENCY AND EFFECTIVENESS

1.3 THE RELEVANCE AND CONTRIBUTION OF ANAL YTICAL REVIEW RESEARCH TO AUDIT PRACTICE

$\begin{array}{llr}1.4 & \text { RESEARCH QUESTIONS } & 18\end{array}$

$\begin{array}{ll}1.5 & \text { RESEARCH CONTRIBUTIONS } \\ \end{array}$

$\begin{array}{lll}1.6 & \text { OUTLINE OF THIS THESIS } & 21\end{array}$

2 THE USE AND EFFECTIVENESS OF ANALYTICAL REVIEW:

A LITERATURE REVIEW

$\begin{array}{lll}2.1 & \text { INTRODUCTION } & 22\end{array}$

2.2 AUDIT PLANNING DECISIONS AND ANALYTICAL. REVIEW 23

2.3 ANALYTICAL REVIEW AS A DECISION-MAKING PROCESS

2.4 CONTINGENT VARIABLES RELATED TO ANALYTICAL. REVIEW 31

2.4.1 Introduction 3I

2.4.2 Contingent variable on audit efficiency: Cumulative knowledge of the client 34

2.4.3 Contingent variable on audit efficiency: Risk assessments 36

2.4.4 Contingent variable on analytical review effectiveness:

Developing expectations $\quad 40$

$\begin{array}{lll}2.5 & \text { SUMMARY } & 47\end{array}$

3 DEVELOPMENT OF DETAILED RESEARCH QUESTIONS 49

$\begin{array}{lll}3.1 & \text { INTRODUCTION } & 49\end{array}$

3.2 MEASUREMENT OF ERROR SIGNALING AND ERROR DETECTION BY

ANALYTICAL REVIEW

3.2.1 Introduction 51

3.2.2 Type I and type II errors related to error signaling and error detection 54

3.2.3 The signaling ratio $\quad 55$

3.2.4 The non-signaling ratio 56

3.2.5 The non-detection ratio $\quad 59$

3.3 DEVELOPMENT OF RESEARCH QUESTIONS

3.3.1 Introduction 61

3.3.2 Research questions on the contribution of analytical review in error signaling 62

3.3.3 Research questions on audit efficiency 66

3.3.4 Research question on analytical review effectiveness $\quad 67$

3.3.5 Introduction of a control variable: prefinal audit procedures 68

$\begin{array}{lll}3.4 & \text { SUMMARY } & 68\end{array}$ 
$\begin{array}{lll}4.1 & \text { INTRODUCTION } & 70\end{array}$

4.2 SAMPLE $\quad 70$

4.2.1 The audit firm 70

$\begin{array}{lll}4.2 .2 & \text { Country } & 71\end{array}$

4.2.3 Electronic archives 71

4.3 SAMPLING METHOD AND DATA QUALITY CONSIDERATIONS

4.4 SAMPLE-SIZE CONSIDERATIONS $\quad 72$

4.4.1 Introduction $\quad 72$

4.4.2 Sample size considerations 73

4.5 SElection STRATEGY

$\begin{array}{ll}4.6 & \text { THE QUESTIONNAIRE }\end{array}$

4.6.1 Structure $\quad 76$

4.6.2 Language 76

4.6.3 Definitions and measurement

4.6.4 Pilot test 79

4.7 SAMPLE SIZE AND RESPONSE RATE $\quad 79$

$\begin{array}{lll}4.8 & \text { SUMMARY } & 80\end{array}$

5 DESCRIPTIVE STATISTICS $\quad 81$

$\begin{array}{lll}5.1 & \text { INTRODUCTION } & 81\end{array}$

5.2 Client CHARACTERISTICS

5.2.1 Summary financial data $\quad 81$

5.2.2 Cumulative knowledge $\quad 83$

$5.2 .3 \quad$ Risk assessments $\quad 84$

5.2.4 Prefinal audit procedures $\quad 88$

5.3 ERROR CHARACTERISTICS $\quad 89$

5.3.1 Number of errors and their follow-up $\quad 89$

5.3.2 Summarized error statistics per audit area 91

5.3.3 Effect of errors on earnings 93

5.3.4 Assessment of the error cause $\quad 94$

5.4 ANALYTICAL REVIEW 96

5.4.1 Introduction 96

5.4.2 Relative contribution of analytical review in error signaling 97

5.4.3 Cumulative knowledge and analytical review 103

5.4.4 Risk assessments and analytical review 105

5.4.5 Summary 106

5.5 UNIVARIATE ANALYSES OF THE RESEARCH QUESTIONS 107

5.5.1 Introduction 107

5.5.2 Independent variables on the signaling ratio and the non-signaling ratio 108

5.5.3 Univariate analyses on the contribution of analytical review in error signaling 109 
5.5.4 Univariate analysis on audit efficiency 111

5.5.5 Univariate analysis on analytical review effectiveness $\quad 116$

$\begin{array}{lll}5.6 & \text { SUMMARY } & 119\end{array}$

6 MULTIVARIATE ANALYSES OF THE RESEARCH QUESTIONS 121

$\begin{array}{llr}6.1 & \text { INTRODUCTION } & 121\end{array}$

6.2 THE CONTRIBUTION OF ANALYTICAL REVIEW IN ERROR SIGNALING

6.2.1 Introduction $\quad 121$

$\begin{array}{ll}6.2 .2 & \text { Multivariate results } \\ 6 & 123\end{array}$

6.2.3 Concluding remarks $\quad 125$

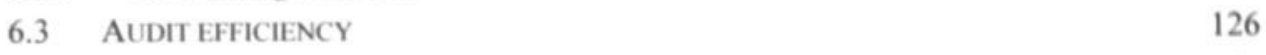

$\begin{array}{lll}6.3 .1 & \text { Introduction } & 126\end{array}$

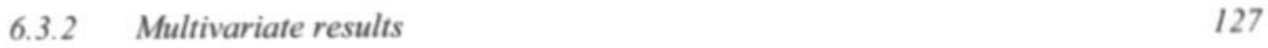

6.3.3 Concluding remarks $\quad 129$

$\begin{array}{lll}6.4 & \text { SUMMARY } & 130\end{array}$

7 SUMMARY AND CONCLUSIONS $\quad 134$

$\begin{array}{llr}7.1 & \text { INTRODUCTION } & 134\end{array}$

$\begin{array}{llr}7.2 & \text { SUMMARY } & 134\end{array}$

$\begin{array}{llr}7.3 & \text { DISCUSSION OF RESULTS } & 138\end{array}$

$\begin{array}{ll}7.3 .1 & \text { Implications for practice } \\ 7.3 .2 & 138\end{array}$

7.3.2 Strengths and weaknesses $\quad 140$

7.3.3 Suggestions for further research 144

7.4 Closing REMARKS $\quad 145$

APPENDIX A: ASSESSMENT OF CONTROL ENVIRONMENT ASPECTS 147

APPENDIX B: QUESTIONNAIRE $\quad 148$

$\begin{array}{lr}\text { REFERENCES } & 169\end{array}$

SUMMARY IN DUTCH (NEDERLANDSE SAMENVATTING) 175

$\begin{array}{lr}\text { CURRICULUM VITAE } & 181\end{array}$ 


\section{INTRODUCTION}

\subsection{The relevance of analytical review ${ }^{\prime}$}

This thesis deals with the contribution of analytical review to audit efficiency as well as analytical review effectiveness. Selecting analytical review as a topic for a thesis in the field of auditing is not without reason. In the past decades the attention on analytical review as an audit procedure has increased and has never lost the attention of practitioners and researchers.

The underlying premise of the continuing attention on analytical review is the fact that analytical review is largely considered as an audit procedure that has signaling power (effectiveness aspect) as well as an audit procedure that is rather cost-effective (efficiency aspect). Improving the understanding of the analytical review process may help auditors improve analytical review effectiveness as well as audit efficiency and audit effectiveness.

In the 1980's and 1990's, attention on analytical review was related to the ongoing audit fee pressures that motivated audit firms to structure their audits efficiently, without loosing audit effectiveness. Recently, the Public Oversight Board in the United Stated published a report on audit effectiveness (Panel On Audit Effectiveness, 2000, hereafter: 'POAE' or the 'Panel'). 'The Panel was

' The terms 'analytical review' and 'analytical procedures' are both used in the audit literature. In this thesis the term analytical review will be used in favor of analytical procedures in order to reflect that this audit procedure is a decision-making process rather than a technical procedure. 'Analytical review' is defined as the diagnostic process of identifying, investigating, and resolving unexpected fluctuations (Koonce, 1993). 'Analytical procedures' in contrast is a narrower concept and refers to the analysis of significant ratios and trends including the resulting investigation of fluctuations and relationships that are inconsistent with other relevant information or deviate from predicted amounts (IFAC, ISA 520). The reader will observe the term 'analytical procedures' in this thesis when referring to prior publications in audit research or professional standards. Additionally, the term 'analytical review procedures' is used for specific procedures as part of analytical review, such as ratio analysis, comparison with industry, and regression analysis. 
charged with the responsibility to review and evaluate how independent audits of financial statements of public companies are performed and assess whether recent trends in audit practices are in the public interest" (POAE, 2000, page xi). In the POAE publication, the Panel confirms the contribution of analytical review to audit effectiveness, with its attention for analytical review as a relevant topic in the discussion of audit effectiveness.

The Panel underlined the significant contribution of analytical review to the effectiveness of the audit, but stressed the need for providing specific guidance to auditors when performing analytical review:

'The Panel noted that the degree of specificity in audit firms' methodologies and their guidance on applying those methodologies varies significantly. It also appears to the Panel that a gap exists between (a) what is available in the firms' audit methodologies, Professional Standards, and other guidance materials and (b) what actually transpires in practice.

The gap closes and the analytical procedures are more effective if a firm's audit methodology contains clear and unequivocal guidance requiring the appropriate use of analytical procedures in different circumstances (including guidance on the characteristics of the data to be used, establishing expectations, setting precision levels, employing explicit materiality thresholds, deciding on the desired levels of assurance, and resolving differences). In addition to guidance materials and methodology, training auditors in the effective use of analytical procedures by using 'real-life, practical, how-to' cases would appear to be invaluable".

Source: POAE (2000), section 2.117

This quote indicates a strong need for standard setting bodies and audit firms to provide more guidance to auditors, and also urges the need for field data describing the context in which analytical review is performed. Specifically, guidance is requested on the characteristics of the data used in analytical review. These characteristics include the nature, size and extent of errors identified during the audit and the risk profile of the client and its activities.

Analytical review is one of several types of audit procedures the auditor can use during the audit. The auditor selects the nature, timing and extent of audit procedures to be used based on professional judgment while using the basic requirements as provided in the professional standards. For instance, the professional standards require auditors to develop an audit strategy setting the nature, timing and extent of planned audit procedures. When preparing the audit program, the auditor considers the specific assessments of inherent risk and 
control risk. Analytical review in the planning stage is specifically aimed at understanding the business and identifying potential risks. Based on an assessment of inherent risk and control risk, the auditor plans the nature, timing and extent of the audit procedures to be used.

Also, during planning, performing and evaluation of the audit, the auditor considers the risk of material misstatements in the financial statements resulting from fraud or error. According to ISA No. 240 (par. 3), the term 'fraud' refers to an intentional act by one or more individuals among management, employees or third parties, which results in a misrepresentation of the financial statements. The term 'error' refers to unintentional mistakes in the financial statements (ISA No. 240, par. 4).

Based on the risk assessment, the auditor should design audit procedures to obtain reasonable assurance that misstatements arising from fraud and error that are material to the financial statements as a whole, are detected. In this thesis, a misstatement is considered to be an 'error', irrespective whether it is intentional (fraud) or unintentional (error). Potential limitations to this approach will be discussed in chapter 7 .

Previous research has shown that analytical review is an important procedure for identifying errors in financial statements. Wright and Ashton (1989) reported that simple audit procedures are important for the identification of the majority of errors in financial statements. They found that half of the errors were identified by three types of attention-directing audit procedures, specifically comparison of the current year with prior year balances, review of prior year's audit findings, and client inquiry (efficiency aspect). The participants in the Wright and Ashton study indicated that analytical review would likely have signaled many errors whereas some other audit procedures had not (effectiveness aspect). Therefore, increased effort in analytical review may contribute to the improvement of audit efficiency as well as audit effectiveness.

Although the focus by the professional standards on analytical review is largely on the technique of the procedure (see footnote 1 in this chapter), analytical review can also be considered as a decision making process. Audit researchers have established a long stream of publications on the auditors' decision-making process. Importantly, the elements within this process may prevent the auditor from an effective use of analytical review. For instance, previous research findings recommend that auditors develop their own expectations before reviewing unaudited book values, and develop their own explanations before consulting management, in order to increase analytical review effectiveness and audit efficiency (see e.g. Bell and Wright, 1995 and Eimers, Biggs and Mock, 1997). Hirst and Koonce (1996) contributed to the audit researchers' understanding of the audit process by reporting on interviews 
with practitioners. These interviews were focused on how analytical review is used in audit practice.

Corroborative findings on the importance of independent development of expectations during analytical review come from the Panel On Audit Effectiveness (POAE, 2000). The Panel performed a quasi-peer review on a number of audit engagements and observed that, in general, analytical review used in the planning stage is performed appropriately and contributes effectively to the audit strategy. In contrast, less encouraging observations were reported on analytical review when used during the final stage of the audit and during substantive testing. For instance, the Panel observed that analytical review was not effective as the primary procedure when "expectations were not properly developed, ... explanations were not corroborated, and the documentation was not adequate" (POAE, par. 2.116). All in all, the Panel concluded that the effectiveness of analytical review needs improvement.

\subsection{Analytical review, efficiency and effectiveness}

As discussed, analytical review is considered to be an audit procedure which involves relatively low costs, and which is potentially quite effective (Wright and Ashton, 1989; Eimers, Biggs and Mock, 1997). In other words, if analytical review is used properly, analytical review is used effectively and contributes to an efficient and effective audit simultaneously.

In contrast, if analytical review is used improperly, analytical review is not effective in identifying errors, with two potential consequences. Firstly, the audit looses efficiency if the errors are identified by an alternative, more costly audit procedure. Secondly, if the error is not detected by subsequent audit procedures, the audit is ineffective. These situations are addressed in figure 1.1.

The concepts of efficiency and effectiveness can be explained using three stages as follows. Firstly, consider all errors in the draft financial statements (area 1 in figure 1.1). An unknown number of errors are not assessed ('detected') (area 1a) partly due to the auditor's acceptance of detection risk as part of the audit risk model (see section 2.2 in chapter 2). If errors that are not detected could have been identified ('signaled') by analytical review, then audit effectiveness and analytical review effectiveness ([A] in figure 1.1) could be improved. Note that this opportunity is to be considered in the context of the assessment of audit materiality (ISA No. 320). As the auditor accepts the non-detection of immaterial errors, the concept of increasing audit effectiveness for errors that are not material, is not expected to be an opportunity for practice. 
Secondly, for errors signaled with more extensive audit procedures (area 1b1), identification by analytical review improves audit efficiency ([B] in figure $1.1)$, based on the premise that using analytical review is cost-effective.

Thirdly, unexpected fluctuations in the figures initially signaled by analytical review might not be assessed as an error immediately, if somewhere in the decision making process of analytical review the auditor incorrectly concludes that the unexpected fluctuation has a non-error cause. If the error nevertheless has been detected sequentially in the audit by an alternative audit procedure (area 1b21), the auditor may have spent too much time during the audit for the error assessment. In that case, analytical review effectiveness ([C] in figure 1.1) as well as audit efficiency ([B] in figure 1.1) can be improved. Note that the concepts of error identification ('error signaling') and final assessment ('error detection') are extensively addressed in section 3.2 of this thesis.

In this thesis, both the topics on improving audit efficiency by using analytical review in favor of more extensive procedures, as well as analytical review effectiveness are addressed. The inherent limitations of a field study imply that addressing the potential improvement of audit effectiveness can not be covered due to the absence of field data on errors that are not detected by the auditor.

In order to test the contribution of analytical review to audit efficiency and analytical review effectiveness, these concepts are operationalized as follows: audit efficiency is operationalized by the concept of the contribution of analytical review in error signaling. Analytical review effectiveness is operationalized by error detection by analytical review. These concepts will be elaborated in chapter 3. Limitations to these definitions are addressed in section 7.3.2.2. 
Figure 1.1: The concepts of efficiency and effectiveness related to analytical review

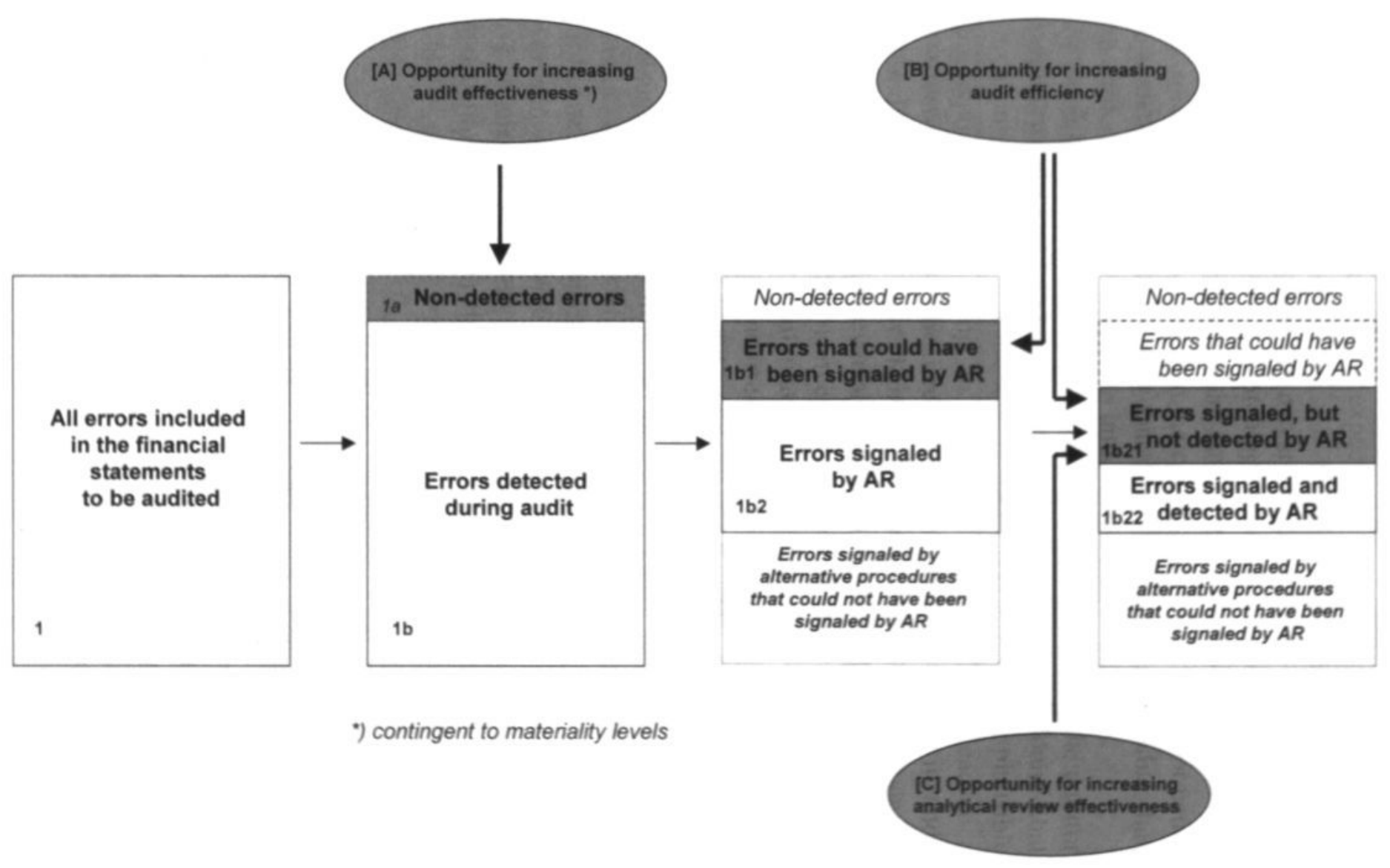


16 ChApter 1

\subsection{The relevance and contribution of analytical review research to audit practice}

The continuing and strong need of audit practice for improving the effectiveness and efficiency of the audit process has stimulated audit researchers to search for potential contributions concerning analytical review. Researchers are anxious to perform research aimed at contributing to audit practice, as expressed by Ashton and Ashton (1995, p 25):

"The challenge of the field today is to identify important topics and to apply rigorous research methods to them in ways that preserve the technical, organizational, economic, and institutional features that make them important to the accountants and auditors who perform them and to the people who rely on the results".

Communicative efforts by researchers and audit education contribute to enlarging the understanding of practitioners for the added value of audit research. An example of communicative efforts is the joint AICPA/AAA Auditing Section publication Auditing Practice, Research, and Education: A Productive Collaboration (in: Bell and Wright eds., 1995). In this publication, researchers present - among other research areas - the state of the art of analytical review research and the implications of its findings for audit practice. One important recommendation for practice is: "Auditors should develop their own expectations before reviewing unaudited book values and their own explanations before consulting management" (Biggs, Mock and Watkins, 1995, p. 142). This recommendation is based on a stream of analytical review research that is focused on the potential bias of unaudited book values and client representations during the decision making process of analytical review. Based partly on the recommendations by researchers, the Auditing Standards Board in the United States adapted the professional standard on analytical review accordingly (SAS 56, AU 329.05). The AICPA instructed auditors with guidance on how the expectations should be considered:

"An expectation (...) might be considered independent and reliable if they are consistent with current business conditions and not subject to influence or manipulation by persons involved in the accounting functions related to the account balance being tested" (AICPA, 1998)

Despite the seemingly reasonableness of the recommendation for practice, it is still unclear how the auditor should develop his expectations. In the POAE publication (POAE, 2000), the Panel stressed the need for more practical guidance to auditors on how to develop expectations. In addition, the Panel 
stressed the need for specific guidance on related areas, which are shown in the following box:

"The Panel recommends that audit firms:

Ensure that their audit methodologies provide definitive guidance on analytical procedures.

At a minimum, specific guidance should be provided in the following areas:

Developing expectations

Characteristics and reliability of different types of data (...)

Relating control risk assessments to the objectives of analytical procedures

Considering the role of account-level or assertion-level risk assessments (e.g. low risk versus high risk assessments) in designing analytical procedures (...)

Identifying, investigating and evaluating the results of analytical procedures (including corroborating the responses to inquiries) (...)"

Source: POAE (2000), section 2.119

A major constraint of previous research on developing one's own expectations is the fact that most previous research was based on experimental settings and therefore the external validity may be limited for two important reasons. Firstly, the research findings on unaudited book values are almost all based on the same simple data set and only one research method (Kinney and Uecker, 1982; Biggs and Wild, 1985; Heintz and White, 1989; Heintz, White and Bedard, 1997). In addition, each of the experiments is based on a task that is rather unrealistic in a field setting (see section 2.4).

Secondly, research regarding client representations is mainly focused on the potential negative influence of client representations, without paying appropriate attention to contingent circumstances, which may decrease the risk of a poor client representation. For instance, if a client officer is highly competent, the risk of obtaining a poor representation may decrease. In this context, 'poor' is defined as a biased or insufficient representation. Bedard and Biggs (1991a and 1991b), Bedard, Biggs and DiPietro (1998) and Bierstaker, Bedard and Biggs (1999) all used the same experimental case-setting, without manipulating contingent factors that might mitigate the suggested negative influence on performance.

The previous examples of research on unaudited book values and client representations indicate that the related research findings may have limited external validity. In order to assess the generalizability of the experimental findings on analytical review, corroborative tests are needed in a field setting. In 
$18 \mid$ Chapter 1

this thesis, further evidence is gathered on the effect of developing expectations by the auditor and its effects on analytical review effectiveness.

\subsection{Research questions}

The notion in the preceding sections that analytical review is considered to be an important element for improving the effectiveness and efficiency of the audit process, gives rise to the general observation that analytical review research should focus on the current and potential role of analytical review in the audit process. This general observation leads to the following three primary research questions ('RQ's):

$R Q$ 1: How does analytical review contribute to error signaling?

$R Q$ 2: How does analytical review contribute to audit efficiency?

RQ 3: How does developing expectations affect analytical review effectiveness?

The first research question addresses the contribution of analytical review in error signaling and forms the starting point for the analyses concerning the second and third research questions. The need for a better understanding of the context in which analytical review is to be performed was discussed in section 1.2. There it was noted that the Panel on Audit Effectiveness (POAE, 2000) stressed that audit firms should ensure that their audit methodologies provide definitive guidance on analytical review. Investigating the context in which analytical review is performed (including the number and size of errors, the contribution of analytical review in the identification of errors and the contingent variables affecting the errors) is the first step in developing improved guidance for practice.

Professional standards stress the importance of using the cumulative knowledge of the client - including risk assessments - in the audit planning process. These variables are introduced as contingent variables in the current study and will be discussed further in chapter 2. Figure 1.2 visualizes the relationship between these contingent variables and analytical review in the audit planning process. Focusing on these contingent variables does not automatically imply that there are no additional contingent variables in place that may influence the contribution of analytical review in error signaling. This limitation in the current study is addressed in section 7.3.2.3. 
Figure 1.2: The relationship between cumulative knowledge and risk assessments with analytical review in the audit planning process

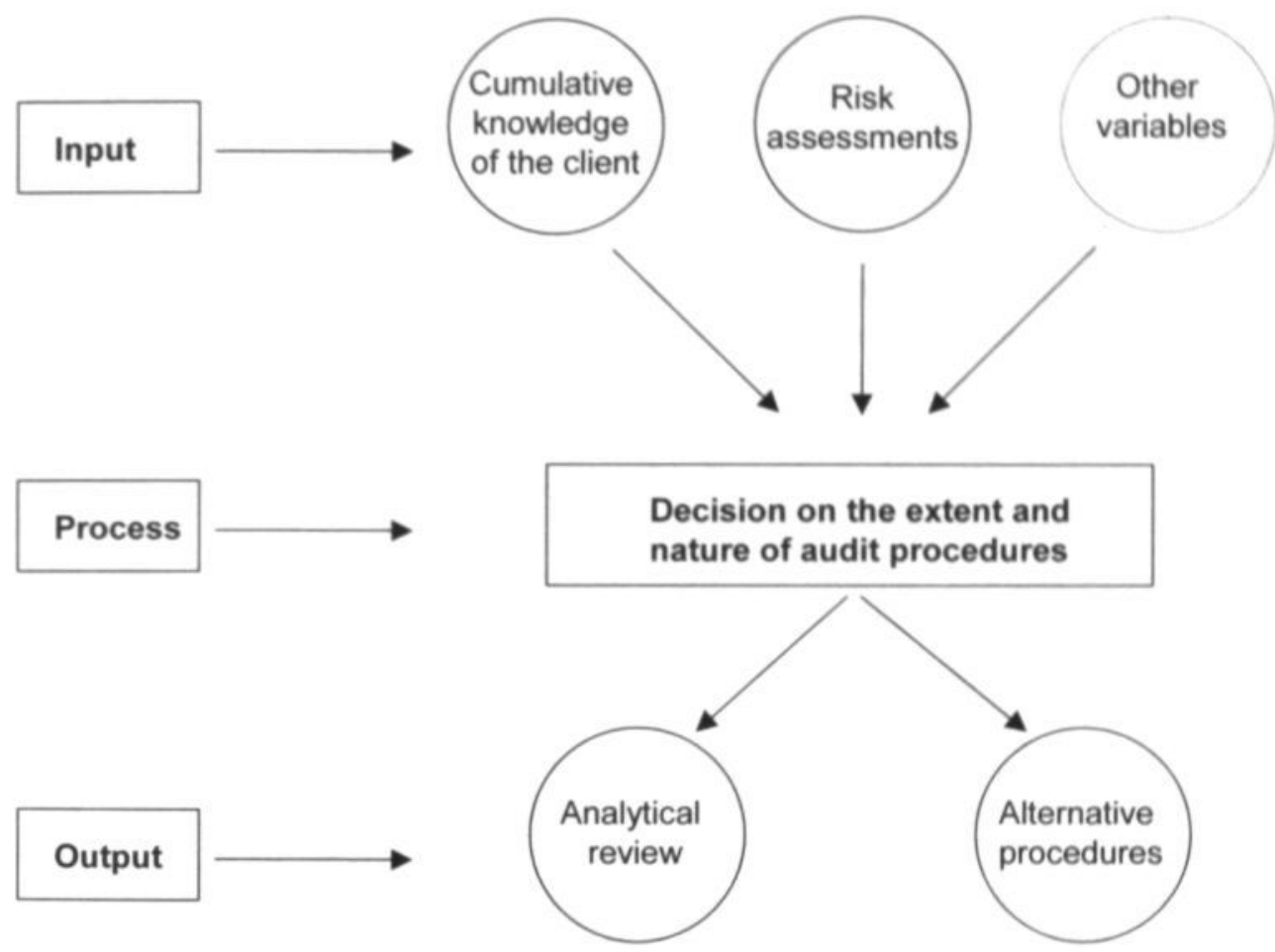

An important part of the contingent variables that are considered in this thesis relates to risk assessments, as these are the basis for the decision on the use of specific audit procedures. This decision making process of initial audit planning will be addressed in section 2.2 .

The second research question addresses the potential improvement of audit efficiency and relates to situations where an error could have been signaled by analytical review (area $1 \mathrm{bl}$ in figure 1.1). If analytical review could be used instead of alternative and more expensive procedures, audit efficiency can be improved. A basic premise for the auditor to use analytical review instead of alternative procedures is that he is aware which contingent factors may influence the existing error. It is expected that risk assessments are related to the frequency, nature and size of the error (POAE, 2000, section 2.119). Asare and Davidson (1995, page 14/15) found that "... the auditors' audit value/error expectations are sensitive to account-specific control risk. 
Consistent with the audit risk model ... expectations of errors were decreasing with stronger related control procedures".

The third research question addresses analytical review effectiveness and relates to situations where an error has been signaled by analytical review, but that for some reason, the auditor incorrectly concludes that the unexpected fluctuation has a non-error nature (area $1 \mathrm{~b} 21$ in figure 1.1). The notion that signaling the error does not automatically lead to error detection is based on previous research, which indicates that the analytical review process is a difficult task. As discussed in section 1.3, audit researchers have shown a number of potential causes for not detecting an error. Investigating the concepts of error signaling and error detection in a field setting contributes to our understanding of variables that may prevent the auditor from detecting the error directly after signaling the error by analytical review. Improving our understanding of the development of expectations in a field setting contributes to more practical guidance on how to develop expectations in the audit field.

All three primary research questions will be addressed in chapter 3 and will be elaborated with secondary research questions. The secondary research questions will be supported by an archival study, which is addressed beginning in chapter 4 .

\subsection{Research contributions}

The contribution of this study is related to audit research as well as audit practice. The main contribution for audit practice is to improve the auditor's understanding of the specific context in which analytical review is performed. Specifically, the current field study provides detailed error statistics in a field setting, including the number and size of errors, the audit procedures involved, and the ultimate follow-up of the error. Moreover, this study explores the contribution of analytical review in error signaling, contingent on cumulative knowledge of the client and risk assessments. Finally, items investigated in the current study address the call by the Panel On Audit Effectiveness for the improvement of guidance to auditors when performing analytical review.

The main contribution for audit research is the analysis of the previous research findings on analytical review in a field setting including the effects of risk assessments, cumulative knowledge and developing expectations. Further, the current study categorizes error identification into error signaling and error detection, resulting in the development of the 'signaling ratio', the 'nonsignaling ratio' and the 'non-detection ratio'. These ratios measure the contribution of analytical review in error signaling, the opportunity for improvement of audit efficiency and analytical review effectiveness 
respectively. The non-signaling ratio and the non-detection ratio can be used in future research projects as a measurement scale for the efficiency and effectiveness of audit procedures in general and analytical review in particular.

Finally, the research design of the current study contains important improvements of data quality as compared with prior archival studies in the audit area. Firstly, the files were archived electronically, whereas previous archive studies were based on paper files. Within the electronic archiving system, an audit trail can be observed starting from the final considerations with a reference to the audit procedures performed. Secondly, data quality is increased due to the fact that the researcher had direct access to the participants, whereas most researchers in previous studies did not have direct access for reasons of confidentiality. Direct contact with the participants enabled the researcher to request additional clarifications when specific replies were not clear.

\subsection{Outline of this thesis}

The remainder of this study is structured as follows. Chapter 2 is a literature review on the use and effectiveness of analytical review and forms the basis for the research questions in chapter 3. Note that this thesis focuses on the contribution of analytical review in signaling errors more than the use of analytical review in general. An important distinction between the contribution of analytical review in error signaling and its use in general is that the latter concept is broader than the former. Specifically, the purpose of analytical review can be twofold: the identification of an error as well as the indication that there is actually no error.

In order to introduce the concept of analytical review before addressing the contribution of this audit procedure in signaling errors, the next chapter starts with an outline of the use of analytical review as part of and following the initial audit planning decisions. In section 2.3 , the technique of analytical review is addressed, followed by an overview of the decision-making process of analytical review, and an overview of previous research findings on contingent variables in the analytical review context.

In Chapter 3, the primary research questions of section 1.4 are elaborated with secondary research questions. Chapter 4 deals with the research design of the field study. The descriptive statistics are provided in chapter 5 , followed by multivariate analyses of the research questions in chapter 6. This study is finalized with a summary of findings and conclusions in chapter 7 . 


\section{THE USE AND EFFECTIVENESS OF ANALYTICAL REVIEW: A LITERATURE REVIEW}

\subsection{Introduction}

As described in chapter 1, analytical review is an audit procedure with the potential of improving audit effectiveness as well as audit efficiency. Despite being a relatively simple technique, analytical review can also be characterized as an extensive and complex decision-making process. Decision-making models related to the audit process are extensively investigated for analytical review.

The auditor's decision-making process is applied in a field context that is dynamic and complex. The auditor uses professional judgment when using audit procedures in each contingent situation. Contingency, excerpted by "each situation is different", has been an important area for researchers in auditing and other fields of research. Considering relevant contingent variables, such as the outcome of risk assessments, improves our understanding of the decisionmaking process and might contribute to a more efficient and effective audit.

The purpose of this chapter is to form the basis for the development of the primary research questions on the contribution of analytical review in error signaling and the potential improvements for audit effectiveness and efficiency as introduced in section 1.4. The current chapter contains a literature overview of the use and effectiveness of analytical review by auditors, focusing on the technique, the decision-making process and contingent variables affecting this process. The International Standards on Auditing ('ISA') issued by the International Federation of Accountants ('IFAC') are used as a framework, as ISA is incorporated in the audit approaches of the Big Four audit firms. Specific reference is made to the respective paragraphs of ISA in brackets.

The next section starts with considering analytical review as an audit procedure in audit planning. This discussion is followed by an overview of analytical review as prescribed in the professional standards. Then, an overview of the analytical review decision-making process is presented. Contingent variables that are related to audit efficiency and analytical review effectiveness, are addressed in section 2.4 . Section 2.5 closes this chapter with a summary. 


\subsection{Audit planning decisions and analytical review}

The auditor's professional judgment on the nature, timing and extent of audit procedures is made during the planning stage of the audit. Audit evidence can be obtained by conducting one or more of the following procedures: inspection, observation, inquiry and confirmation, computation and analytical review (ISA No. 500, par. 19). The decision-making process related to the initial audit planning is depicted in figure 2.1 .

\section{Figure 2.1: The decision-making process of initial audit planning}

Source: ISA No. 300

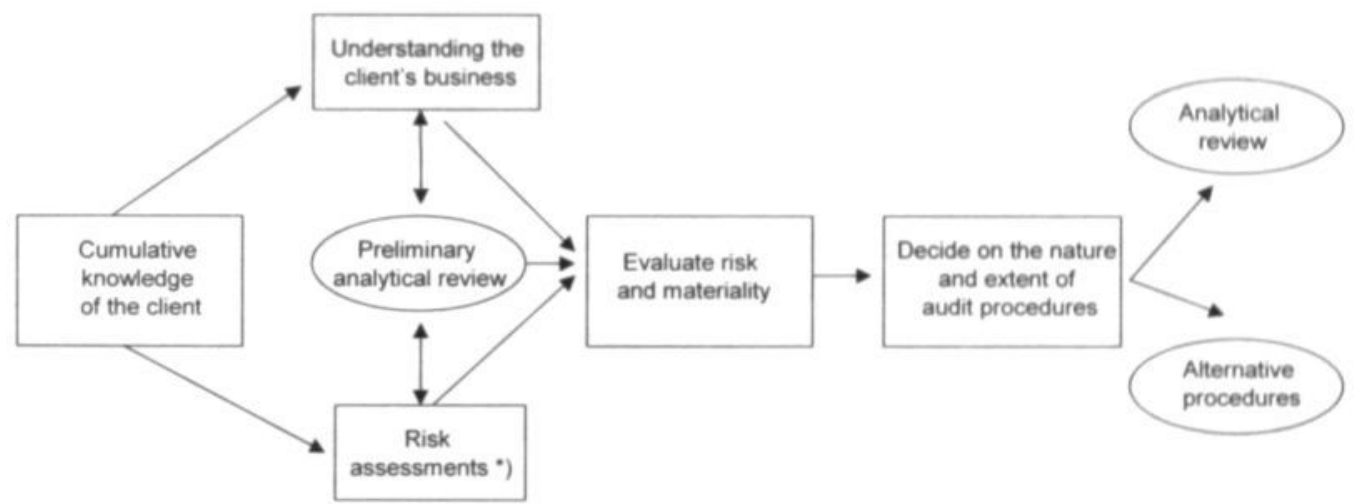

*)

- inherent and fraud risk

- control environment condition

- accounting and internal control system
Related Primary Research Questions (see chapter 3) :

RQ 1: How does analytical review contribute to error signaling?

RQ 2: How does analytical review contribute to audit efficiency?

Initial audit planning is aimed at ensuring that appropriate attention is devoted to important areas of the audit, that potential problems are identified and that the work is completed expeditiously (ISA No. 300, par. 4). During initial audit planning, preliminary analytical review is applied to assist the auditor in understanding the business and in identifying areas of potential risk.

The extent of planning will vary according to the size of the entity, the complexity of the audit and the auditor's experience with the entity and knowledge of the business (par. 5). Obtaining knowledge of the business is an important part of planning the work. The auditor's knowledge of the business assists in the identification of events, transactions and practices, which may have a material effect on the financial statements (par. 6). The auditor should develop 
and document an overall audit plan describing the expected scope and conduct of the audit. While the record of the overall audit plan needs to be sufficiently detailed to guide the development of the audit program, its precise form and content will vary depending on the size of the entity, the complexity of the audit and the specific methodology and technology used by the auditor (par. 8).

Matters to be considered by the auditor for developing the overall plan include (par. 9):

- Knowledge of the Business,

- Understanding the Accounting and Internal Control Systems,

- Risk and Materiality, with the consideration of the possibility of material misstatement, including the experience of past periods,

- Nature, Timing and Extent of Procedures.

In preparing the audit program, the auditor would consider the specific assessments of inherent and control risks and the required level of assurance to be provided by substantive procedures. The overall audit plan and the audit program should be revised as necessary during the course of the audit. Planning is continuous throughout the engagement because of changes in conditions or unexpected results of audit procedures (par. 12).

Once the auditor has decided on the nature and extent of audit procedures, analytical review is one of the alternatives. ISA No. 520 describes the technique of analytical review. Analytical review means the analysis of significant ratios and trends including the resulting investigation of fluctuations and relationships that are inconsistent with other relevant information or deviate from predicted amounts (ISA No. 520, par. 3).

Various methods may be used in performing analytical review. These vary from simple comparisons to complex analyses using advanced statistical techniques. Analytical review may be applied to consolidated financial statements, financial statements of components (such as subsidiaries, divisions or segments) and individual elements of financial information. The auditor's choice of procedures, methods and level of application is a matter of professional judgment (par. 6).

Analytical review is considered to be an important audit procedure, which is required by the professional standards in the planning stage and the overall review stage of each audit and may also be applied at other stages (par. 2). The application of analytical review is based on the expectation that relationships among data exist and continue in the absence of known conditions to the contrary. The presence of these relationships provides audit evidence as to the completeness, accuracy and validity of the data produced by the accounting system. However, reliance on the results of analytical review will depend on the 
auditor's assessment of the risk that the analytical review may identify relationships as expected when, in fact, a material misstatement exists (par. 14).

The purpose of analytical review in each audit stage is different. Table 2.1, based on ISA No. 520, contains a summary of its main purpose, specific decisions and the potential gain for the audit related to the performance of analytical review.

\section{Table 2.1: Analytical review per audit stage, its main purpose, specific decisions and potential gains for the audit}

Source: Adapted from ISA No. 520

\begin{tabular}{|c|c|c|c|c|c|c|}
\hline Audit stage & & Main purpose & & Specific decisions & & $\begin{array}{l}\text { Main } \\
\text { potential gain } \\
\text { for the audit }\end{array}$ \\
\hline Planning & - & $\begin{array}{l}\text { Understanding the } \\
\text { business } \\
\text { Identifying potential risks }\end{array}$ & . & $\begin{array}{l}\text { Decisions on adapting the } \\
\text { audit plan }\end{array}$ & . & $\begin{array}{l}\text { Effectiveness } \\
\text { Efficiency }\end{array}$ \\
\hline Substantive & - & Reduce tests of details & . & $\begin{array}{l}\text { Decisions on performing } \\
\text { additional tests of detail }\end{array}$ & - & Efficiency \\
\hline $\begin{array}{l}\text { Overall } \\
\text { review }\end{array}$ & & $\begin{array}{l}\text { Corroboration audit } \\
\text { findings } \\
\text { Obtain overview over } \\
\text { financial statements }\end{array}$ & - & $\begin{array}{l}\text { Decision on performing } \\
\text { specific additional } \\
\text { procedures } \\
\text { Preparing an overall } \\
\text { conclusion on the } \\
\text { financial statements }\end{array}$ & - & Effectiveness \\
\hline
\end{tabular}

In the planning stage, analytical review is applied to assist the auditor in understanding the business and in identifying areas of potential risk (par. 8). The auditor's reliance on substantive procedures to reduce detection risk relating to specific financial statement assertions may be derived from tests of details, from analytical review, or from a combination of both. The decision about which procedures need to be used to achieve a particular audit objective is based on the auditor's judgment about the expected effectiveness and efficiency of the available procedures in reducing detection risk for specific financial statement assertions (par. 10).

The auditor should apply analytical review at or near the end of the audit when forming an overall conclusion as to whether the financial statements as a whole are consistent with the auditor's knowledge of the business. The conclusions drawn from the results of such procedures are intended to corroborate conclusions formed during the audit of individual components or 
elements of the financial statements and assist in arriving at the overall conclusion as to the reasonableness of the financial statements. However, they may also identify areas requiring further procedures (par. 13).

The auditor will ordinarily inquire of management as to the availability and reliability of information needed to apply analytical review and the results of any such procedures performed by the entity. It may be efficient to use analytical data prepared by the entity, provided the auditor is satisfied that such data is properly prepared (par. 11).

The auditor will need to consider testing the controls, if any, over the preparation of information used in applying analytical review. When such controls are effective, the auditor will have greater confidence in the reliability of the information and, therefore, in the results of analytical review (par. 16). When analytical review identifies significant fluctuations or relationships that are inconsistent with other relevant information or that deviate from predicted amounts, the auditor should investigate and obtain adequate explanations and appropriate corroborative evidence (par. 17). The investigation of unusual fluctuations and relationships ordinarily begins with inquiries of management, followed by: (a) corroboration of management's responses, for example, by comparing them with the auditor's knowledge of the business and other evidence obtained during the course of the audit; and (b) consideration of the need to apply other audit procedures based on the results of such inquiries, if management is unable to provide an explanation or if the explanation is not considered adequate (par. 18).

The contingent variables addressed in the following sections 2.4 .2 and 2.4 .3 on the contribution of analytical review in error signaling and audit efficiency focus on two relevant factors in the decision making process of audit planning: cumulative knowledge of the client and risk assessments. As introduced in section 1.4, it is expected that cumulative knowledge of the client, indicated by client tenure and the client-specific experience of the audit manager in charge, affect the current and potential contribution of analytical review in error signaling.

\subsection{Analytical review as a decision-making process}

Previous research on analytical review shows us that the auditor's decisionmaking process in analytical review is a difficult task. During each stage of the process, the potential risk exists that the task is not performed accurately, which may have significant influence on the effectiveness of analytical review and the 
effectiveness of the entire audit. Koonce (1993, p. 57) describes analytical review as:

"...the diagnostic, sequential, and iterative (DSI) process of identifying, investigating, and resolving unexpected fluctuations. Diagnostic, because diagnostic reasoning appears to be an important part of analytical review. Analytical review is sequential, since the auditor must acquire sufficient information to identify an unexpected fluctuation before generating potential causes for an observed fluctuation and seeking out and evaluating information relevant to those causes. Finally, the task is iterative since the auditor may re-perform component".

Biggs, Mock and Watkins (1995) elaborated the cognitive process into a 12-step decision model based on the findings of Biggs, Mock and Watkins (1989) and Koonce (1993). This model is presented in figure 2.2. The model contains 12 subsequent steps divided in two parts. The first part (figure 2.2-A) starts with goal setting and ends with the evaluation of discrepancies between expectations and unaudited values. The second part (figure 2.2-B) starts with the identification of significant discrepancies and ends with the decision on subsequent audit efforts.

The elaborated process step model starts with the goal setting. The specific goal (step 1 in the model) of analytical review depends on the stage of the audit (see table 2.1). To accomplish this goal, the auditor retrieves from memory, factors that might have an impact on the unaudited values ('problem representation', step 2). A problem representation is a cognitive structure that represents the auditor's knowledge about conducting analytical review. This knowledge is based on various sources. For instance, it could contain general knowledge about accounting and auditing, industry and economy, but also specific client-related knowledge such as prior-year audit findings and knowledge about the client's business.

The next step is to develop expectations, combining the relevant available knowledge from history (step 3) with financial expectations, such as benchmarks and other ratios, client budgets and extrapolations of prior year figures. The end result in step 3 is the generation of a set of expectations that the auditor would use as a basis of comparison with unaudited numbers.

The auditor then compares the actual unaudited values with the expectations that were developed for those accounts (step 4). All discrepancies between expectations and unaudited values are evaluated to determine their significance, based on assessed materiality. If no significant discrepancy for an account is found (step 5), the auditor may firstly decide that the analytical review has provided sufficient, competent evidence and the account balance may be accepted. Secondly, based on the desired assurance level, the auditor may feel that analytical review provided sufficient evidence to reduce the extent of other 
$28 \mid$ CHAPTER 2

audit tests, but that additional corroborative evidence is needed. Finally, he may decide to not make any changes in the planned audit work.

Figure 2.2-A: The decision making process of analytical review Source: Biggs, Mock and Watkins (1995)

\section{Process}

1. Set goal

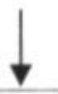

2. Generate problem representation

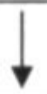

3. Develop expectations

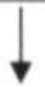

4. Compare reported figures with expectations to identify significant discrepancies

\section{Primary Activities}

Identify financial problems that need further investigation and financial strengths that allow reduction of further audit work.

Retrieve from memory knowledge relevant to understanding causes of balances, ratios and trends.

Eotablish expeulations for accounts using knowledge of client, industry, economy, etc.

Compare and evaluate differences between expectations and unaudited account values.

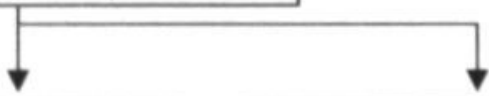

\section{If no significant} discrepancy, assess audit program impact

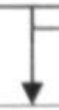

5.1 Accept assertion or financial balance
6. If significant discrepancy is identified

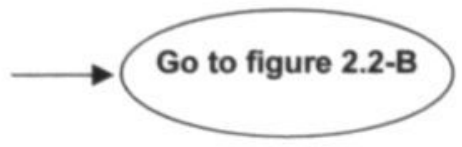

5.2 Reduce specific detailed tests
5.3 Conduct planned detailed test

Related primary research question (see chapter 3):

RQ 3: How does developing expectations affect analytical review effectiveness? 
THE USE AND EFFECTIVENESS OF ANAL YTICAL REVIEW: A LitERATURE OVERVIEW $\mid 29$

Figure 2.2-B: The decision making process of analytical review continued for cases where significant discrepancies exist

Source: Biggs, Mock and Watkins (1995)

Process

6. Significant discrepancies identified

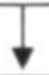

7. Generate enhanced problem representation

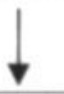

8. Generate hypotheses

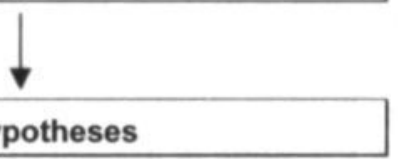

9. Evaluate hypotheses

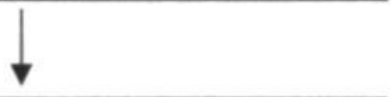

10. Identify most plausible hypotheses

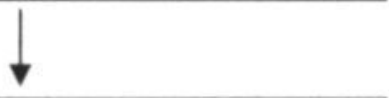

11. Design \& perform audit test of hypotheses
Primary Activities

Retrieve from memory knowledge relevant to understanding causes of significant discrepancies

Identify one or more possible causes of the discrepancies.

Determine if hypothesized errors will account for discrepancies.

Select hypotheses to investigate.

Develop and perform appropriate audit tests.

Evaluate audit evidence.

12. Draw audit conclusion

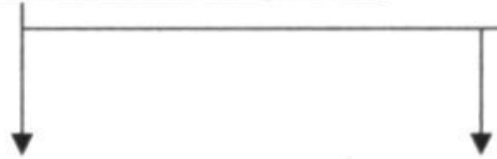

12.1 Re-perform one or more prior steps
12.2 Require client to adjust the books
12.3 Conclude that a nonerror explanation is valid 
$30 \mid$ CHAPTER 2

The second part of the model deals with the investigation of signaled discrepancies between expectations and unaudited values (step 6). The generation of an enhanced problem representation (step 7) and a set of hypotheses (step 8 ) are aimed to consider whether the discrepancy is due to a non-error (e.g. random fluctuations, business changes, unusual transactions or events) or an error (misstatements) cause. The problem representation in step 7 is an enhanced and more specific problem representation than step 2. The problem representation in step 7 focuses more specifically on knowledge relevant to the type of problem that the auditor believes may underlie the discrepancy, whereas problem representation in step 2 refers to background knowledge.

Once a set of hypotheses has been generated, the auditor evaluates each hypothesis on the extent to which it can explain the discrepancy (step 9). After this evaluation of hypotheses, the auditor uses his knowledge about the client to identify the most plausible hypothesis or hypotheses of the remaining hypotheses that could account for the discrepancy (see step 10). For these hypotheses, the auditor plans subsequent audit procedures (step 11) in order to accomplish the goal in step 1 that would provide substantive evidence of the presence of a misstatement, or corroborative evidence of a non-error cause.

Once the selected test procedures have been performed, the auditor evaluates the results (step 12) and decides whether additional analytical review or other audit procedures should be performed, whether the error has been identified, or whether a non-error cause is valid.

The third primary research question in section 1.4 - How does developing expectations affect analytical review effectiveness? - addresses the hypothesis generation stage of the decision-making process (figure 2.2) once the auditor has signaled the error. This research question is addressed in the remaining part of this chapter with a discussion of the previous literature, and will be elaborated with secondary research questions in the next chapter. 
THE USE AND EFFECTIVENESS OF ANALYTICAL. REVIEW: A LITERATURE OVERVIEW | 31

\subsection{Contingent variables related to analytical review}

\subsubsection{Introduction}

A contingency can be defined as "Something liable to happen as a change feature or accompaniment of something else" (Webster's Third New International Dictionary, 1986). Contingent variables are factors, which may influence systems or decisions in different circumstances. A contingency approach is not restricted to auditing. For instance, Otley (1980) notes that the contingency framework in the organization literature was developed in the 1960 's, and that in the mid-1970's the contingency framework was introduced in management accounting. Otley summarizes the contingency approach to management accounting as "... the premise that there is no universally appropriate accounting system which applies equally to all organizations in all circumstances" (Otley, 1980, p. 413).

The explicit notion of a contingency framework in auditing research is limited. Only Wright and Mock (1985) have tried to introduce the contingency approach into the auditing area. Wright and Mock defined the contingency framework in auditing as follows: "The contingency view is based on the assumption that the quality of evidential sources must be carefully analyzed on each engagement. The relative competence of a given form of evidence appears to be dependent on several factors, including the account or cycle audited, the client's industry, internal controls, and the method(s) employed to gather and evaluate the evidence" (Wright and Mock, 1985, p. 96-97).

Wright and Mock's contingency view in the auditing area is based on research efforts in other research areas. Whereas contingency is applicable for the accounting system and organizational fit in management accounting ${ }^{2}$ and strategic management areas ${ }^{3}$, the same concept is applicable in the field of auditing. Specifically, planning decisions on the nature, timing and extent of audit procedures to be used are dependent on contingent circumstances. Wright and Mock stress that the quality and the competence of evidence depend on several factors. Specific audit procedures may give a strong form of evidence for one client, but may be a weak form of evidence for other clients. For example, analytical review on trade debtors might provide sufficient evidence for a client with tight debtor controls, but might be insufficient for a client with weak controls in this area.

\footnotetext{
${ }^{2}$ I refer to Emmanuel, Otley and Merchant (1990) for a summary of the contingency theory in management accounting.

${ }^{3}$ I refer to Burns and Stalker (1961), Chandler (1962) and Lawrence and Lorsch (1967)
} 
The Wright and Mock initiative for a contingency framework of auditing has not been followed by subsequent publications. Nevertheless, the absence of a research stream on the contingency framework in the field of auditing does not imply that audit practice and audit research do not need to consider contingent variables. For instance, professional standards consider contingent variables in the planning stage of the audit. Further, previous research related to analytical review has focused on understanding the relevant factors that influence the auditor in his decision-making process during analytical review.

Despite the limited attention for the contingency framework by audit research, professional standards are based on the consideration of contingent variables. In section 2.2 , the audit planning considerations were addressed referring to ISA No. 300. ISA No. 300 describes the planning stage of the audit, involving relevant contingent factors the auditor should consider. ISA No. 300 demonstrates the incorporation of such contingent variables. For instance, 'knowledge of the business' as defined in ISA No. 300 and 'understanding the accounting and internal control systems' are examples of contingent factors.

Previous literature on analytical review and the professional standards provide a number of relevant contingent variables affecting the use and effectiveness of analytical review. In table 2.2 , these contingent variables are summarized and categorized.

The main research findings will be addressed in the following sections. I will limit my overview to those aspects, which are relevant for the scope of this thesis. In table 2.2, reference is made for the remaining aspects that are not addressed in this thesis. 


\section{Table 2.2: Analytical review aspects, contingent variables, addressing the decision process step and literature reference}

\begin{tabular}{|c|c|c|c|}
\hline Aspect & Contingent variable & $\begin{array}{l}\text { Decision process step } \\
\text { (BMW, 1995) }\end{array}$ & Reference \\
\hline General & 1. Materiality & $\begin{array}{l}\text { (Step 1) Set goal } \\
\text { (Step 11) Design and } \\
\text { perform audit tests of } \\
\text { hypotheses }\end{array}$ & ISA No. 320 \\
\hline \multirow[t]{3}{*}{$\begin{array}{l}\text { Audit efficiency } \\
\text { (RQ I and 2) }\end{array}$} & $\begin{array}{l}\text { 2. Control } \\
\text { environment } \\
\text { condition }\end{array}$ & $\begin{array}{l}\text { (Step 1) Set goal } \\
\text { (Step 3) Develop } \\
\text { hypotheses }\end{array}$ & $\begin{array}{l}\text { Marden, Holstrum and } \\
\text { Schneider (1997), } \\
\text { ISA No. } 300\end{array}$ \\
\hline & $\begin{array}{l}\text { 3. Inherent Risk and } \\
\text { Control Risk }\end{array}$ & $\begin{array}{l}\text { (Step 2) Generate } \\
\text { problem representation } \\
\text { (Step 3) Develop } \\
\text { hypotheses }\end{array}$ & $\begin{array}{l}\text { Cohen and Kida (1989), } \\
\text { Asare and Davidson } \\
\text { (1995), Waller (1993), } \\
\text { ISA No. } 400\end{array}$ \\
\hline & $\begin{array}{l}\text { 4. Cumulative } \\
\text { knowledge of the } \\
\text { client }\end{array}$ & $\begin{array}{l}\text { (Step 2) Generate } \\
\text { problem representation } \\
\text { (Step 7) Generate } \\
\text { enhanced problem } \\
\text { representation }\end{array}$ & $\begin{array}{l}\text { Libby (1985) } \\
\text { Bedard and Biggs } \\
(1991 \text { a and b) } \\
\text { Biggs, Mock and Watkins } \\
(1988) \\
\text { Cohen and Kida (1989) } \\
\text { Bonner (1990) } \\
\text { Bonner and Lewis (1991) } \\
\text { Bierstaker, Bedard and } \\
\text { Biggs (1999) }\end{array}$ \\
\hline \multirow[t]{3}{*}{$\begin{array}{l}\text { Analytical review } \\
\text { effectiveness } \\
\text { (RQ 3) }\end{array}$} & $\begin{array}{l}\text { 5. Developing } \\
\text { expectations }\end{array}$ & $\begin{array}{l}\text { (Step 8) Generate } \\
\text { hypotheses }\end{array}$ & $\begin{array}{l}\text { Bedard and Biggs } \\
(1991 \mathrm{a} \text { and b) } \\
\text { Bedard, Biggs and } \\
\text { DiPietro (1998) } \\
\text { ISA No. } 580 \\
\end{array}$ \\
\hline & & $\begin{array}{l}\text { (Step 3) Develop } \\
\text { expectations }\end{array}$ & $\begin{array}{l}\text { Kinney and Uecker (1982) } \\
\text { Biggs and Wild (1985) } \\
\text { Kinney (1987) }\end{array}$ \\
\hline & & $\begin{array}{l}\text { (Step 9) Evaluate } \\
\text { hypotheses } \\
\text { (Step 11) Design and } \\
\text { perform audit tests of } \\
\text { hypotheses }\end{array}$ & $\begin{array}{l}\text { Kinney (1987) } \\
\text { Anderson and Koonce } \\
\text { (1995) } \\
\text { Asare and Wright (1997) }\end{array}$ \\
\hline
\end{tabular}

Sources: Koonce (1993), Biggs, Mock, Watkins (1995), IFAC (2000), updated for recent publications by the author 


\subsubsection{Contingent variable on audit efficiency: Cumulative knowledge of the client}

\subsubsection{Introduction}

As discussed in section 2.2, during the audit strategy planning, the cumulative knowledge of the client is an important source for the evaluation of risk. Cumulative knowledge of the client comprises two general categories: knowledge of the audit firm on the audit engagement and knowledge of the current audit team. In audit research, the term 'knowledge' as used in the auditing standards, is expressed as 'expertise'. In this thesis, the term 'expertise' is only used when addressing previous research. In all other cases, the term 'knowledge' is used.

Client tenure can be used as the surrogate for cumulative knowledge of the audit firm related to the specific client. It is expected that the higher the client tenure, the more knowledge on the client and its business has been gathered up to the current audit year. Client-specific experience can be used as the surrogate for the cumulative knowledge of the current audit team related to the specific client. It is expected that the client-specific knowledge of the audit firm is at least the knowledge of the current audit team.

Although the client-specific knowledge can be located at each team member, this thesis focuses on the team members who are in charge of the audit planning and the decision making process on the nature and extent of audit procedures to be used. Audit strategy planning is a joint responsibility of the audit partner and the highest level of staff involved, which is usually the audit manager. The role of the audit partner will normally be limited to the identification of risks, whereas the audit manager is responsible for the decisionmaking process related to the nature, timing and extent of the audit procedures to be used. Therefore, the audit manager is the key player in the decision process whether or not to use analytical review as the most appropriate audit procedure.

Little is known on the effects of client tenure on the contribution of analytical review in error signaling, as most research was performed in experimental settings without manipulating client tenure and the limited number of field studies did not report client tenure information. Cumulative knowledge of the client as a contingent variable for contribution of analytical review in signaling errors will be discussed in section 3.3.2.1

In the current section, the elements of experience of the audit manager in charge are addressed as the basis for the elaboration in section 3.3.2.1. 
THE USE AND EFFECTIVENESS OF ANALYTICAL. REVIEW: A LITERATURE OVERVIEW | 35

\subsubsection{Experience as a surrogate for expertise}

The quality of the analytical review decision-making process might, amongst others, be contingent on the expertise of the audit manager. In general, an expert is someone "who has acquired skill in or knowledge of a particular subject through professional training or practice experience" (Webster's Third New International Dictionary, 1986). Expertise, the skill of an expert, is difficult to measure. The distinction between categories of knowledge as sources for expertise is important in order to identify the best testable surrogate for the concept of expertise. Audit researchers often use experience as a surrogate for expertise. However, "An auditor may have twenty years of auditing experience, but not exhibit more 'expertise' in evaluating internal control than a senior. because of these twenty years of experience, only three involve evaluating internal control systems" (Bédard, 1989). Bonner and Lewis (1990) distinguish four determinants of auditor expertise ${ }^{4}$, which each differ with the source of knowledge:

- General domain knowledge, defined as a basic level of accounting and auditing knowledge, including knowledge of generally accepted accounting principles, generally accepted Auditing Standards, and the flow of transactions through an accounting system. General domain knowledge can be obtained by regular practice experience and training.

- Domain-specific knowledge, which is defined as "related to specialized industries or clients, acquired by persons who have experience with specific audit clients, with certain industries, and/or firm training in those specialized areas" (Bonner and Lewis, 1990, p. 5). An auditor can obtain domain-specific knowledge by specific experiences in practice; it is less likely to be acquired by general experience.

- General business knowledge, which can be characterized as the ability to have feeling for specific business situations, not specifically focused on financial data and internal controls. Formal instruction and various personal experiences such as reading can acquire this kind of knowledge.

- General problem-solving ability defined as the ability to recognize relationships, to interpret data and to reason analytically. This category is very individual, but can be related to the level of types of experience that are mentioned above.

Researchers in analytical review experiments, who aimed to test the effect of expertise on performance, used general domain knowledge (made operational as

\footnotetext{
${ }^{4}$ Unfortunately, little is known about the potential correlation between the four distinguished categories of knowledge.
} 


\section{CHAPTER 2}

general audit experience by Biggs, Mock and Watkins, 1988; Bedard and Biggs, 1991a) or domain-specific knowledge (made operational as industry-specific knowledge by Bedard and Biggs, 1991b; Bedard, Biggs and DiPietro, 1998) as surrogates for expertise. Industry-related experience might be a workable surrogate for expertise in experimental settings, but may not a priori be applicable as a surrogate for expertise in a field setting. For instance, a senior with four years of industry experience, who enters a new industry-client, may have less domain-experience than a two-year experienced assistant who has two years of experience at this specific client. I will address this issue in section 3.3.2.1. In that section, client-specific experience is used as a surrogate for domain-specific knowledge.

\subsubsection{Contingent variable on audit efficiency: Risk assessments}

\subsubsection{Introduction}

In section 2.2 the decision-making process of initial audit planning was addressed, including the evaluation of inherent risk and fraud risk and its impact on internal controls. It was observed that the decision on the nature and extent of using analytical review is dependent on the specific risk assessments. Therefore, it is expected that the client's control situation affects the use of analytical review. For instance, ISA No. 520 states:

"The auditor will need to consider testing the controls, if any, over the preparation of information used in applying analytical review. When such controls are effective, the auditor will have greater confidence in the reliability of the information and, therefore, in the results of analytical review" (ISA No. 520, par. 16).

Based on the previous auditing literature, little is known about the influence of the client's control condition on the use of analytical review. In order to address the first primary research question on the contribution of analytical review in error signaling (see section 1.4), the influence of the control condition on the use of analytical review needs further exploration. This aspect will be addressed in chapter 3 . In the current section, I describe the more general research findings on the influence of the control environment and risk assessment on the audit plan. This forms the basis for exploring in the next chapter the expected influence of the client's control situation on the contribution of analytical review in error signaling. 
THE USE AND EFFECTIVENESS OF ANAL YTICAL. REVIEW: A LITERATURE OVERVIEW | 37

\subsubsection{Inherent risk and control risk assessments}

In the audit risk model, three types of risks are addressed: inherent risk, control risk and detection risk. 'Inherent risk' is the susceptibility of an account balance or class of transactions to misstatement that could be material, individually or when aggregated with misstatements in other balances or classes, assuming that there were no related internal controls (ISA No. 400, par. 4).

'Control risk' is the risk that a misstatement, that could occur in an account balance or class of transactions and that could be material individually or when aggregated with misstatements in other balances or classes, will not be prevented or detected and corrected on a timely basis by the accounting and internal control systems (ISA No. 400, par. 5). 'Internal control system' means all the policies and procedures (internal controls) adopted by the management of an entity to assist in achieving management's objective of ensuring, as far as practicable, the orderly and efficient conduct of its business, including adherence to management policies, the safeguarding of assets, the prevention and detection of fraud and error, the accuracy and completeness of the accounting records, and the timely preparation of reliable financial information. The internal control system extends beyond those matters, which relate directly to the functions of the accounting system and comprises the control environment and the control procedures (ISA No. 400, par. 5-7).

'Detection risk' is the risk that an auditor's substantive procedures will not detect a misstatement that exists in an account balance or class of transactions that could be material, individually or when aggregated with misstatements in other balances or classes. (ISA No. 400, par. 8). In section 3.2.2 detection risk will be discussed more extensively when addressing type I and type II errors.

Auditors can combine the assessment of inherent and control risk. ISA No. 400 , section 40 states:

"Management often reacts to inherent risk situations by designing accounting and internal control systems to prevent or detect and correct misstatements and therefore, in many cases, inherent risk and control risk are highly interrelated. In such situations, if the auditor attempts to assess inherent and control risks separately, there is a possibility of inappropriate risk assessment. As a result, audit risk may be more appropriately determined in such situations by making a combined assessment".

The suggestion expressed in ISA No. 400 on the combined assessment of inherent risk and control risk, is not supported by audit research. For instance, Waller (1993) examined the auditors' assessments of inherent risk and control risk in a field setting. His main concern was that the previous literature on the 
audit risk model had focused on a priori analyses of the model's assumptions and implications. He investigated whether there is a statistical association between the auditor's inherent risk and control risk assessments. Based on the empirical evidence, he concluded that there is an insignificant association between inherent risk and control risk. In a predominance of cases, control risk was assessed at the maximum for reasons of efficiency. This means that the auditor keeps control risk at a constant high level in order to test at the same level for all engagements assuming a non-reliance on controls.

Bedard (1989) investigated how and why audit plans for substantive tests are revised. The results of her archival study showed that audit programs for substantive tests were quite stable. Participants in this study indicated that reasons for decreases in substantive tests were internal control strength and favorability of past results. Only few increases in the audit plan were attributed to analytical review. No relationship was found between previous adjusting entries and revision of substantive test programs.

Related to the audit planning process, Mock and Wright (1993) explored the relationship between client- and account-specific inherent risks_and_control risks and subsequent evidential planning decisions on actual audits. Their results indicated moderate variation across clients in perceived risks, but little correlation between the risk assessments and audit planning decisions. Corroborating results came from a small sample study of Quadackers, Mock and Maijoor (1996), who explored audit records and observed that audit risk factors varied between clients, and to some degree there is risk variation across time. Mock and Wright (1999) corroborated and extended the previous studies related to evidential planning. They found a statistical association between the level of and changes in a limited number of assessed client risks and evidential plans. These results indicate the lack of a strong relationship between client risks and audit programs in general.

Experimental research related to analytical review by Cohen and Kida (1989) investigated the impact of analytical review results, internal control reliability and experience on auditor's use of analytical review. They concluded that auditor's decision-making behavior is sensitive to internal control weaknesses, specifically, when internal controls are assessed as weak, the analytical review resulted in an extension of audit testing.

Previous research has indicated a relationship between the number and size of errors and certain contingent risk factors. For instance, Kreutzfeldt and Wallace (1986) found that companies with a better control environment had fewer and smaller errors. Asare and Davidson (1995) tested the influence of control procedures and financial condition on auditors' anticipation of errors in various account balances. They concluded that auditors' expectations about errors are sensitive to account-specific control risk. Further, evaluation of 
THE USE AND EFFECTIVENESS OF ANAL YTICAL REVIEW: A LITERATURE OVERVIEW | 39

controls in a specific cycle did not automatically imply risk assessments in other cycles. Asare and Davidson only manipulated financial condition and management controls, but suggested that other risk factors, such as the strength of the control environment, should be investigated accordingly.

\subsubsection{COSO and the internal control system}

The internal control system as addressed in ISA No. 400 in the previous section, comprises two elements, specifically the control environment and the control procedures. In 1992, the Committee Of Sponsoring Organizations (COSO) published an integrated framework on internal controls (COSO 1992). According to COSO, the process of internal control is affected by an entity's board of directors, management and other personnel, designed to provide reasonable assurance regarding the achievement of objectives in effectiveness and efficiency of operations, reliability of financial reporting, and compliance with applicable laws and regulations (COSO, 1992).

Whereas ISA No. 400 recognized only two elements of the internal control system, the COSO report elaborates this to five interrelated components of internal control, specifically control environment, risk assessment, control activities, information and communication, and monitoring. The five components of COSO largely correspond to the two components of ISA No. 400. Although all five components are interrelated, I will address only two components of the COSO definitions in this thesis, control environment and risk assessments. The reason for the limitation of discussing the components is due to the fact that the standards do not address the remaining three components specifically. It is therefore assumed that the latter three components are included in the first two components when discussing the implications for the audit. For instance, control activities are an integral part of the control environment elements as well as the auditors' risk assessment. The potential correlation between control environment and risk assessment will be addressed in section 5.5.2.

\subsubsection{Control Environment}

The Control Environment is considered to have great impact on the control status of an organization. For instance, the COSO report argues: "The control environment sets the tone of an organization, influencing the control consciousness of its people. It is the foundation for all other components of internal control, providing discipline and structure. Control environment factors 
include the integrity, ethical values and competence of the entity's people; management's philosophy and operating style; the way management assigns authority and responsibility, and organizes and develops its people; and the attention and direction provided by the board of directors." (COSO, 1992).

Little is known about the actual assessment of control environment by auditors. One of the few publications responding to the COSO report is a publication by Marden, Holstrum and Schneider (1997), who examined how the Control Environment condition affects the auditors' assessment of control risk for different types of accounts ${ }^{5}$ at the management assertion level. The results indicate that Control Environment influences the auditors' evaluation of internal controls for all management assertions, relating to both subjective and objective accounts.

\subsubsection{Summary on risk assessments}

Summarizing, previous research shows attention for the auditor's sensitivity to contingent risk assessments, but still little evidence is available on the relationship between risk assessments and the contribution of analytical review in signaling errors. The development of the concept of control environment by COSO has not yet been tested by recent research.

Further evidence is required on the relationship between risk assessments and the contribution of analytical review in error signaling. This matter will be addressed in the next chapter when developing the research questions.

\subsubsection{Contingent variable on analytical review effectiveness: Developing expectations}

\subsubsection{Introduction}

Developing expectations takes place at the start of the analytical review process when searching for unexpected fluctuations, as well as during the process of analytical review, after signaling the error but before the analysis of the unexpected fluctuations. The key issue on developing own expectations by the auditor is the effect of potential bias on analytical review effectiveness when developing own expectations is absent. For instance, the auditor may obtain a

\footnotetext{
${ }^{5}$ This experiment focused on financial institution accounts because of the industry's problems with failures experienced in the last decade (Marden, Holstrum and Schneider, 1997).
} 
client representation as a first follow-up step once signaling the unexpected fluctuation.

The previous literature on developing expectations during the decision making process of analytical review has focused on the use of unaudited book values as a starting point for analytical review and the use of client representations during analytical review. In the remaining part of this section, main research findings of both topics are addressed.

In chapter 3, research questions on the use of client representations are elaborated. The reason for developing research questions on client representations rather than the use of unaudited book values as a starting point for analytical review is twofold. Firstly, obtaining client representations is one of the audit procedures that are used quite often during the audit process. Wright and Ashton (1989) reported that $13.3 \%$ of the errors were initially signaled by client inquiry. Secondly, the use of unaudited book values as a starting point for analytical review is developed in experimental settings, but is difficult to incorporate in a field setting. In effect, it is likely that practitioners are frequently confronted with unaudited book values as starting point for analytical review. Therefore, unaudited book values as starting point for analytical review are not included in the research questions in this study. The absence of a research question on the use of unaudited book values is addressed in the limitations of this study in section 7.3.2.3.

\subsubsection{Use of unaudited book values}

Previous psychological research indicates that people can be biased in a difficult decision process if they have access to simple heuristics that are incorrect. Tversky and Kahnemann (1974) found that people rely on a few heuristics, which reduce the complex tasks of assessing probabilities and predicting values to simpler judgmental operations

Kinney and Uecker (1982) transferred the research concept by Tversky and Kahnemann into an auditing setting and started a line of research that is focused on the influence of using unaudited book values as the basis for the analytical review to be performed. They developed an exercise containing the fluctuation of sales, cost of sales and gross margin and asked auditors to estimate boundaries of investigation. The exercise is presented in example 2.1 and is included in this section in order to show the basic experimental design, and the recommendations followed by subsequent publications related to this model. 


\section{Example 2.1: $\quad$ Analytical review exercise}

Form $1^{*}$ )

You are auditor for a small manufacturing firm. You are conducting an analytical review of the gross margin percentage. The component accounts and ratios based on the audited values for the last two audit years and the current period's unaudited values are reproduced below. Note the $(000$ 's) have been omitted.

$\left.\begin{array}{lcccc} & \multicolumn{2}{c}{} & \multicolumn{2}{c}{\text { Unaudited }} \\ \text { Sales } & 1977 & 1978 & 1979 \\ \text { Cost of Sales } & \$ 19,778 & \$ 23,941 & \$ 24,265 \\ \text { Gross Profit } & \frac{15,893}{\$ 3,885} & \frac{19,749}{\$ 4,192} & \underline{20,868} \\ \text { Gross Profit \% } & \frac{\$ 19,6 \%}{17,5 \%} & \underline{\$ 3,397} & 14 \%\end{array}\right]$

You have no reason to expect major changes from recent historical relationships.

\section{REQUIRED:}

Indicate a range of possible values beyond which you feel that an investigation should be conducted to "explain" the apparent change in the gross profit percentage for 1979 .

Upper bound of range .....................

Lower bound of range

*) Form 2 differed from Form 1 for the bracketed amounts only. The "unaudited" column for Form 2 was:

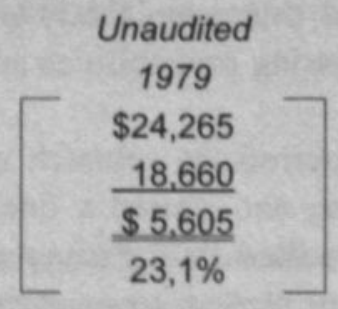

Source: Kinney and Uecker (1982)

In the Kinney and Uecker study, participants were provided with two years of audited figures and manipulated the current year unaudited figures. One part of the subjects received figures containing a continuation of the downward trend in gross margin (form 1 in example 2.1), the other part was provided with a reversal of the downward trend (form 2 ). The subjects were requested to give an 
THE USE AND EFFECTIVENESS OF ANAL. YTICAL. REVIEW: A LITERATURE OVERVIEW | 43

expected value of the current year's real figures and the lower and upper bounds of the non-investigation decisions. Kinney and Uecker found that the auditor subjects showed anchoring and adjustment characteristics. Specifically "they focus on the initial value (anchor) in the decision setting and adjust their responses from that value" (Kinney and Uecker, 1982, page 56). In this case, the participants were biased by the unaudited values supplied by the researchers.

Although the case design was rather simple, this line of research might have important implications for practice. Are auditors really biased by unaudited figures? Does the nature and extent of available background information affect this bias? Should auditors be recommended explicitly not to use unaudited figures as the starting point for the generation of hypotheses? These questions were investigated by other researchers who used the Kinney and Uecker study as a starting point for further research.

Biggs and Wild (1985) extended the Kinney and Uecker study by investigating the effect of an extension of available information. They found that subjects were less biased by unaudited figures if they had been provided with five years of history instead of two years of history. This would imply that an extension of available information would mitigate the potential bias. Heintz and White (1989) elaborated the research by Kinney and Uecker (1982) and Biggs and Wild (1985). Their findings corroborate the previous studies that unaudited values influence auditors' judgments. In addition, they found that decreasing unaudited figures have greater influence than increasing unaudited values, and that a trend reversal has greater influence than an unaudited value that is consistent with prior years. The latter finding is an extension of the Biggs and Wild (1985) finding about trend reversals and this suggests that the auditor is the most biased in circumstances that he has to be alert.

In line with this research stream, Wild and Biggs developed a Bayesian decision theoretic model and concluded that (Wild and Biggs, 1990, p. 227): "... the advantages of incorporating book value in the practice of analytical review appear minimal". Biggs and Wild (1985) argue why an independent development of expectations is important for the auditor. Firstly, they argue that using the unaudited values to form an expectation is a violation of the requirement that auditors make independent evaluations of clients' financial statements. Secondly, unaudited book values are a kind of 'management assertions'. Because management is dependent on the produced values, the auditor should view these assertions with skepticism. Thirdly, if expectation and object of expectation merge, the risk of not detecting material errors increases.

In terms of regulatory standards, an interesting difference can be observed between ISA No. 520 and SAS 56. AU 329.05 prescribes: 
"Analytical procedures involve comparisons of recorded amounts, or ratios developed from recorded amounts, to expectations developed by the auditor. The auditor develops such expectations by identifying and using plausible relationships that are reasonably expected to exist, based on the auditor's understanding of the client and of the industry in which the client operates" (underlining added/PE).

ISA No. 520 does not explicitly refer to building one's expectations before observing the unaudited book values, but only defines analytical procedures as

"Analytical procedures means the analysis of significant ratios and trends including the resulting investigation of fluctuations and relationships that are inconsistent with other relevant information or deviate from predicted amounts" (ISA No. 520, par. 3).

The research studies mentioned in this section have the corroborating finding that the participants in the experiments were influenced by unaudited figures when building expectations. In the joint publication by AICPA/AAA, practitioners were recommended as follows: "Auditors should develop their own expectations before reviewing unaudited book values..."(Biggs, Mock and Watkins, 1995, page 142).

As a direct result of these studies, the Auditing Standards Board in the United States included specific wordings in SAS 56 about the auditor's responsibility to develop independent expectations and to use reliable data when developing such expectations (SAS 56, AU 329.05).

If this finding can be generalized to a field setting, it could have an important implication for practice. It would imply that the effectiveness of analytical review can be improved when auditors develop expectations explicitly as part of the mental representation and hypothesis generation during analytical review. Based on the previous research however, it is unclear how developing expectations is to be operationalized. I will address this issue when developing the research questions in the next chapter.

\subsubsection{Client representations}

During the course of the audit, the auditor has frequent contact with the client and receives written and/or oral representations either unsolicited, or in response to specific inquiries. When such representations relate to matters that are material to the financial statements, the auditor will need to perform certain procedures. ISA No. 580 , par. 6 indicates that auditors need to:

(a) seek corroborative audit evidence from sources inside or outside the entity; 
THE USE AND EFFECTIVENESS OF ANAL YTICAL. REVIEW: A LITERATURE OVERVIEW | 45

(b) evaluate whether the representations made by management appear reasonable and consistent with other audit evidence obtained, including other representations; and

(c) consider whether the individuals making the representations can be expected to be well informed on the particular matters.

Research by Wright and Ashton (1989) indicates that client inquiry and the accompanying client representation is one of the most frequently used sources of audit evidence. Auditing standards state that representations from management ${ }^{6}$ must be approached with skepticism, because this source of evidence is not independent from the object of the audit (ISA No. 580, par. 6). As a result, auditors should always consider the reliability of a client representation.

Hirst (1994) investigated auditors' sensitivity to client reliability (Hirst generalized 'client' to 'source'). He distinguished competence and objectivity as the two elements of source reliability. Source competence refers to "an individual's ability to measure or interpret an item or event accurately" and source objectivity to "the likelihood an individual will report his measurement or interpretation truthfully, regardless of its accuracy" (Hirst 1994, p. 114). Based on his experiment, he found that evidence from a more competent source was considered more diagnostic than less competent evidence and that evidence from a more objective source is considered to be more diagnostic than the same evidence by a less objective source. These results indicate that auditors evaluate the quality of a client representation.

Due to the fact that competence as well as objectivity of sources may differ among circumstances, resulting actions aimed at verification of the evidence will be contingent. For instance, the objectivity of client management may differ in the case of a profit-related management compensation plan from a compensation plan that is independent from profits. Or the competence of a newly hired CFO might differ from a CFO who entered the company five years ago. As a consequence, it is expected that the auditor considers the competence and objectivity when receiving client representations.

Anderson, Koonce and Marchant (1994) investigated auditors' sensitivity to the degree of source competence. Their results confirmed Hirst's findings that auditors judge a client representation as more valuable when they assess that person to be highly competent.

\footnotetext{
${ }^{6}$ In this thesis, the term 'management representation' as presented in the professional standards, is described as 'client representation' in order to reflect that representations can be obtained from client management as well as client staff.
} 
The auditor's ability to evaluate client explanations for signaled discrepancies between expected values and unaudited values can influence the effectiveness of analytical review. Previous research shows that auditors are biased by the quality of client representations. Bedard and Biggs (1991 a) showed that auditors have difficulty with evaluating hypotheses, even if sufficient information is available to disconfirm the suggested cause by the researchers. This finding regarding hypothesis evaluation is an extension of Biggs, Mock and Watkins (1988), Cohen and Kida (1989), Heiman (1990) and Libby and Frederick (1990), who found that auditors have difficulty with hypothesis generation. Further, they found a positive relationship between the ability to recognize patterns of discrepancies and providing the correct hypothesis. This indicates that auditors, once recognizing the unexpected fluctuation during analytical review, are able to formulate the right cause of the error.

In a following study, Bedard and Biggs (1991b) examined the effect of client representations on the quality of hypotheses generated by auditors during the performance of analytical review. They performed an experiment with 176 auditors, using the same case material as in Bedard and Biggs (1991a) and manipulated the quality of client representation as the independent variable. Some participants were provided with a representation that explained the whole sisurpancy ('good' representation'), other participants received a representation that did not account for the discrepancy ('poor representation') and a control group of participants did not receive a client representation at all. Bedard and Biggs revealed two interesting findings. Firstly, the type of client representation influenced the quality of the auditor's responses. An accurate client representation resulted in a better quality response. Secondly, more experienced auditors were more biased by client representations than less experienced auditors. Specifically, experienced auditors who received a good representation performed better than others. Alternatively, experienced auditors who received a poor representation were still focused on the client suggestion and were not able to generate their own plausible hypotheses. These findings were confirmed by Bedard, Biggs and DiPietro (1998).

While the studies discussed above mainly focused on the hypothesis generation stage of the decision-making process, Bedard, Biggs and DiPietro (1998) extended this line of research by exploring the link between hypothesis generation and subsequent audit planning, and especially how hypotheses inherited from management would affect auditor performance at both stages. They found that an accurate hypothesis results in an increase of audit effectiveness and that an inaccurate hypothesis is associated with an overall decline in effectiveness of subsequent audit tests.

Since hypotheses for unexpected fluctuations can be obtained from client management, this conclusion may impact audit practice. Specifically, if the 
client representation for the unexpected fluctuation is accurate, subsequent tests are more effective and consequently, audit efficiency can be improved. Alternatively, if the client representation is inaccurate, the auditor might plan audit tests that insufficiently cover the unexpected fluctuation. As a result, audit efficiency might decline in that case.

Koonce and Phillips (1996) investigated whether the ease of understanding information related to client-suggested causes affects the auditors' judgments about the plausibility of that cause. Their experimental results indicated that when information related to the client's suggested non-error cause was easy to understand, auditors judged that cause to be more plausible than when the same information was difficult to understand.

During hypothesis evaluation in the analytical review process, the auditor judges the validity of the generated hypotheses. Kinney (1987) found that auditors, who quantify a hypothesis, are less likely to accept seemingly plausible but incorrect hypotheses. Accepting an incorrect hypothesis may lead to a decrease in effectiveness in analytical review and maybe a decrease in audit effectiveness and/or audit efficiency. Kinney recommends auditors to quantify the hypothesis, for instance with a reversal journal entry.

Anderson and Koonce (1995) investigated auditors' extent of evaluating client-suggested causes. They manipulated the quality of a client-suggested cause (a correct suggestion and an incorrect suggestion) and observed that only a few auditor-subjects quantified the suggested cause. Had the others done so, the incorrect hypothesis probably would have been detected.

Summarizing, client representations are an important source of evidence during the audit. Research has shown that an incorrect client representation negatively influences the effectiveness of analytical review. Alternatively, the research also showed that correct client representations could increase the effectiveness of analytical review. These findings will be addressed further in the research questions in the next chapter.

\subsection{Summary}

This chapter presented a literature review on the use and effectiveness of analytical review by auditors with embedding analytical review into the audit planning stage decisions. In section 2.2, I described the analytical review embedded in the audit planning decisions based on the International Standards on Auditing. It was addressed in section 2.3 that despite the simple technique of analytical review, the decision making process is rather complex. Section 2.4 addressed the contingent variables of audit efficiency and analytical review effectiveness. The contingent variables addressed in this thesis relate to audit 
efficiency (cumulative knowledge of the client and risk assessments) and analytical review effectiveness (the influence of developing own expectations when investigating the unexpected fluctuations). Section 2.4 .1 addressed the general overview of the contingency framework. Section 2.4 .2 addressed the literature review of the effects of cumulative knowledge of the client on the decision making process of analytical review, followed in section 2.4 .3 by an analysis of the relationship between risk assessments and analytical review. It was observed that previous research shows attention for the auditor's sensitivity to contingent risk assessments, but still little evidence is known on the expected relationship between risk assessments and the contribution of analytical review in signaling errors.

Section 2.4.4 addressed the effect of potential bias on analytical review effectiveness when the auditor does not develop his own expectations. Section 2.4.4.2 started with the potential bias of using unaudited book values as the starting point for analytical review. It was observed that research findings have led to recommendations to practice related to developing own expectations, but it is still unclear how developing expectations should be operationalized.

Finally, section 2.4.4.3 addressed the influence of client representations on analytical review effectiveness. It was observed that the previous research stressed the potential bias by inaccurate client representations, but did not elaborate the opportunity for gaining audit efficiency when receiving accurate client representations.

I will elaborate the primary research questions of chapter 1 when developing the research questions in the next chapter, addressing the influence of the contingent variables. 


\section{DEVELOPMENT OF DETAILED RESEARCH QUESTIONS}

\subsection{Introduction}

In chapter 1,1 described the motivation for this study resulting in three primary research questions:

$R Q$ 1: How does analytical review contribute to error signaling?

$R Q$ 2: How does analytical review contribute to audit efficiency?

$R Q$ 3: How does developing expectations affect analytical review effectiveness?

In the previous chapter, I provided a literature review addressing the use and effectiveness of analytical review, related to contingent variables. For the aspects of the current use and potential use of analytical review, cumulative knowledge of the client and the client's risk assessments were introduced. For the aspect of analytical review effectiveness, the contingent variables relate to the development of expectations by the auditor.

In the current chapter the main research questions will be extended with more specific research questions. For this purpose, I firstly discuss the concepts of error signaling and detection, which were briefly addressed in section 1.2. These concepts are operationalized by the signaling ratio, the non-signaling ratio and the non-detection ratio. Note that the non-signaling ratio and non detectionratio as introduced in the following sections are used as surrogates for measuring audit efficiency and analytical review effectiveness respectively. Limitations of using these ratios for measuring audit efficiency and analytical review effectiveness are addressed in chapter 7.

In section 1.6, it was briefly addressed that this thesis focuses on the contribution of analytical review in error signaling rather than the use of analytical review in general. In this context, 'contribution' is defined as the percentage of errors signaled by analytical review as compared to all detected errors. However, the role of analytical review during the audit is more 
comprehensive than only identifying errors (see the 'main purpose' column in table 2.1). This limitation will be addressed in section 7.3.2.3.

The detailed research questions are summarized in table 3.1. In general, the research questions are categorized following the three primary research questions on the contribution of analytical review in error signaling, on audit efficiency and analytical review effectiveness respectively. All categories include the primary research question and one or more related secondary questions.

Table 3.1: Summary of research questions

\begin{tabular}{lll}
\hline Potential Category & Research Question \\
contribution &
\end{tabular}

\begin{tabular}{lcc}
\hline $\begin{array}{l}\text { Understanding the } \\
\text { contribution of } \\
\text { analytical review } \\
\text { in error signaling }\end{array}$ & Primary & 1. How does analytical review contribute to error \\
signaling?
\end{tabular}

Secondary 1.2 How does cumulative knowledge of the client affect the relative contribution of analytical review in error signaling?

Secondary 1.3 How do risk assessments affect the relative contribution of analytical review in error signaling?

\begin{tabular}{ll}
\hline Audit efficiency & Primary 2. How does analytical review contribute to audit \\
efficiency?
\end{tabular}

Secondary 2.1 How does cumulative knowledge of the client affect audit efficiency as measured by the non-signaling ratio? Secondary 2.2 How do risk assessments affect audit efficiency as
measured by the non-signaling ratio?

\begin{tabular}{llc}
$\begin{array}{l}\text { Analytical review } \\
\text { effectiveness }\end{array}$ & Primary & $\begin{array}{c}\text { 3. How does developing expectations affect analytical } \\
\text { review effectiveness? }\end{array}$ \\
\cline { 2 - 3 } & Secondary & $\begin{array}{l}\text { 3.1 How does starting investigating the unexpected } \\
\text { fluctuations with client inquiry affect analytical review } \\
\text { effectiveness? }\end{array}$
\end{tabular}




\section{DEVELOPMENT OF DETAILED RESEARCH QUESTIONS | 51}

The remainder of this chapter is structured into three parts. The next section addresses the concepts of error signaling and error detection. These concepts are operationalized by the signaling ratio, the non-signaling ratio and the nondetection ratio. The non-signaling ratio and the non-detection ratio are used as surrogates for audit efficiency and analytical review effectiveness respectively. In section 3.3, the primary research questions of chapter 1 are extended with more specific research questions concerning the contribution of analytical review in error signaling, and the potential effects on audit efficiency and analytical review effectiveness. The chapter concludes with a summary.

\subsection{Measurement of error signaling and error detection by analytical review}

\subsubsection{Introduction}

In section 2.4, I addressed the decision-making process of analytical review and described that the auditors' decision-making process comprises five stages, including mental representation, hypothesis generation, information search, hypothesis evaluation and decisions about subsequent audit actions. Using the five stages of the decision-making process, I recognize the aspects "error signaling' and 'error detection' as the critical elements of the decision making process. Error signaling takes place in the first stage of mental representation. Error detection refers to the other stages of the process, but mainly to the stages of hypothesis evaluation and decisions on subsequent audit actions.

The two aspects of error signaling and error detection are visualized in figure 3.1. The starting point is the evaluation of audit findings at the end of the audit (area 1b in the figure), as all detected errors are known at that time. Note that existing, but non-detected errors in the financial statements (area 1a) cannot be covered in the current field study due to the absence of data on errors that are not detected by the auditor.

Signaling the error is defined as the "audit procedure, circumstance or event that initially led the auditor to suspect that an error had occurred' (Wright and Ashton, 1989) and refers to the mental representation stage of the decisionmaking process. Example 3.1A describes error signaling by analytical review. 
Figure 3.1: The relationship between error signaling and error detection

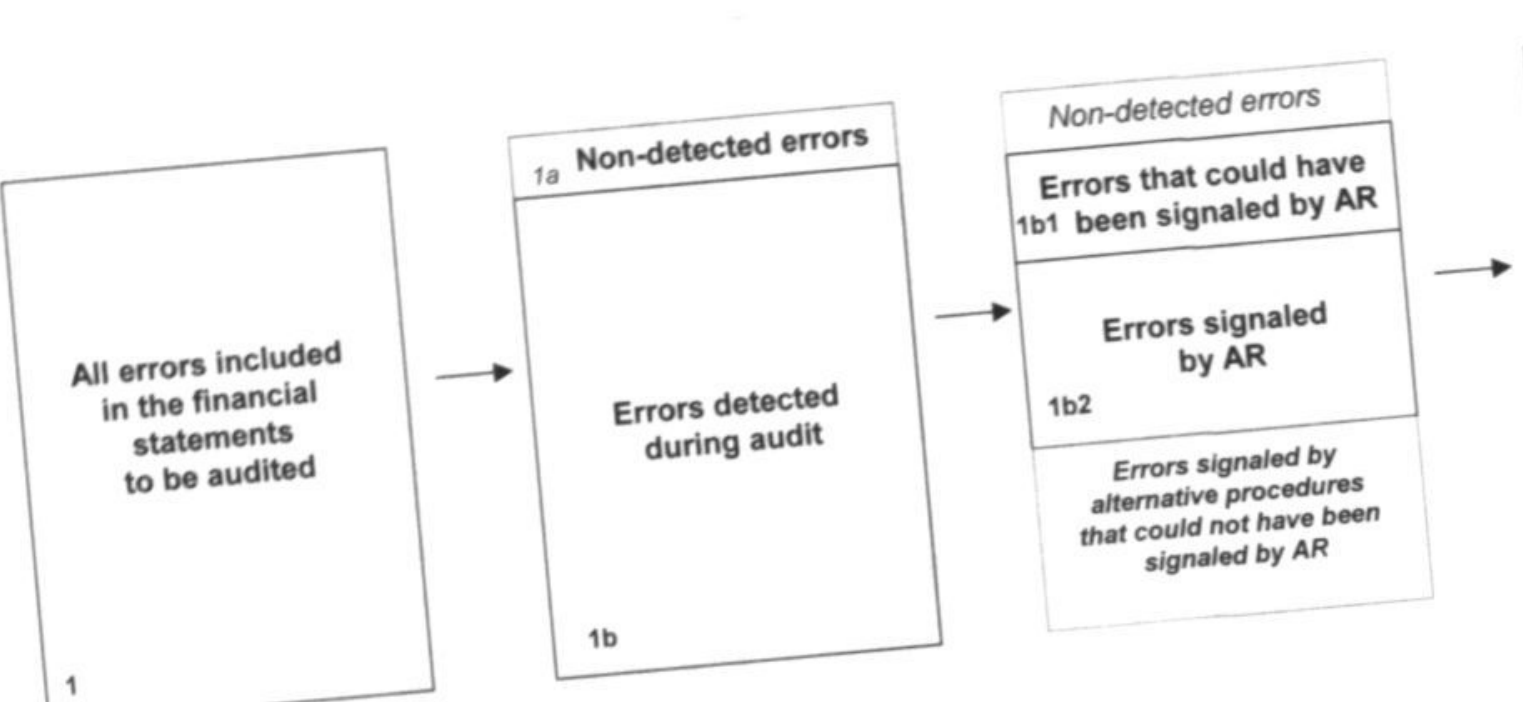

Non-detected errors

Errors that could have

been signaled by $A R$

Errors signaled, but 1b21 not detected by AR

Errors signaled and $1 \mathrm{~b} 22$ detected by AR

Errors signaled by Iternative procedures altermativ not have been that could not by $A R$
signaled 


\section{Example 3.1A: Accounts receivable}

The draft financial statements of trading company $X Y Z$ contain a material error in the valuation of accounts receivable due to financial problems at one of its major clients. Due to these problems, $X Y Z$ has large outstanding aged amounts from this major client. $X Y Z$ has not reflected the increased risk in the provision for bad debtors.

During the preliminary analytical review, the auditor observes a significant increase of trade debtors as compared to the prior year, while revenues are rather constant. Based on his cumulative knowledge of the client and his business, the auditor has the mental representation that the increase of trade debtors is inconsistent with the constant revenues and therefore may have an error nature.

$\rightarrow$ The error is signaled by analytical review

(area 1 b2 in figure 3.1)

After signaling the error, the auditor performs additional procedures to assess whether the unexpected fluctuation is due to an error or non-error. A non-error may be applicable if the unexpected fluctuation can be explained by developments in the course of business. The non-error fluctuations are not covered in this thesis, as these fluctuations are not included in the evaluation of audit findings at the end of the audit.

For unexpected fluctuations that are the result of an error, signaling the error has potentially two follow-up categories: detection and non-detection. Detecting the error with analytical review can be defined as the final assessment that the unexpected fluctuation is due to an error as a direct follow-up of signaling the error by analytical review. This category is described in example 3.1B.

\section{Example 3.1B: Accounts receivable (continued)}

Once the auditor has signaled the unexpected fluctuation, he hypothesizes that the unexpected fluctuation in accounts receivable might be due to one or more aged debtors (=hypothesis generation). As a direct follow-up procedure (=information search), he reviews the accounts receivable aging list and observes the large amount of aged amounts related to the large customer. The subsequent client representation confirms the undeserved absence of the provision for bad debts.

$\rightarrow$ The error is detected due to direct follow-up after signaling by analytical review (area 1 b22 in figure 3.1) 
Alternatively, signaling the error does not automatically imply that the error is detected, as improper hypothesis generation, information search and hypothesis evaluation might lead to non-detection of the error. This category is described in example 3.1C.

\section{Example 3.1C: Accounts receivable (continued)}

Once the auditor has signaled the unexpected fluctuation, he hypothesizes that the unexpected fluctuation in accounts receivable might be due to one or more aged debtors (=hypothesis generation) but can also be due to fluctuations in the monthly sales volumes. As a direct follow-up procedure (=information search), he asks the client for an explanation. The client represents that the increased receivables are due to relatively higher sales in November and December as compared to September and October. As a result, the yearly revenues are in line with prior year, but the outstanding receivables are relatively high (=inaccurate client representation).

The auditor evaluates the client representation as reasonable and decides not to perform additional steps to corroborate these findings with other evidence (=hypothesis evaluation).

$\rightarrow$ The error is not detected as a direct follow-up after signaling by analytical review. (area 1 b21 in figure 3.1)

\subsubsection{Type I and type II errors related to error signaling and error detection}

In section 2.4.3.2, the audit risk model was referred to, including 'detection risk', which is defined as: “... the risk that the auditor's substantive procedures will not detect a misstatement that exists in an account balance or class of transactions that could be material, individually or when aggregated with misstatements on other balances or classes" (ISA No. 400, par. 8). Defining the hypothesis $\mathrm{H}_{0}$ that the audited financial statements do not include a material error, the Type I error is the risk that the auditor assesses that the financial statements do not include one or more material errors, but in fact include one or more material errors. The alternative hypothesis $\mathrm{H}_{\mathrm{A}}$, defined as not accepting the financial statements under the assumption of an error, but which in fact does not exists, is a type II error.

In this thesis, type I errors specifically related to analytical review refer to errors that are not signaled by analytical review that could have been signaled (area 1 b1 in figure 3.1), or errors that were signaled by analytical review, but 
not detected (area $\mathbf{1 b 2 1}$ in figure 3.1). Type II errors, signaling unexpected fluctuations that have a non-error nature, are not included in this thesis. The type I and type II errors are further discussed in section 7.3.2.3.

\subsubsection{The signaling ratio}

Investigating the contribution of analytical review in error signaling starts with the analysis of the audit procedure that signaled each individual error. For each individual error, an audit procedure initially signaled the error. As a result, the contribution of analytical review in error signaling for all errors found in a population of audit files can be measured.

For the investigation of the contribution of analytical review in error signaling for each individual audit, I developed the 'signaling ratio'. The introduction of a ratio instead of using an interval scale on the number of errors is aimed at eliminating the potential correlation between the number of errors signaled by analytical review and the total number of errors detected during the audit.

Figure 3.2: Signaling errors by analytical review

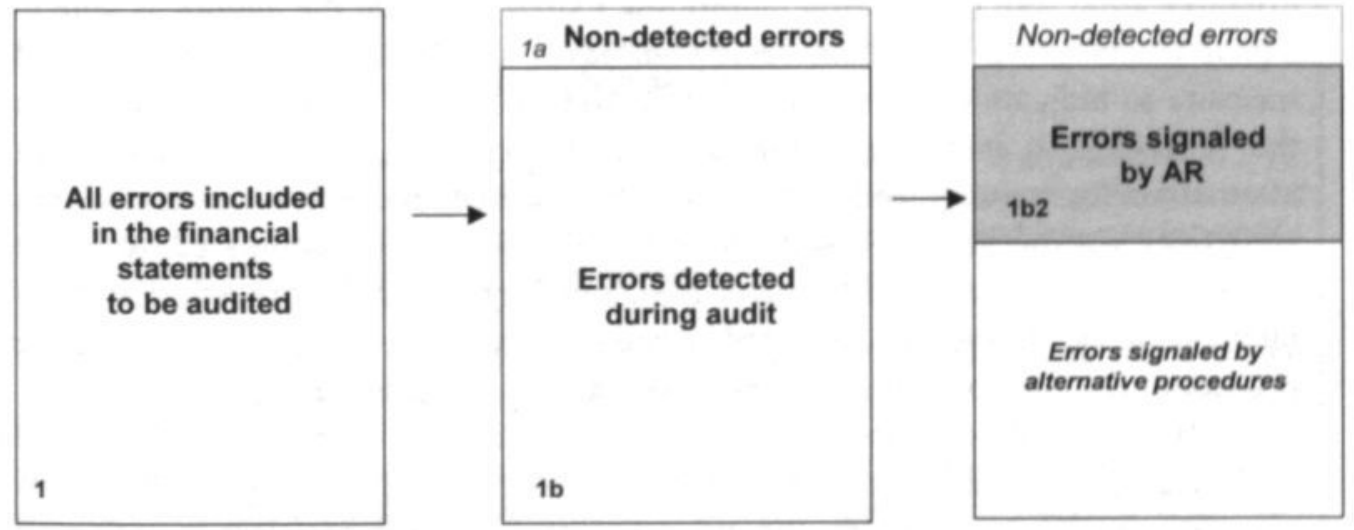

The extent the auditor has signaled errors (category $\mathbf{1 b 2}$ of figure 3.2 ) related to the number of errors detected during the audit (1b) is defined as the signaling ratio: 


\section{$E_{s}$ \\ $E_{D}$}

Where:

- $\quad E_{S}$ refers to the errors signaled by analytical review (area 1 b2 in figure 3.2)

- $\quad E_{D}$ refers to all errors detected during the audit (area 1b in figure 3.2)

Using the current definition for the signaling ratio, the potential outcomes of the signaling ratio vary from nil to one, where the minimum score of nil indicates, that no errors were initially signaled by analytical review. The maximum score of one indicates that all errors that are detected during an audit, are signaled by analytical review.

\subsubsection{The non-signaling ratio}

Audit efficiency can be improved if errors are identified by audit procedures that are cost-effective. As analytical review is generally considered to be a costeffective audit tool (see POAE, 2000), the extent to which the auditor is able to signal errors using analytical review in favor of alternative procedures is a measure to indicate the contribution of analytical review on audit efficiency. In the following, it is assumed that analytical review is always a sound audit alternative for gaining audit efficiency. In practice, in certain circumstances, analytical review is not always more cost-effective as compared to other procedures. For instance, if the error is signaled by a 'simple' procedure such as client inquiry, it can be doubted whether analytical review as alternative procedure is more cost-effective. This limitation is considered in chapter 7.

Based on the premise that audit efficiency can be improved by the use of analytical review as an alternative audit procedure, I developed the 'nonsignaling ratio' to measure the opportunity for the improvement of audit efficiency. The introduction of a ratio instead of using an interval scale on the number of errors is aimed at eliminating the potential correlation between the number of errors not signaled by analytical review and the total number of errors detected during the audit.

When measuring the opportunity for audit efficiency as related to error signaling based on the current use of audit procedures, I recognize three categories of error signaling. These categories are visualized in figure 3.3. 
Figure 3.3: Signaling and non-signaling of errors by analytical review

\begin{tabular}{|c|c|c|}
\hline \multirow{4}{*}{$\begin{array}{l}\text { All errors included } \\
\text { in the financial } \\
\text { statements } \\
\text { to be audited }\end{array}$} & ${ }_{1 a}$ Non-detected errors & Non-detected errors \\
\hline & \multirow{3}{*}{$\begin{array}{l}\text { Errors detected } \\
\text { during audit }\end{array}$} & $\begin{array}{l}\text { Errors that could have } \\
1 \mathrm{~b} 1 \text { been signaled by AR }\end{array}$ \\
\hline & & $\begin{array}{cc}\text { Errors signaled } \\
1 \mathrm{~b} 2 & \text { by } A R\end{array}$ \\
\hline & & $\begin{array}{l}\text { Errors signaled by } \\
\text { alternative procedures } \\
\text { that could not have been } \\
\text { signaled by AR } \\
\text { 1b3 }\end{array}$ \\
\hline
\end{tabular}

The first category of error signaling contains errors already signaled by analytical review (1 b2 in figure 3.3) and has been addressed in example 1 A of the previous section. The second category contains errors signaled by other procedures, for cases where analytical review is considered not to be an alternative procedure (1b3). This category is described in example 3.2.

\section{Example 3.2: Errors signaled by alternative procedures that could not have been signaled by analytical review}

The company $X Y Z$ has a legal dispute with one of his clients. It is expected that $X Y Z$ will suffer a material loss due to this dispute. At the moment, the dispute is in court and is not yet reflected in the draft financial statements and related lawyers expenses are not yet included in the accounting system.

Signaling this material error by analytical review is not possible, as the financial consequences are not included in the financial statements.

Alternative procedures, such as reviewing the minutes of the management board, asking for a management representation, and/or requesting a lawyer's letter can reveal the error.

The error can be signaled by other procedures, and analytical review is not regarded as an alternative.

(area 1 b3 in figure 3.3)

The third category contains errors signaled by other procedures that could alternatively have been signaled by analytical review (1b1). This category is described in example 3.3. 


\section{Example 3.3: Errors that could have been signaled by analytical review}

In the draft figures of the company $X Y Z$, a material overstatement is included in the tangible fixed assets due to the absence of entering the depreciation charge for the last quarter. The absence of entering the depreciation charge is due to personnel problems at the accounting department. As a result, the depreciation charge in the profit and loss statements is understated.

The auditor assesses this error when performing tests of detail on the tangible fixed assets by computation of the depreciation rate * purchase value for a new capital expenditure originated in this year. He then observes that the depreciation charge is partly absent not only for this new item, but for all items in the tangible fixed asset ledger. The time effort for revealing the total impact of the error is four hours.

Performing analytical review on the profit and loss statement when starting the audit might have signaled the error immediately.

$\rightarrow$ The error is signaled by another procedure (test of detail), but could alternatively have been signaled by analytical review. In the latter case, the time needed to signal the error is minimal as compared with the test of detail.

(area 1 b1 in figure 3.3)

The latter category has the potential for improving audit efficiency and needs further investigation. The extent the auditor has errors in category $\mathbf{1 b} \mathbf{1}$ of the figure related to the number of errors detected during the audit (1b) is defined as the non-signaling ratio:

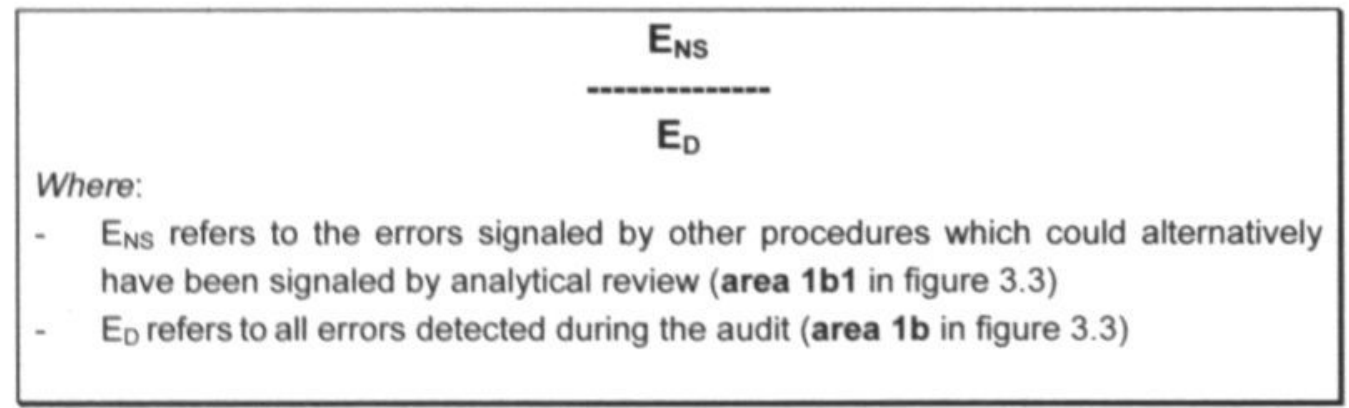

Using the current definition for the non-signaling ratio, the potential outcomes of the non-signaling ratio vary from nil to one, whereas the minimum score of nil indicates, that all errors during an audit which are signaled with other procedures could not alternatively have been signaled with analytical review. The maximum score of one indicates that all errors during an audit, which are signaled by other 
procedures than analytical review might have been signaled by analytical review alternatively. In other words, the higher the non-signaling ratio, the better the opportunities for gaining audit efficiency by using analytical review more frequently.

It was considered to define the non-signaling ratio as area $1 \mathrm{bl}$ as compared to area $1 \mathrm{~b} 2$ instead. Using such a definition, the outcomes would have been more distributed, but neglect the relativity to the total number of errors observed in the audit file.

\subsubsection{The non-detection ratio}

In chapter 2, I addressed that previous research shows that auditors have difficulty with hypothesis generation, information search and hypothesis evaluation during the performance of analytical review. I described in section 2.4.4.3 that client representations may bias the auditor during the information search of his decision making process of analytical review. Specifically, starting a fluctuation analysis with asking a client representation for the unexpected fluctuation, without developing one or more own hypotheses on the potential causes of the fluctuation, may prevent the auditor from detecting the error. Besides, I described in section 2.5.5 that previous research showed that the nature, timing and extent of investigation might also influence the auditors' ability to detect the error. Example 1C explained the risk of non-detection if the auditor does not corroborate the finding with other (internal or external) evidence. The two possible follow-up steps after signaling the error by analytical review, detection and non-detection, are visualized in figure 3.4.

If the auditor does not detect the error as a direct follow-up of signaling the error during analytical review, analytical review is performed ineffectively. Analytical review effectiveness can be improved if the ratio of detected errors relative to the number of signaled errors by analytical review can be increased. I therefore developed the 'non-detection ratio'. The introduction of a ratio instead of using an interval scale on the number of errors is aimed at eliminating the potential correlation between the number of errors not detected as direct follow-up of analytical review and the total number of errors signaled by analytical review. 


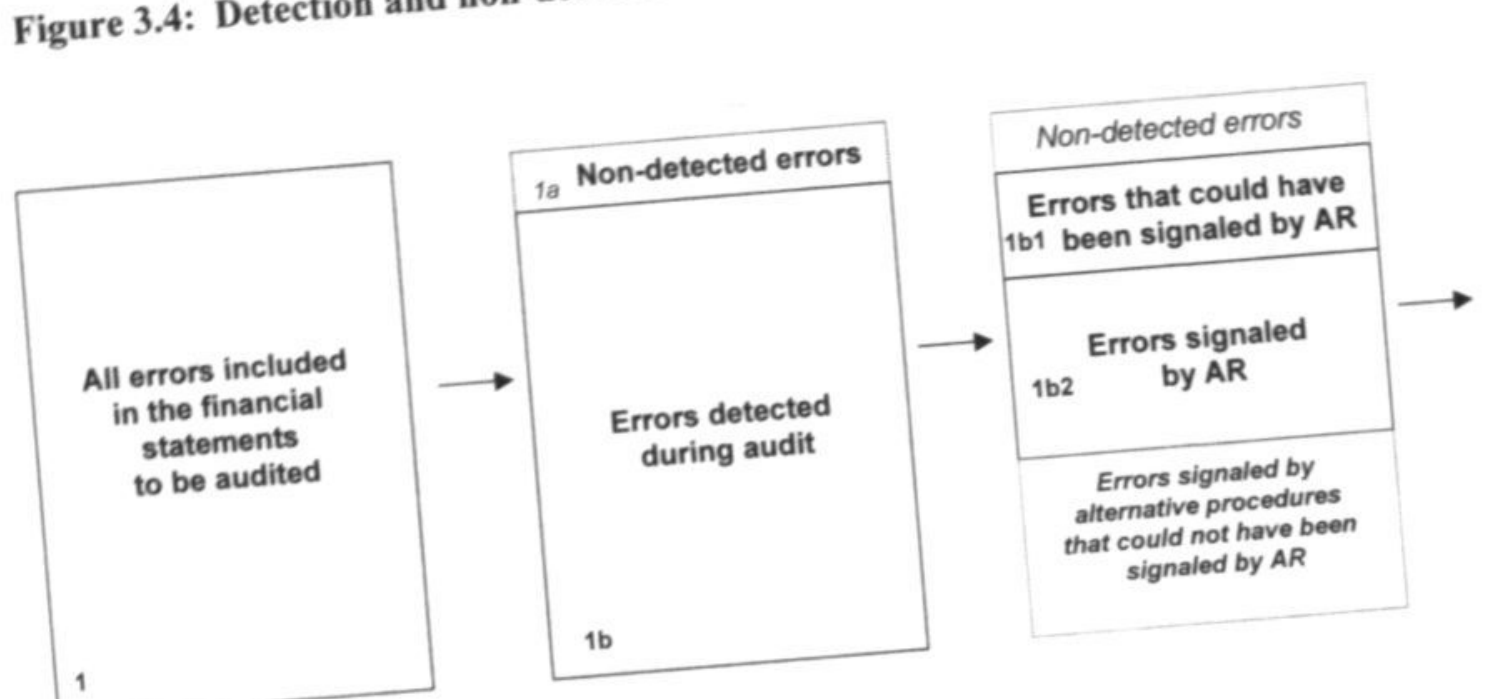

\begin{tabular}{|c|}
\hline Non-detected errors \\
Errors that could have \\
been signaled by AR \\
\hline $\begin{array}{c}\text { Errors signaled, but } \\
\text { not detected by AR } \\
1 \mathrm{~b} 21\end{array}$ \\
\hline $\begin{array}{c}\text { Errors signaled and } \\
\text { detected by AR }\end{array}$ \\
\hline $\begin{array}{c}\text { Errors signaled by } \\
\text { alternative procedures } \\
\text { that could not have been } \\
\text { signaled by AR }\end{array}$ \\
\hline
\end{tabular}


For instance, assume audit $\mathrm{A}$ with 4 errors signaled by analytical review and of which 2 were not detected as direct follow-up. Further assume audit B with 2 errors signaled by analytical review and 1 not detected as direct followup. Audit B has only one error not detected as direct follow-up, whereas audit A has twice as much errors not detected as direct follow-up. This double hit is related to the double numbers of errors signaled by analytical review (A: 4; B: 2 ). At the end, the non-detection ratio is .5 for both audits.

The extent the auditor is able to detect errors during analytical review can be made operational as the number of errors signaled and detected by analytical review (area 1 b22 in figure 3.4 ) relative to the number of errors signaled by analytical review during the audit (area 1 b2 in figure 3.4). Negatively stated, the 'non-detection ratio' is defined as:

\begin{tabular}{|c|c|}
\hline & $\mathbf{E}_{\mathrm{ND}}$ \\
\hline & $E_{s}$ \\
\hline & $\begin{array}{l}E_{N D} \text { refers to the actual errors not detected as a direct follow-up of signaling the } \\
\text { error by analytical review (area } \mathbf{1 b 2 1} \text { in figure } 3.4 \text { ) }\end{array}$ \\
\hline- & $E_{S}$ refers to all errors initially signaled by analytical review (area 1 b2 in figure 3.4 ) \\
\hline
\end{tabular}

Using the current definition for the non-detection ratio, the potential outcomes of the non-detection ratio vary from nil to one, where the minimum score of nil indicates, that all errors initially signaled by analytical review, were detected as a direct follow-up procedure. Inherent to the field study concept in which only known errors are covered, the error is detected by an alternative audit procedure during the remaining part of the audit. The maximum score of one indicates that during the audit all errors initially signaled by analytical review were not detected as a direct follow-up procedure. In general, the higher the non-detection ratio, the greater the opportunity for improving analytical review effectiveness by improving the quality of the fluctuation analysis.

\subsection{Development of research questions}

\subsubsection{Introduction}

In this section, the three primary research questions will be extended with more specific, secondary research questions. The next section addresses the 
$62 \mid$ CHAPTER 3

contribution of analytical review in error signaling. Section 3.3.3 addresses the potential of analytical review for increasing audit efficiency. Section 3.3.4 addresses analytical review effectiveness. The research questions are addressed in a field study as presented in the next chapters.

\subsubsection{Research questions on the contribution of analytical review in error signaling}

Wright and Ashton (1989) investigated the role of analytical review in error signaling. They performed an archival study on the 1984 audit files of Peat Marwick in the United States. Their findings indicate that relatively simple audit procedures, such as analytical review, client inquiry and recalling prior year audit findings, signal more than $50 \%$ of the errors during the audit. Their study also indicated that the role of analytical review in error signaling was only weakly dependent on the internal control strength of the company.

Note that the Wright and Ashton files were based on the mid 1980's audit settings, and in the past 15 years, the audit environment has evolved, which will be discussed in section 4.2.1. Therefore, it is relevant to replicate their study in a current audit context and test whether the contribution of analytical review is still significant in error signaling as it was in the Wright and Ashton study.

The related research question is:

\section{RQ 1.1: What is the relative contribution of analytical review in error signaling as compared to other audit procedures?}

The first research question has a descriptive nature and is the introduction to the remaining research questions.

Part of the analysis of research question 1.1 is the investigation which specific analytical review procedure was involved in signaling the error. Analytical review can be performed with a range of specific procedures varying from a simple comparison of current with prior year figures to extended regression analysis. In the previous studies, researchers stressed the added value of regression techniques. For instance, Kinney and Uecker (1982, p. 67) argued that "the only inappropriate information is the book value, which compromise the basis for comparison". This argument implies that all other information is appropriate. Consequently, models based on information, such as regression models, should be appropriate and useful in audit practice as a predictor of expected values in the unaudited figures. However, inappropriateness in practice 
of regression models has resulted in only minimal use of these models in practice (Biggs and Wild, 1984; Ameen and Strawser, 1994).

Professional standards do not prescribe which specific analytical review procedures are to be used. Based on the Wright and Ashton (1989) findings and on the limited attention for regression analysis in the audit practice, it is expected that also in the current field study mainly simple analytical review procedures are used.

\subsubsection{Contingent variable: cumulative knowledge of the client}

Professional standards prescribe the auditor to use his cumulative knowledge of the client when developing the audit plan. As introduced in section 2.4.2, cumulative knowledge comprises the cumulative experience of the audit firm as well as the experience of the audit manager in charge. In this thesis, the cumulative knowledge is operationalized by the number of years of experience of the audit firm (client tenure) and the number of years the audit manager is involved in the specific engagement.

Previous research findings show that the quality of audit work depends on the auditor's expertise. Houghton and Fogarty (1991) found that auditors with prior knowledge about their client could identify during the audit planning process those audit areas having the highest risk of error. In section 2.4.2, I addressed that previous research used general experience (e.g. Biggs, Mock and Watkins, 1988; Bedard and Biggs, 1991a) or industry-specific (as surrogate for domain-specific) experience (Bedard and Biggs, 1991b; Bedard, Biggs and DiPietro, 1998) as surrogates for expertise. The learning effect implies that the more experienced auditors have the ability to select the audit procedure that is the most applicable for signaling errors. As the audit manager is responsible for making the audit plan operational with the decision on the nature and extent of audit procedures to be used, is it expected that the expertise of the audit manager is a contingent factor on signaling errors with analytical review. The same relationship is expected for client tenure as the surrogate for the audit firm's experience. The signaling ratio is used to test the research question below.

The related research question is:

RQ 1.2: How does cumulative knowledge of the client affect the relative contribution of analytical review in error signaling? 
$64 \mid$ CHAPTER 3

As analytical review is an attention directing procedure, it is expected that cumulative knowledge has a positive effect on the contribution of analytical review in error signaling.

\subsubsection{Contingent variable: Risk assessments}

In section 2.4.3, I described the relationship between risk assessments and the audit procedures. I noted that professional standards require that the risk assessments are to be addressed in the audit plan, including the decision on the nature and extent of the audit procedures to be used.

Wright and Ashton (1989) investigated the potential relationship between the assessment of internal control procedures and the audit procedure that signaled the error. They argued that the reliability of accounting records and financial statement data should be enhanced as internal control procedures are strengthened. Thus, when control procedures are strong, the auditor should be able to place greater reliance on internal accounting records and analytical review procedures. Hence, if controls are weak, the auditor should place less reliance on such evidence. The Wright and Ashton findings indicate that the contribution of analytical review in error signaling is the largest at clients with moderate internal control procedures in the specific transaction cycle incorporating the error, as compared with clients who have strong or weak internal control procedures.

The apparent contradiction that analytical review contributes more to error signaling at clients with moderate internal controls than at clients with strong internal controls, can be explained by the presumption that the reliance on analytical review is indeed higher when internal controls are strong, but that the error incidence is lower than cases where the controls are moderate or weak. As a result, analytical review may be used more frequently, but the chance to signal an error is less at clients with strong controls as compared to clients with moderate controls. Note that the extent and nature of audit procedures is contingent to the desired level of assurance by the auditor. This consideration assumption will be addressed in chapter 7 .

Despite the increased attention for the assessment of control environment condition in the current audit approaches of the audit firms, which were initiated by the COSO report (COSO, 1992), little is known about the relationship between inherent and control risk assessments, control environment assessment, errors, and the implications of these elements for the audit plan. Specifically, no research findings are available on the influence of control environment on the contribution of analytical review to error signaling. Further research is needed to 
investigate the influence of the control environment condition on analytical review. Marden, Holstrum and Schneider (1997) explored the effects of control environment on risk assessments. The results indicate that the control environment has potentially a large impact on the auditors' assessment of risk and consequently the audit plan, including the decision on the nature and extent of audit procedures to be used. In an earlier study, Kreutzfeldt and Wallace (1986) found in an archival setting that companies with better management controls ${ }^{7}$ have fewer and smaller errors in the financial statements than others.

As indicated before, the understanding of the influence of internal controls on financial statements has evolved from internal control procedures towards control environment in the last decade. The COSO report indicates a relationship between the assessment of control environment and control risk, as follows:

"The control environment sets the tone of an organization, influencing the control consciousness of its people. It is the foundation for all other components of internal control, providing discipline and structure" (COSO, 1992).

Consistent with the current framework of internal controls, it might be more relevant now to investigate the influence of the control environment condition on the contribution of analytical review in error signaling, rather than to replicate the Wright and Ashton (1989) approach with internal control procedures in the specific transaction cycle. Nevertheless, consistent with the Wright and Ashton (1989) findings, it is to be investigated whether the contribution of analytical review in error signaling is lower at clients with an excellent control environment condition than at clients with a moderate control environment condition. The signaling ratio is used to test the following research question.

The related research question is:

$R Q$ 1.3: How do risk assessments affect the relative contribution of analytical review in error signaling?

As previous research did not show a strong relationship between risk assessments and analytical review, the research question is stated without an expected direction.

\footnotetext{
${ }^{7}$ Kreutzfeldt and Wallace (1986) specified management controls by (a) management expertise in recording routine transactions, (b) competence of accounting personnel, (c) turnover of accounting personnel, and (d) management attitude toward accounting policies.
} 
$66 \mid$ CHAPTER 3

\subsubsection{Research questions on audit efficiency}

3.3.3.1 Contingent variable: the influence of the cumulative knowledge of the client

In section 3.3.2.1, the expected effect of cumulative knowledge of the client was investigated in relationship to the contribution of analytical review in error signaling. Similar to the arguments on testing the cumulative knowledge in section 3.3.2.1, it is expected that the cumulative knowledge of the client affects the potential of analytical review for audit efficiency. The non-signaling ratio is used to test the following research question.

The related research question is:

RQ 2.1: How does cumulative knowledge of the client affect audit efficiency as measured by the non-signaling ratio?

\subsubsection{Contingent variable: risk assessments}

Similar to the arguments for testing risk assessments related to the contribution of analytical review in error signaling, the relationship between analytical review and risk assessments is relevant for the auditor when considering the potential of analytical review for audit efficiency. For instance, the opportunity to gain audit efficiency by using analytical review can be greater at clients with a moderate control environment condition, than at clients with an excellent control environment condition. The non-signaling ratio is used to test the following research question. In this specific case, it is to be investigated whether the nonsignaling ratio as a measurement scale for audit efficiency is negatively related to the control environment condition, as the a priori reliance on analytical review might be already higher at clients with an excellent control environment condition.

The related research question is:

RQ 2.2: How do risk assessments affect audit efficiency as measured by the non-signaling ratio? 


\subsubsection{Research question on analytical review effectiveness}

\subsubsection{Introduction}

In this section, the primary research question related to analytical review effectiveness -How does developing expectations affect analytical review effectiveness- is addressed with a more specific research question on client representations. In section 2.4.4.3 it was discussed that previous research stressed the potential bias by inaccurate client representations. Less attention in previous research was paid to the potential negative effect on analytical review effectiveness when a client representation is accurate. In that case, starting the fluctuation analysis is effective and contributes to audit efficiency additionally. Further evidence from a field setting may contribute to a better understanding of the potential effects of using client representations during the fluctuation analysis.

\subsubsection{Starting the fluctuation analysis with client representations}

Client representations are an important source of audit evidence. In section 2.4.4.3, it was addressed that professional standards require the auditor to be skeptical towards this source of evidence, as it is presumed that the source is motivated only to disclose information to the auditor that is in its own interest. Previous research indicates that the auditor may indeed be biased by client representations (Bedard and Biggs, 1991b, Bierstaker, Bedard and Biggs, 1999) when the client representation is inaccurate. In section 3.2, the difference between signaling and detection was addressed. It is expected that if an auditor signals the errors and then immediately notes the (incorrect) client representation, he runs the risk of a non-detection of the error. As a result, analytical review effectiveness is not obtained.

Contrarily, if the client representation is accurate, the auditor has the opportunity to detect the error quickly. Therefore, if the auditor is able to evaluate the objectivity and competence of the source, he might have opportunities to improve analytical review effectiveness.

As the previous research on the influence of client representations has provided only evidence by experimental settings, corroboration is needed in a field setting. The non-detection ratio is used to test the following research question. 
$68 \mid$ CHAPTER 3

The related research question is:

RQ 3.1: How does starting investigating the unexpected fluctuations with client inquiry affect analytical review effectiveness?

\subsubsection{Introduction of a control variable: prefinal audit procedures}

As mentioned in section 2.2, the audit planning stage enables the auditor to be flexible in the nature, timing and extent of the audit procedures. As part of audit planning at a number of engagements, the auditor has the possibility to perform 'prefinal audit procedures', which are performed during the interim stage of the audit. Prefinal audit procedures are meant as an early warning procedure for multi-location audits. All local audit teams report preliminary audit findings, including errors that should be resolved before year-end in order to prevent audit adjustments at year-end.

In general, the nature of prefinal audit procedures is similar to the audit procedures that can be used during the final audit. However, the auditor may have re-organized the audit plan in terms of timing, nature and extent of audit procedures as compared with audits without prefinal audit procedures. For instance, prefinal audit procedures on the third quarter figures may reveal errors that otherwise could have been discovered by the client in the fourth quarter. In that case, the auditor may not have observed the error at all in an audit without prefinal audit procedures. Also, it is possible that the auditor has identified the error during the prefinal audit procedures with an audit procedure that would not have been used during an audit without prefinal audit procedures. As a result, the contribution of audit procedures in error signaling may vary between audits with and without prefinal audit procedures respectively.

The existence of prefinal audit procedures is therefore introduced as a variable that may have an effect on the contribution of analytical review in error signaling. The existence of prefinal audit procedures is included in the descriptive and statistical analyses of chapter 5 and 6 as a control variable for the signaling ratio and the non-signaling ratio.

\subsection{Summary}

In this chapter I developed research questions based on the primary research questions, which were formulated in chapter 1. The further development of research question was based on the literature overview in chapter 2 . The 


\section{DeVElopment of DetaIled RESEARCH Questions $\mid 69$}

research questions refer to the contribution of analytical review in a field setting, and the effects of specific contingent variables on audit efficiency and analytical review effectiveness. I will introduce the research design in the next chapter, followed by preliminary descriptive statistics in chapter 5. Multivariate analyses are performed in chapter 6. As mentioned in section 3.3.2, research question 1.1 has a descriptive nature and is fully addressed in the descriptive analysis of chapter 5 . 


\section{RESEARCH DESIGN}

\subsection{Introduction}

The literature overview in chapter 2 noted that most previous research on analytical review is based on experimental studies. In order to add to our knowledge concerning the efficiency and effectiveness of analytical review, it is important to use a research method that overcomes the limitations of previous experimental research. An archival setting enables us to observe documented audit decisions from actual audits including the documentation of contingent variables that may affect audit efficiency and effectiveness.

This chapter describes the research design used in this study. Section 4.2 introduces the audit firm engaged in this study, followed by the sampling method in section 4.3. Sample size considerations are described in section 4.4, followed by the selection strategy in section 4.5 . This chapter ends with a description of the questionnaire used in the study in section 4.6 and the response rate in section 4.7.

\subsection{Sample}

\subsubsection{The audit firm}

The audit firm involved in the sample is PricewaterhouseCoopers ( $\mathrm{PwC}$ ) in The Netherlands, more specifically the ex-legacy Coopers and Lybrand (C\&L) just before the merger with Price Waterhouse and prior to the introduction of new documentation standards. The main reason for choosing this firm is my involvement as an auditor within this firm. This position enabled me, in my role as researcher, to facilitate the data collection process and to obtain clarifications from participants in cases where the replies in the questionnaire were not completed or were unclear.

Previous archival studies on error findings have been performed at various audit firms, but mainly at KPMG Peat Marwick (Hylas and Ashton, 1982, Wright and Ashton, 1989, Mock and Wright, 1993) and Arthur Andersen (Kreutzfeldt and Wallace, 1986). Due to the wide implementation of US- and 
IFAC- GAAS in all Big Four audit firms, it is not expected that various audit approaches would generate substantially different audit findings between these audit firms. The considerations for this remark will be addressed further in section 7.3.2.

Since the publication of previous archival error studies around 1990, the audit environment has evolved. For example, the COSO report (COSO, 1992) is considered to be an important milestone for audit approaches when introducing the element of control environment as part of the internal control system. Many audit firms, including C\&L in 1994, revised their audit approaches following the issuance of the COSO report. As a consequence, a sample based on recent C\&L files may differ from previous archival studies, partly as a result of the evolution of audit approaches. These methodological issues are addressed in chapter 7, when discussing the limitations of the current study.

\subsubsection{Country}

The majority of field studies in audit research and experimental studies in the analytical review area have been performed in the US. Unfortunately, Europe has only a limited tradition in empirical audit research and archival studies in particular. Potentially, the results in a European context may deviate from a US setting due to economic, regulatory and cultural differences. However, I do not expect significant differences between the Dutch and US C\&L audit process due to the fact that the audit approach has been implemented based on global audit standards.

\subsubsection{Electronic archives}

C\&L introduced an electronic audit support system 1995. This electronic system comprises an audit planning, performing and filing process, based on a database structure. Amongst others, an important advantage of this electronic system as compared with hardcopy files is the audit trail from the audit work performed to the main audit findings at the end of the audit. For instance, when recording an observation during an audit procedure, upcoming issues are recorded specifically for follow-up by the audit manager and partner. They record the resolution of the issue as a review comment in the same working paper. Another advantage is the standardized documentation of audit evidence as compared with paper files. As a consequence, participants were able to recall the audit findings by following the audit trail, which had been recorded in the audit database. Note that my study refers to the $\mathrm{C} \& \mathrm{~L}$ audit files prior to the introduction of the new documentation 
72 | CHAPTER 4

standards in the merged firm with Price Waterhouse. The new documentation standards focus, amongst others, on the outcomes of each audit procedure and not on recording the process. As a result, in the renewed documentation standards, posted errors (adjusted errors during the audit work) are not documented anymore.

\subsection{Sampling method and data quality considerations}

The sampling method used in this study is based on Wright and Ashton (1989), who investigated audit errors and audit procedures in an archival study. They asked audit managers to review their files and to report on audit errors and earnings effects, error causes, materiality, initial detection review and internal control strength.

The research design of the current study contains important improvements of the data quality as compared with prior archival studies in the audit area. The current design overcomes the limitations previous researchers had with data collection. For instance, Mock and Wright (1999) summarize the data quality problems with limitations due to confidentiality and data coding. In the current study, data quality is improved due to the fact that the researcher has direct access to the participants, whereas previous researchers did not have direct access for reasons of confidentiality. Direct contact with the participants enabled me to ask for additional clarifications when specific replies were not clear. Data quality is further due to the fact that the files are archived electronically, whereas previous archival studies were based on paper files. Within the electronic archiving system, an audit trail can be observed from the final considerations back to the audit procedures performed.

\subsection{Sample-size considerations}

\subsubsection{Introduction}

A number of previous audit archival studies did not use a randomly selected sample, but used non-probability samples. The main reason for a non-probability sample is the exploratory nature of current and previous archival studies. The current study combines the probability and non-probability aspects from previous studies. 


\subsubsection{Sample size considerations}

When considering the desired sample size of the current study, I concluded from previous research (see table 4.1) that the sample size should take three factors into account. Firstly, the research objectives of the field study influence the number of observations needed. Given the research questions developed in chapter 3, not only the number of audit files in the sample is relevant, but also the number of errors included in each file and statistics on signaling and detecting errors.

Secondly, the sample size should lead to an acceptable response rate as the response rate in previous field studies varied significantly. For instance, Waller's study on risk assessments (1993) used 385 files in various industries and had a response of $215(56 \%)$. Wright and Ashton (1989), who limited their investigation to explorations on audit errors, had a sample of 630 randomly selected files resulting in 186 files used $(29,5 \%)$. Mock and Wright (1993), who focused their study on planning judgments, had a sample of 345 engagements and a response of 159 audits $(46 \%)$.

Finally, I had practical sample size limitations as I involved practitioners in this study. Based on my discussions with the responsible partners, I observed that completing the questionnaire would lead to a significant workload of managers and staff. The audit firm involved was willing to co-operate, but required a restricted effort. A random sample approach requiring a larger sample was considered to be too costly for the participating audit firm. Alternatively, I chose for a combination of a probability and non-probability sample, which will be addressed in the following section. 
74 | ChAPTER 4

Table 4.1: Overview of previous field studies, focus, sample size and response

\begin{tabular}{|c|c|c|c|c|c|c|}
\hline Study & Focus & Sample & $\begin{array}{r}\text { Sample } \\
\text { size }\end{array}$ & $\begin{array}{r}\text { Respon- } \\
\text { se }^{8}\end{array}$ & $\begin{array}{r}\text { Respon- } \\
\text { se rate }\end{array}$ & Errors \\
\hline $\begin{array}{l}\text { Hylas and Ashton } \\
\text { (1982) }\end{array}$ & 5 largest errors & $\begin{array}{l}\text { Non- } \\
\text { probability }\end{array}$ & 200 & 152 & $76 \%$ & 281 \\
\hline $\begin{array}{l}\text { Kreutzfeldt and } \\
\text { Wallace (1986) }\end{array}$ & All errors & $\begin{array}{l}\text { Non- } \\
\text { probability }\end{array}$ & 260 & 260 & $100 \%^{9}$ & 1506 \\
\hline $\begin{array}{l}\text { Wright and Ashton } \\
\text { (1989) }\end{array}$ & $\begin{array}{l}5 \text { largest exceeding } \\
20 \% \text { of materiality }\end{array}$ & $\begin{array}{l}\text { Non- } \\
\text { probability }\end{array}$ & 630 & 186 & $29.5 \%$ & 368 \\
\hline $\begin{array}{l}\text { Mock and Wright } \\
\text { (1993) }\end{array}$ & $\begin{array}{l}\text { Planning judgments in } \\
\text { accounts receivable } \\
\text { and accounts payable } \\
\text { (manufacturing, } \\
\text { merchandising) }\end{array}$ & Probability & $345^{10}$ & 159 & $46.0 \%$ & N/A \\
\hline Waller (1993) & $\begin{array}{l}\text { Control assessment in } \\
\text { accounts receivable, } \\
\text { inventory, accounts } \\
\text { payable (various } \\
\text { industries) }\end{array}$ & Probability & 385 & 215 & $55.8 \%$ & $\mathrm{~N} / \mathrm{A}$ \\
\hline $\begin{array}{l}\text { Maletta and } \\
\text { Wright (1996) }\end{array}$ & $\begin{array}{l}\text { Industry error } \\
\text { characteristics in } 6 \\
\text { industries }\end{array}$ & Probability & 406 & 171 & $42.1 \%$ & 368 \\
\hline $\begin{array}{l}\text { Mock and Wright } \\
\text { (1999) }\end{array}$ & $\begin{array}{l}\text { Audit plan } \\
\text { adjustments reflecting } \\
\text { changed risks in } \\
\text { general manufacturing } \\
\text { and high tech } \\
\text { manufacturing }\end{array}$ & Probability & 160 & 74 & $46.3 \%$ & $\mathrm{~N} / \mathrm{A}$ \\
\hline Eimers (current) & $\begin{array}{l}8 \text { largest errors in } \\
\text { various industries }\end{array}$ & $\begin{array}{l}\text { Probability/ } \\
\text { Non- } \\
\text { probability }\end{array}$ & 184 & 147 & $79.9 \%$ & 624 \\
\hline
\end{tabular}

${ }^{8}$ After reduction of non-usable responses.

${ }^{9}$ The study was an internal Arthur Andersen project, with compulsory participation.

${ }^{10}$ Based on a random sample of 600 minus 255 engagements that did not meet the selection criteria or were no client anymore. 


\subsection{Selection strategy}

The sampling strategy was based on the organizational structure of the Dutch PwC audit practice. PwC is structured with Quality Assurance (QA) partners responsible for quality assurance in their local business unit. These partners act under responsibility of the Assurance \& Business Advisory Services (ABAS) Board". The ABAS Board supported this study by an introductory memo requesting each QA partner to randomly select 10 audit clients for this study. Selection criteria were medium sized and large companies in the profit sector ${ }^{12}$. Holding companies and non-profit organizations were not selected because of their specific audit characteristics. Once the QA partner selected the files, the ABAS Board sent a support memo to the participants (managers and assistantmanagers) involved. A few days later the participants received the questionnaire by mail including an explanatory memo.

In order to improve the auditor's involvement and to obtain useful data, the selection strategy included specific steps to increase the participation rate. the improvement of the willingness to participate was considered to be crucial. This was accomplished by (a) the cover letter by the ABAS Board, (b) explaining the purpose of the project and the potential advantages for practice in the introduction memo, and (c) QA-partner involvement in order to instruct and monitor the follow-up by the participants. It was further considered that the results would not be used for individual partner and/or staff performance measurement, and that no individual client data would be published internally and/or externally.

The audit engagements involved referred to audits performed early 1998 on the 1997 financial statements. Selection of the engagements took place in May and June 1998. The questionnaires were distributed in July 1998 with anticipated return towards the end of August 1998. Selecting the engagements was scheduled at a time that the audits were already completed. I considered moving the questionnaire to January 1998 in order to facilitate the participants in recording the errors. I concluded that the benefits of sending the questionnaire per January 1998, in terms of the accuracy of recording, did not weigh against the potential bias in the audit process due to the availability of the questionnaire during the fieldwork. Besides, the summertime is the appropriate period for the audit teams to evaluate the latest audit and to formulate the audit strategy for the next year audit. Completing the questionnaire enabled the participants to

\footnotetext{
11 This is the former Business Assurance Steering Committee (BASC) at the C\&L-legacy.

${ }^{12}$ The categories were according to the Dutch law, which is based on European Union

Company Law Directives.
} 
structure their evaluation. Finally, the availability of the electronic filing enabled the participants to recall their findings quickly.

\subsection{The questionnaire}

\subsubsection{Structure}

The investigation method used in this study uses audit findings in a field setting. The starting point of my investigation is the evaluation of audit findings at the end of the audit. In this stage, the audit manager and partner evaluate the main audit findings and discuss these findings with client management.

The questionnaire is included in Appendix B of this book. The questionnaire consisted of four sections, prefaced by an introduction section. The introduction section described the purpose of the study and the definitions used, including relevant examples. The first section contained general engagement information to he sompleted The sessnd seation sontaines sonto' environment/risk specific questions on the engagement level. Section 3 contained the audit findings to be completed, including the details of a maximum of the largest 8 errors. Section four contained a number of debriefing questions.

\subsubsection{Language}

The language used in the questionnaire was English. The choice of English was based on a number of arguments. Firstly, the questionnaire was based on the Wright and Ashton (1989) study as I anticipated reporting in the same categories as the previous study. Changing the language might have caused interpretation problems. Secondly, when developing the selection strategy, I had to anticipate some non-Dutch participants completing their exchange program in the Dutch PwC firm. The use of two languages within one study would not stimulate unambiguous interpretation by participants. Also, an English questionnaire would not cause major problems for the participants, as all participants were used to English documents, such as the audit approach, general instructions, and specific updates. In order to test this proposition, I included a debriefing question in the questionnaire on this topic. The outcomes of the debriefing questions are addressed in section 5.2.1. 


\subsubsection{Definitions and measurement}

I explained the definitions of key concepts used in the questionnaire to the participants in the introduction section. The definitions used are summarized as follows:

\section{Errors}

Consistent with Wright and Ashton (1989) and Hylas and Ashton (1982), the starting point for investigating the effects of analytical review performance is the evaluation of errors at the end of the audit just before the decision on the auditor's statement. At the evaluation stage, the auditor mainly considers all detected errors, but focuses on material errors in the financial statements. As a result, each detected error can either be adjusted or waived ${ }^{13}$.

In order to obtain the full scope of all material errors, whether or not adjusted by the client, participants were asked to report all errors including waived errors.

Deviating from Wright and Ashton (1989), who asked for only the four largest errors that equaled or exceeded 20 percent of planning materiality, I did not put a size restriction on the errors and enlarged the maximum number of errors to eight. The main reason for this was to prevent losing data due to this constraint, but still considering the participant's efforts in reviewing the audit file. Comparing the results of this project with the Wright and Ashton (1989) study is still ensured by relating the number and magnitude to materiality levels.

\section{Initial events and error causes}

Participants were asked to identify the initial event and error cause. 'Initial event' refers to the audit procedure, circumstances or event that initially leads the auditor to suspect that an error has occurred. 'Error causes' refer to the auditor's judgment as to the likely cause of the error. The same nine categories of initial events and seven categories of error causes are used as in Wright and Ashton (1989).

\section{Error signaling and error detection}

Deviating from Wright and Ashton (1989), I expanded the error identification at the initial event to the difference between error signaling and error detection. Error signaling is defined as "the audit procedure, circumstances or event that initially led the auditor to suspect that an error had occurred". For instance, the

\footnotetext{
${ }^{13}$ Defined as being not adjusted.
} 
identification of unexpected differences during preliminary analytical review is such an event.

After signaling the potential error, the auditor analyzes and verifies the potential causes of the unexpected fluctuation. The ultimate step is the detection of the error. Error detection may occur during analytical review as described above, or may occur during subsequent audit procedures. See section 2.3 for the discussion on the decision process.

\section{Starting point of fluctuation analysis}

Participants were asked to report on the timing and usage of client representations during analytical review. 'Client representations as a starting point for fluctuation analysis' refers to the situation that the auditor already identified the unexpected fluctuation in the unaudited book values and starts the further investigation with asking the client for a representation of this fluctuation. Client representations can be written (e.g. in monthly or quarterly reporting) or can be verbal explanations by client's management and its staff.

\section{Inherent and control risk assessments}

Two types of scales were used in the questionnaire to measure the auditors' risk assessments on the inherent risk and internal control procedures levels. The first scale is a 3-point scale, which was used at C\&L. This scale contains risk assessments as 'max', 'below max' and 'low'. The second scale is a 7-point scale with ' $\max$ risk' and 'low risk' as end points. The main reason for introducing the second scale is the rather rough scale used in audit practice. The second scale was used to have a more detailed indication of the location on the continuum between high and low risk assessments. I specifically asked the participants to complete the risk assessment information on both scales, where the 1-3 scale was based on the audit file and the other based on the participant's estimate of the risk profile on a 1-7 scale.

I validated the 1-7 scales by testing the correlation between the 1-3 scale and the 1-7 scale and found a significant correlation between both measurement scales on all aspects of inherent risk and control risk assessment. Table 4.2 shows the statistical results on each individual assessment using the Spearman rank-order correlation coefficient. I concluded that both measurements are highly correlated $(p=.000)$. Consequently, the 1-7 scale of risk assessment is used for analyses of inherent and control risk assessments in the following chapters. 


\section{Table 4.2: Correlation between scales 1-3 and 1-7 for inherent risk and control risk}

\begin{tabular}{lrr}
\hline Scale 1-3 (1=max risk, $3=$ min risk) & \\
N & 139 & 136 \\
Mean & 2.25 & 2.38 \\
Std & .53 & .50 \\
Scale 1-7 (1=max risk, 7=min risk) & & \\
N & & 144 \\
Mean & 142 & 4.652 \\
Std & 4.234 & 1.103 \\
\hline Spearman rho correlation & 1.156 & .815 \\
p-value & .749 & .000 \\
\hline
\end{tabular}

\subsubsection{Pilot test}

Before the questionnaire was finalized, a pilot version was distributed to one of the local offices. This office was excluded from the final sample. The observations and feedback from the pilot version were included in the final revised questionnaire.

\subsection{Sample size and response rate}

The selection strategy as described in section 4.5 , resulted in requests sent to 23 Quality Assurance (QA) partners. All QA partners, except two, were willing to cooperate. After the selection process, 184 questionnaires were sent to 21 business units in 17 Dutch offices of the audit firm. The questionnaires were sent by postal service, pre-announced with an email message from the ABAS Board.

The questionnaires were distributed at the beginning of July 1998 with expected return towards the end of August 1998. Where applicable, second and third requests were sent by email to remind the participants of the questionnaire. The number of questionnaires returned amounted 149, which is $81 \%$ of the questionnaires distributed. Two files were kept out of the sample, as the participants did not report the errors due to the combination of compilation services and the audit (resulting in an effective response rate of $79.9 \%$ ). Of the 35 non-returned questionnaires, 19 potential participants responded on the 
requests sent. Of them, 7 participants promised to reply, but did not, even after an additional request. Twelve questionnaires were not returned for plausible reasons: (1) audit not yet finalized during survey period (3), questionnaire lost in mail (2), participant left the firm (1), no audit client anymore (2), and other (4). The remaining 16 potential participants did not reply, even after two additional requests.

The response rate is rather high compared to average response rates in field settings. The high response rate can be explained by the ABAS Board support with the cover letter to the partners and participants as well as the researcher's direct contact with the participants.

In general, participants perceived the questionnaire as clear or moderately clear. Only two participants $(1.4 \%)$ concluded that the questionnaire was unclear. As the questionnaire was written in English (ref. section. 4.6.2), participants were also asked to respond whether the English wording was inconvenient. One quarter of the participants replied that the English wording was inconvenient, but only one participant contacted the researcher for a Dutch version.

Average completion time was 74.54 minutes (std. 35.73 min.), varying from 15 to 240 minutes. The variation in completion time can be explained by the variation in the number of errors. The average tenure of the relationship between PwC and the client was 12.8 years (std. 9.92). For two clients, the current year was the first audit.

\subsection{Summary}

In this chapter, the research design was described beginning with a description of the sampling procedure. The justification for the sample size was addressed in section 4.4 , considering sample sizes of previous analytical review field studies and specific sample size considerations of the current study.

The selection strategy was explained in section 4.5 and included the involvement of Quality Assurance partners of the sample organization. Specific aspects of the questionnaire were addressed in section 4.6. This chapter ended with the reporting of a response rate of $79.9 \%$. This response rate is rather high as compared with previous field studies. The descriptive statistics of the collected data will be addressed in the following chapter. 


\section{DESCRIPTIVE STATISTICS}

\subsection{Introduction}

In the previous chapter, the research design was discussed, followed by the construction and distribution of a questionnaire sent to 184 auditors of the audit firm's offices in the Netherlands. Of these, 149 questionnaires were returned. This chapter contains the descriptive statistics on the sample and error data in the questionnaire and contains the basis for the detailed analysis of the research questions to be provided in chapter 6 .

This chapter is organized as follows. In the next section, client characteristics will be discussed (5.2) including general characteristics with respect to the contingent variables. The descriptive analyses of the error statistics are discussed in section 5.3, including the number and size of errors per audit area, their earnings effects, and the assessments of the most likely error causes. Section 5.4 provides descriptive statistics of analytical review. Univariate analyses of the independent variables that are used in the research questions are presented in section 5.5. Sections 5.4 and 5.5 are the basis for the multivariate analyses of the research questions in chapter 6 . The chapter concludes with a summary.

\subsection{Client characteristics}

\subsubsection{Summary financial data}

Key data on the audit engagements are summarized in table 5.1. Of all engagements, $96 \%$ (141 of the 147 responses $^{14}$ ) concerned main industry types like manufacturing, merchandising and services. The clients involved vary considerably in size. For example, revenues vary from (Euro '000) 864 to $1,452,096$ and total assets vary from (Euro ‘000) 1,516 to $1,391,529$.

\footnotetext{
${ }^{14}$ Two of the 149 files could not be used for further analyses.
} 
Table 5.1: Summary data on audit engagements (financial data in Euro '000)

\begin{tabular}{|c|c|c|c|c|c|c|}
\hline & Total sample & Mamufacturing ${ }^{15}$ & Merchandising & Services & Banking insurance & Government \\
\hline \multirow[t]{2}{*}{ Number of engagements } & 147 & 73 & 34 & 34 & 3 & 3 \\
\hline & $(100 \%)$ & $(50 \%)$ & $(23 \%)$ & $(23 \%)$ & $(2 \%)$ & $(2 \%)$ \\
\hline \multicolumn{7}{|l|}{ Revenues: } \\
\hline - Mean & 90,839 & 81,289 & 115,315 & 94,878 & 26,800 & 50,672 \\
\hline - Range & $864-1,452,096$ & $864-769,156$ & $5,615-895,234$ & $925-1,452,096$ & $2,816-50,218$ & $24,784-76,560$ \\
\hline \multicolumn{7}{|l|}{ Net Income (loss): } \\
\hline - Mean & 4,323 & 4,366 & 4,522 & 4,900 & 2,552 & $(3,720)$ \\
\hline - Range & $(12,074)-73,512$ & $(3,566)-53,415$ & $(1,522)-60,319$ & $(1,793)-73,512$ & $410-4,997$ & $(12,074)-912$ \\
\hline \multicolumn{7}{|l|}{ Total Assets: } \\
\hline - Mean & 45,366 & 51,310 & 41,570 & 35,857 & 22,335 & 68,219 \\
\hline - Range & $1,516-1,391,529$ & $1,516-1,391,529$ & $2,537-328,828$ & $2,562-223,713$ & $4,499-37,275$ & $15,860-165,077$ \\
\hline \multicolumn{7}{|l|}{ Equity: } \\
\hline - Mean & 14,911 & 15,595 & 16,848 & 12,780 & 6,982 & 7,665 \\
\hline - Range & $(1,482)-332,222$ & $(1,122)-332,222$ & $(1,482)-196,364$ & $22-93,685$ & $3,049-11,110$ & $4,619-9,616$ \\
\hline
\end{tabular}

${ }^{15}$ The industry types used in the questionnaire were more detailed than presented above and were based on the 'Branchecodeboek' issued by the Dutch Central Bureau for Statistics (CBS). Manufacturing includes Manufacturing, Energy and Mining, and Building/Construction. 'Services' include General services, transport and environmental services. 
The substantial variation in client size in the sample is comparable to previous field studies (Wright and Ashton, 1989; Kreutzfeldt and Wallace, 1986). The effect of including small clients in the sample was tested. No significant differences were found between the results for small versus large clients.

\subsubsection{Cumulative knowledge}

\subsubsection{Introduction}

In this section, the descriptive statistics on both elements of cumulative knowledge (client tenure and experience of the manager in charge) are presented. Further analyses of these elements with respect to analytical review are presented in section 5.4.3.

\subsubsection{Client tenure}

Participants were asked to complete questions concerning the cumulative knowledge of the client. Table 5.2 includes the stratification of client tenure for the whole sample.

\section{Table 5.2: Client tenure}

\begin{tabular}{lrr}
\hline Client temure (in years) & $\begin{array}{c}\text { Number of } \\
\text { audit files }\end{array}$ \\
\hline First year & 2 & 1.4 \\
$2-5$ years & 41 & 27.9 \\
6-10 years & 42 & 28.6 \\
$11-15$ years & 16 & 10.9 \\
$16-20$ years & 15 & 10.2 \\
$21-25$ years & 14 & 9.5 \\
26 years and more & 14 & 9.5 \\
Question not completed & 3 & 2.0 \\
\hline All & $\mathbf{1 4 7}$ & $\mathbf{1 0 0}$ \\
\hline
\end{tabular}




\subsubsection{Client-specific experience of the audit manager in charge}

Participants, each being the manager in-charge working under direct supervision of the responsible partner, were asked to complete questions about their general experience, experience related to the industry and the specific client.

The descriptive statistics are presented in table 5.3.The average years of general experience is 5 years above industry-specific experience. The latter is one year above client-specific experience. Note that in a number of cases, the team member working under direct supervision of the requested participant completed the questionnaire. The managers, who were originally requested to respond, indicated in a number of cases that the person who completed the questionnaire was highly involved in the audit and in fact can be considered as the manager in-charge on the engagement.

\section{Table 5.3: Average years of experience of the audit manager in charge}

All respondents

$(n=147)$

Average years of experience

Mean Std

General experience

11.46

Industry-specific experience

6.46

5.57

Client-specific experience

5.47

5.48

\subsubsection{Risk assessments}

\subsubsection{Introduction}

In this section, descriptive statistics on three elements of audit risk (control environment condition and inherent risk \& control risk) are presented. The relationship with analytical review is discussed in section 5.4.4.

\subsubsection{Control environment condition}

In chapter 3, it was discussed that the internal control system is expected to influence the number of errors. For instance, the probability of generating errors is expected to be higher in weak internal control systems than in excellent internal control systems. It was discussed in chapters 2 and 3 that the assessment of the control environment ('CE') condition is an important audit procedure in 
the planning stage of the audit, but that - except for Marden, Holstrum and Schneider (1997) - no research data are available about the consequences of control environment conditions on the subsequent audit procedures.

The control environment condition is included in the questionnaire used in the current study. Participants were asked to specify their assessment of the control environment condition. Participants easily complied with this request as the assessment of the control environment condition is a required step in the audit approach of the audit firm involved in the study. During the planning stage of the audit, these auditors evaluate the aspects of control environment, which are based on the COSO report (COSO, 1992). Participants were asked to complete the control environment assessment on a 7-point interval scale (1-poor -7-excellent quality) for each aspect of the control environment. Refer to appendix A for a description of the control environment aspects used in the current study.

The descriptive results are presented in table 5.4. The table shows the assessments of the control environment condition for the six aspects investigated in this study. The mean score for each aspect is between 4.5 and 5 on a scale of 1 to 7 . The last row of the table includes the average of the six aspects in order to be able to use one control environment variable for further statistical analysis in the current and next chapter.

Note that the calculation of an average may not be the best surrogate for the assessment of the control environment, as the relationship between the six aspects may differ from weighing each aspect equally. However, due to lack of previous research findings on the relationship of the control environment aspects, the current calculation of the average is a best estimate. Where applicable, all statistics in chapter 6 were run on each of the six aspects and were compared with the average. The predictive value of the models did not significantly differ when using the average as compared with individual control environment aspects. In cases where one or more variables were missing, the average was calculated by the average of the remaining variables. Additional tests were performed for the potential bias of the omitted variables. These tests did not indicate any bias. Further considerations and limitations for using the average calculation are addressed in section 7.3.2.3. 
86 CHAPTER 5

Table 5.4: Descriptive statistics per Control Environment aspect

\begin{tabular}{|c|c|c|c|c|c|}
\hline \multirow[b]{2}{*}{ Control environment aspect } & \multicolumn{5}{|c|}{$\begin{array}{c}\text { Descriptive statistics } \\
(I=\text { poor }-7=\text { excellent quality })\end{array}$} \\
\hline & Number & Minimum & Maximum & Mean & Std \\
\hline The role of the Board of Directors & 135 & 2.6 & 6.1 & 5.036 & .809 \\
\hline $\begin{array}{l}\text { Effectiveness of the organization and key } \\
\text { management }\end{array}$ & 145 & 2.0 & 6.8 & 4.800 & .977 \\
\hline Human resource policies and procedures & 145 & 2.0 & 6.1 & 4.672 & .866 \\
\hline $\begin{array}{l}\text { Awareness of compliance with laws and } \\
\text { regulations }\end{array}$ & 145 & 2.0 & 7.0 & 4.952 & .931 \\
\hline $\begin{array}{l}\text { Reasonableness of management plans } \\
\text { and budgetary controls }\end{array}$ & 141 & 1.0 & 6.9 & 4.611 & 1.127 \\
\hline Reliability of overall financial reporting & 142 & 1.5 & 6.9 & 5.011 & 1.054 \\
\hline Average $\mathrm{CE}$ aspects & 146 & 2.75 & 6.33 & 4.836 & .748 \\
\hline
\end{tabular}

Further analysis was performed on the relationship between the control environment condition and the number of errors found. The results are presented in table 5.5. The table shows that the number of errors found is negatively related to the control environment condition. Specifically, the increase in the number of errors found is related to a decrease in the control environment condition. For instance, the average of CE aspects is 5.033 (on a scale from 1 to 7) for audit files with 0 or 1 error, whereas for the audit files with 8 or more errors, the average of $\mathrm{CE}$ aspects is 4.520 .

\section{Table 5.5: Control Environment condition related to the number of errors}

\begin{tabular}{|c|c|c|c|c|c|c|}
\hline \multirow[b]{2}{*}{ Control environment aspect } & \multicolumn{6}{|c|}{ Number of errors } \\
\hline & $\begin{array}{r}\text { Total } \\
(\mathrm{n}=146)\end{array}$ & $\begin{array}{r}0-1 \\
(\mathrm{n}=38)\end{array}$ & $\begin{array}{r}2-3 \\
(n=24)\end{array}$ & $\begin{array}{r}4-5 \\
(n=30)\end{array}$ & $\begin{array}{r}6-7 \\
(n=20)\end{array}$ & $\begin{array}{c}8 \text { and } \\
\text { more } \\
(\mathrm{n}=34)\end{array}$ \\
\hline Average CE aspects" & 4.836 & 5.033 & 4.889 & 4.905 & 4.826 & 4.520 \\
\hline
\end{tabular}

"F 2.362 at $\left.141 \mathrm{df}, \mathrm{p}=.056^{*}\right)$

*) significant at the 10 level (2-tailed)

The results in table 5.5 confirm the preliminary analysis in chapter 3 that the control environment condition is related to the number of errors in the audit file. 


\subsubsection{Inherent risk and control risk}

Participants were asked to complete questions on inherent risk and control risk. The descriptive statistics are presented in table 5.6. The table shows that the mean assessment of inherent risk (4.234) is lower than control risk (4.652). Note that these risks are presented at overall basis and not at assertion level. The reason for this presentation is the very weak variation of means across assertions. Additional tests were performed and concluded that using the overall basis risks would not affect the results as compared to risks at assertion level.

\section{Table 5.6: Descriptive statistics of inherent risk and control risk}

\begin{tabular}{lrrrrr}
\hline & \multicolumn{5}{c}{ Descriptive statistics } \\
& Number & Minimum & Maximum & Mean & Std \\
\hline Inherent risk & 142 & 1.1 & 6.9 & 4.234 & 1.156 \\
Control risk & 144 & 1.5 & 6.9 & 4.652 & 1.103 \\
\hline
\end{tabular}

Table 5.7 shows that the assessment of inherent risk and control risk varies with the number of errors found. Note that the outcomes vary from 1 for maximum risk to 7 for low risk. In general, risk is assessed higher for audit files including 8 and more errors than for audit files without any or with less than 8 errors. Note that inherent risk assessments do not keep pace with the number of errors found for the other groups less than 8 errors. Specifically, inherent risk scores vary from 3.923 (2-3 errors) to 4.820 (6-7 errors). Control risk assessments are rather stable varying from 4.671 ( 0 -1 errors) to 4.805 (6-7 errors). Additional analysis of the correlation between inherent risk and control risk showed a correlation of $.611(\mathrm{p}=.000)$ using the Spearman rank test.

\section{Table 5.7: Inherent risk and control risk related to the number of errors}

\begin{tabular}{|c|c|c|c|c|c|c|}
\hline \multirow[b]{2}{*}{ Risk aspect } & \multicolumn{6}{|c|}{$\begin{array}{c}\text { Number of errors } \\
(0-8)\end{array}$} \\
\hline & $\begin{array}{r}\text { Total } \\
(\mathrm{n}=144)\end{array}$ & $\begin{array}{r}0-1 \\
(\mathrm{n}=38)\end{array}$ & $\begin{array}{r}2-3 \\
(n=23) \\
\end{array}$ & $\begin{array}{r}4-5 \\
(n=30) \\
\end{array}$ & $\begin{array}{r}6-7 \\
(n=20) \\
\end{array}$ & $\begin{array}{r}8 \text { and } \\
\text { more } \\
(\mathrm{n}=33)\end{array}$ \\
\hline Inherent risk ${ }^{a}$ & 4.234 & 4.171 & 3.923 & 4.459 & 4.820 & 3.961 \\
\hline Control risk $^{b}$ & 4.652 & 4.671 & 4.796 & 4.730 & 4.805 & 4.367 \\
\hline $\begin{array}{l}\left.{ }^{2} \mathrm{~F} 2.556 \text { at } 137 \mathrm{df}, \mathrm{p}=.042^{*}\right) \\
{ }^{\mathrm{b}} \mathrm{F} .782 \text { at } 139 \mathrm{df}, \mathrm{p}=.539\end{array}$ & & & & & & \\
\hline
\end{tabular}




\subsubsection{Prefinal audit procedures}

In section 3.3.5, prefinal audit procedures were introduced as a control variable for the contribution of analytical review in error signaling. Table 5.8 shows the descriptive statistics with respect to the effects of prefinal audit procedures on the number and size of errors, the audit procedure that signaled the error and the timing of signaling. The results indicate that for audits including prefinal audit procedures, relative small errors (on average $78 \%$ of planning materiality) are identified as compared to audits without prefinal audit procedures (on average $143 \%$ of planning materiality), and that errors are identified earlier during the audit process.

Further, the contribution of analytical review in error signaling for audits containing prefinal audit procedures $(11.7 \%)$ is significantly less than the contribution of analytical review in error signaling for audits without prefinal audit procedures $(22.9 \%)$.

\section{Table 5.8: Characteristics of audit files and the effects of prefinal audit procedures}

\begin{tabular}{|c|c|c|c|c|}
\hline & \multicolumn{4}{|c|}{ Prefinal audit procedures performed } \\
\hline & \multicolumn{2}{|c|}{$\begin{array}{c}\text { Yes } \\
(\mathrm{n}=30)\end{array}$} & \multicolumn{2}{|c|}{$\begin{array}{c}\text { No } \\
(\mathrm{n}=116)\end{array}$} \\
\hline & Mean & Std. & Mean & Std. \\
\hline Number of errors in related file " & 4.90 & 2.64 & 4.07 & 2.96 \\
\hline $\begin{array}{l}\text { Average size of the error in } \\
\text { percentage of planning materiality }{ }^{b}\end{array}$ & $78 \%$ & 164 & $143 \%$ & 370 \\
\hline $\begin{array}{l}\text { Percentage of errors signaled with } \\
\text { analytical review }\end{array}$ & $11.7 \%$ & .17 & $22.9 \%$ & .27 \\
\hline \multicolumn{5}{|c|}{ Timing of error signaling ${ }^{d}$ (comparison on individual error level) } \\
\hline - Before final audit & & $17.9 \%$ & & $5.5 \%$ \\
\hline - During final audit & & $82.2 \%$ & & $94.5 \%$ \\
\hline \multicolumn{5}{|l|}{ " $t$ value -1.400 at $144 \mathrm{df}, \mathrm{p}=.164$} \\
\hline \multicolumn{5}{|l|}{${ }^{b} \mathrm{t}$ value .955 at $143 \mathrm{df}, \mathrm{p}=.341$} \\
\hline \multicolumn{5}{|l|}{ 't value 2.053 at $\left.125 \mathrm{df}, \mathrm{p}=.042^{*}\right)$} \\
\hline \multicolumn{5}{|c|}{$\begin{array}{l}\text { 'Pearson chi square } 21.171,1 \mathrm{df}, \mathrm{p}=, 000 * *) \text {, based on individual error level ( } \mathrm{n}=146 \text { and } \mathrm{n}=459 \\
\text { for the 'Yes' and 'No' groups respectively }\end{array}$} \\
\hline
\end{tabular}

**) significant at the .01 level (2-tailed)

*) significant at the .05 level (2-tailed) 
Summarizing, the descriptive statistics confirm the potential effect of prefinal audit procedures on the nature and timing of other audit procedures used during the audit as discussed in section 3.3.5. Further analyses on performing prefinal audit procedures, as a control variable will be continued in section 5.5 onwards.

\subsection{Error characteristics}

\subsubsection{Number of errors and their follow-up}

Participants were asked to specify all errors detected during the audit. In the case that more than 8 errors were identified, participants were requested to report only the 8 largest errors. Table 5.9 includes the statistics on the number of detected errors per audit file. The 147 audit files in the survey contained 624 errors $^{16}$, varying from 0 to 8 per file.

\section{Table 5.9: Number of detected errors per audit file}

\begin{tabular}{rrrrr}
\hline $\begin{array}{r}\text { Number of detected } \\
\text { errors per audit }\end{array}$ & $\begin{array}{r}\text { Number of } \\
\text { audit files }\end{array}$ & $\begin{array}{r}\text { Number of errors in } \\
\text { the sample }\end{array}$ & $\%$ \\
\hline 0 & 19 & 12.9 & 0 & - \\
1 & 19 & 12.9 & 19 & 3.0 \\
2 & 11 & 7.5 & 22 & 3.5 \\
3 & 13 & 8.8 & 39 & 6.3 \\
4 & 16 & 10.9 & 64 & 10.3 \\
5 & 15 & 10.2 & 75 & 12.0 \\
6 & 7 & 4.8 & 42 & 6.7 \\
7 & 13 & 8.8 & 91 & 14.6 \\
8 and more & 34 & 23.2 & 272 & 43.6 \\
\hline Total & $\mathbf{1 4 7}$ & $\mathbf{1 0 0}$ & $\mathbf{6 2 4}$ & $\mathbf{1 0 0}$ \\
\hline
\end{tabular}

\footnotetext{
${ }^{16}$ The total number of files and errors in various tables may deviate from the number of 147 files and 624 errors due to missing data.
} 


\section{Errors}

\begin{tabular}{|c|c|c|c|c|c|c|c|c|c|c|c|c|}
\hline & \multicolumn{2}{|c|}{ Total } & \multicolumn{2}{|c|}{$\begin{array}{l}\text { Less than } 0,2 \\
\text { " materiality" }\end{array}$} & \multicolumn{2}{|c|}{$\begin{array}{l}\text { Between } 0,2 \text { and } \\
1,0 * \text { materiality }\end{array}$} & \multicolumn{2}{|c|}{$\begin{array}{c}\text { Between } 1,0 \text { and } 2,0 \\
{ }^{*} \text { materiality }\end{array}$} & \multicolumn{2}{|c|}{$\begin{array}{l}\text { More than } 2 \\
\text { * materiality }\end{array}$} & \multicolumn{2}{|c|}{$\begin{array}{c}\text { No materiality data } \\
\text { available }^{\prime s}\end{array}$} \\
\hline & $\mathrm{n}$ & $\%$ & $\mathrm{n}$ & $\%$ & $\mathrm{n}$ & $\%$ & $\mathrm{n}$ & $\%$ & $\mathrm{n}$ & $\%$ & $\mathrm{n}$ & $\%$ \\
\hline Posted ${ }^{19}$ & 193 & 32 & 36 & 22 & 59 & 31 & 19 & 41 & 37 & 46 & 42 & 32 \\
\hline Adjusted $^{20}$ & $\underline{156}$ & $\underline{26}$ & $\underline{11}$ & 7 & $\underline{53}$ & $\underline{28}$ & $\underline{16}$ & 35 & $\underline{30}$ & 37 & $\underline{46}$ & $\underline{36}$ \\
\hline Subtotal & 349 & 58 & 47 & 29 & 112 & 59 & 35 & 76 & 67 & 83 & 88 & 68 \\
\hline Waived & 256 & 42 & 113 & 71 & 77 & 41 & 11 & 24 & 14 & 17 & 41 & 31 \\
\hline Total & 605 & 100 & 160 & 100 & 189 & 100 & 46 & 100 & 81 & 100 & 129 & 100 \\
\hline
\end{tabular}

${ }^{17}$ Refers to planning materiality as reported by the participants.

${ }^{18}$ Net reported by participants.

${ }^{19}$ Adjusted by the client during the audit fieldwork.

${ }^{20}$ Adjusted by the client after the clearance meeting. 
Participants were asked to specify the ultimate follow-up of each error. As can be observed in table $5.10,58 \%$ of all detected errors were adjusted in the financial statements, whereas $42 \%$ were waived. As expected, the percentage of the errors adjusted is related to the error size. For example, the waived errors decline from $71 \%$ for very small errors $(<0.2 *$ planning materiality) to $17 \%$ for large errors $(>2 *$ planning materiality). It should be noted that the materiality level reported by participants refers to the planning materiality and not the financial statement materiality, which conceptually also includes undetected errors (ISA 320). Besides, further investigation on the size characteristics of errors was beyond the scope of this thesis. As a result, it cannot be concluded that these errors were incorrectly not adjusted based on the current outcomes.

\subsubsection{Summarized error statistics per audit area}

Participants were asked to specify the audit areas and monetary impact for each error. The number of errors affecting the specific audit area is shown in table 5.11. Note that the number of errors per audit area is not the same as the number of errors in the financial statements as presented in the tables 5.9 and 5.10. Since an error affects at least two accounts in one or more audit areas, the number of errors per audit area must be approximately twice as large as the number of audit errors in the financial statements. For errors affecting more than two areas, only the two largest areas were recorded. Errors affecting two or more accounts in the same audit area are presented separately in table 5.11 as 'no effect' and only refer to reclassifications that are isolated within one audit area. For instance, a reclassification error between 'raw materials' and 'finished goods' has no effect on the inventory area as a whole.

As indicated in table 5.11, the number and size of the errors vary significantly between various audit areas. Of all detected errors, $54 \%$ relate to current assets, current liabilities, purchases and other operating expenses, but have a quite diverse monetary impact. Long-term liabilities, interest expense, depreciation and amortization show only a few errors, and also have a significant variation in monetary impact. The large variation between the number of errors and the monetary impact per audit area can be explained by the fact that errors related to daily and routine transactions, such as other operating expenses, generate a huge potential for making errors, but have less monetary impact on the financial statements as compared to non-routine transactions, such as equity and long term liabilities.

The distribution of the errors between understatements or overstatements varies per audit area. For example, the majority of errors related to current liabilities and operating expenses result in understatements of these areas, 
Table 5.11: Summarized error statistics per audit area (amounts in Euro '000)

\begin{tabular}{|c|c|c|c|c|c|c|c|c|c|c|c|c|c|c|}
\hline \multirow[b]{2}{*}{ Audit area } & \multirow{3}{*}{$\begin{array}{l}\text { No. } \\
65\end{array}$} & \multirow{2}{*}{\multicolumn{2}{|c|}{$\begin{array}{cr} & \text { Direction } \\
\text { Over- } & \text { Under- } \\
\text { state- } & \text { state- } \\
\text { ment } & \text { ment } \\
\end{array}$}} & \multirow[b]{2}{*}{$\begin{array}{r}\text { No } \\
\text { effect } \\
n\end{array}$} & \multicolumn{4}{|c|}{ Average size } & \multicolumn{6}{|c|}{ Percentage of total errors detected ${ }^{21}$} \\
\hline & & & & & Amount & $\begin{array}{r}\text { In \% } \\
\text { of } \\
\text { assets }\end{array}$ & $\ln \%$ & $\operatorname{Sad}^{3}$ & $\begin{array}{l}\text { Total } \\
\text { sample }\end{array}$ & $\begin{array}{c}\text { Mamu- } \\
\text { factu- } \\
\text { ring } \\
\end{array}$ & $\begin{array}{l}\text { Mer- } \\
\text { chan- } \\
\text { dising }\end{array}$ & Services & $\begin{array}{l}\text { Banking' } \\
\text { Insurance }\end{array}$ & Other \\
\hline Fixed assets & & 33 & 32 & 0 & 364 & 1.4 & 222 & 527 & 5.4 & 5.6 & 5.4 & 4.7 & 2.9 & 11.1 \\
\hline Inventory & 96 & 51 & 45 & 0 & 200 & .8 & 116 & 302 & 7.9 & 9.1 & 8.6 & 5.8 & 5.9 & .0 \\
\hline Current assets & 172 & 94 & 81 & 3 & 192 & 0.9 & 208 & 528 & 14.2 & 14.3 & 14.3 & 13.5 & 17.6 & 14.8 \\
\hline Equity & 23 & 14 & 10 & 1 & 687 & 1.9 & 591 & 1113 & 1.9 & 1.5 & 2.9 & 1.5 & .0 & 7.4 \\
\hline Provisions/accr taxes & 96 & 51 & 46 & 0 & 207 & .8 & 154 & 369 & 8.0 & 8.1 & 6.4 & 9.1 & 8.8 & 11.1 \\
\hline Long term liabilities & 8 & 2 & 6 & 0 & 290 & 3.0 & 175 & 171 & 0.7 & 0.0 & 1.8 & 0.7 & 2.9 & .0 \\
\hline Current liabilities & 216 & 93 & 128 & 5 & 273 & 1.0 & 270 & 969 & 17.9 & 17.9 & 15.7 & 19.3 & 20.6 & 22.2 \\
\hline Revenues & 65 & 33 & 32 & 0 & 363 & 2.1 & 332 & 1487 & 5.4 & 4.4 & 6.8 & 6.9 & 2.9 & .0 \\
\hline Purchases & 110 & 54 & 56 & 0 & 197 & 1.2 & 70 & 120 & 9.1 & 9.6 & 10.0 & 8.0 & 8.8 & .0 \\
\hline Salary expenses & 89 & 48 & 42 & 1 & 154 & 8 & 302 & 1579 & 7.4 & 6.9 & 5.0 & 9.9 & 11.8 & 11.1 \\
\hline Depr/amort. & 27 & 14 & 13 & 0 & 365 & 1.6 & 109 & 282 & 2.2 & 3.0 & 1.1 & 1.5 & 2.9 & 3.7 \\
\hline Other op. expenses & 155 & 58 & 97 & 0 & 150 & .7 & 188 & 1239 & 12.8 & 13.3 & 11.4 & 12.8 & 14.7 & 14.8 \\
\hline Interest expense & 13 & 5 & 8 & 0 & 40 & .5 & 38 & 50 & 1.1 & 1.5 & 1.4 & .0 & .0 & .0 \\
\hline Income tax expenses & 32 & 13 & 19 & 0 & 204 & 1.3 & 170 & 198 & 2.6 & 2.7 & 1.8 & 3.6 & .0 & 3.7 \\
\hline Other accounts ${ }^{24}$ & 39 & 20 & 26 & 7 & & & & & 2.4 & 1.9 & 7.6 & 2.5 & .0 & .0 \\
\hline Total errors/area & 1,208 & 583 & 641 & 16 & & & & & 1,208 & 593 & 280 & 274 & 34 & 27 \\
\hline
\end{tabular}

${ }^{21}$ Note that the bottom row of this table presents the mumber of errors instead of the percentages

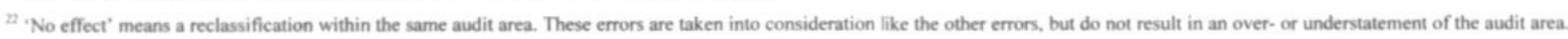

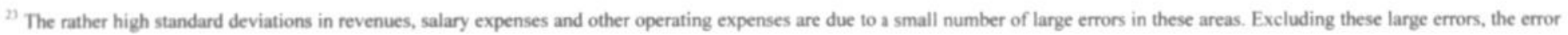
amount, $\%$ of assets, error in $\%$ of materiality and std. are $(188 ; 1.7 ; 117 ; 202),(108 ; .5 ; 118 ; 264)$ and $(125 ; .5 ; 73 ; 143)$ respectively.

${ }^{24}$ Results from investments, extra-ordinary results, amongst others 
whereas the majority of errors related to inventory and current assets result in overstatements. Only 16 errors referred to reclassifications in the same audit area.

\subsubsection{Effect of errors on earnings}

In the previous section, it was discussed that the number and size of errors vary per audit area. Actually, errors have also a different effect on earnings as shown in table 5.12. The 1,208 errors in the audit areas resulted in 612 errors in the financial statements. Of these adjustments, $44.0 \%$ would reduce earnings and $35.9 \%$ would increase earnings if all errors were adjusted in the financial statements. The remaining errors $(20.1 \%)$ only resulted in reclassification effects between balance sheet areas or between profit and loss areas.

These results corroborate Wright and Ashton (1989) that are included in table 5.12 as a reference. The error amount in the current study remains slightly behind the Wright and Ashton findings, which can be explained by the exclusion of errors less than 0.2 times materiality in the Wright and Ashton study.

Further analyses of the effects of errors on earnings are beyond the scope of this thesis; in section 7.3.3 a suggestion for further research is included addressing the factors affecting earnings management.

\section{Table 5.12: Effect of errors on earnings}

(Results from Wright and Ashton (1989) in parentheses ${ }^{25}$ )

\begin{tabular}{|c|c|c|c|c|c|c|}
\hline \multirow[b]{2}{*}{ Effect } & \multirow[b]{2}{*}{ Number } & \multirow[b]{2}{*}{ Percentage } & \multicolumn{3}{|c|}{ Average size } & \multirow{2}{*}{$\begin{array}{c}\text { Average } \\
\text { earnings effect } \\
\text { Percentage of } \\
\text { net income }\end{array}$} \\
\hline & & & $\begin{array}{r}\text { Amount } \\
\text { Euro } 000\end{array}$ & $\begin{array}{r}\text { Percentage } \\
\text { of assets }\end{array}$ & $\begin{array}{r}\text { Percentage of } \\
\text { materiality }\end{array}$ & \\
\hline \multirow[t]{2}{*}{ Reduce earnings } & 269 & 44.0 & 166 & .8 & 144 & 28.1 \\
\hline & (158) & (42.9) & (398) & (2.2) & (141) & \\
\hline \multirow[t]{2}{*}{ Increase earnings } & 220 & 35.9 & 186 & .6 & 95 & 5 \\
\hline & (104) & (28.3) & (418) & (.6) & (86) & .3 \\
\hline \multirow{2}{*}{$\begin{array}{l}\text { No earnings effect } \\
\text { (reclassifications) }\end{array}$} & 123 & 20.1 & 444 & 2.3 & 572 & \\
\hline & (106) & $(28.8)$ & $(1,889)$ & (1.5) & (169) & \\
\hline \multirow[t]{2}{*}{ Total } & 612 & 100 & & & & \\
\hline & (368) & (100) & & & & \\
\hline
\end{tabular}

${ }^{25}$ Exchange rate 1 Euro $=1$ USD for the Wright and Ashton figures. 


\subsubsection{Assessment of the error cause}

In chapter 2 and 3 it was argued that the quality of the internal control system is expected to influence the actual number of errors. As internal control also includes the entity's ability to generate reliable financial reporting, participants were asked to indicate, in their judgment, the cause of the error that led to each proposed adjustment. The participants could choose from six types of causes that were also used by Wright and Ashton (1989) and Hylas and Ashton (1982) ${ }^{26}$. I added a short explanation in the questionnaire for each category, as described in table 5.13.

\section{Table 5.13: Clarifications used in the questionnaire for each category of error cause}

\begin{tabular}{ll}
\hline Error category & Explanation \\
\hline 1. Personnel problems & $\begin{array}{l}\text { Turnover, new/inexperienced employes, } \\
\text { carelessness, time pressures, incompetence etc. }\end{array}$ \\
2. Insufficient accounting knowledge & $\begin{array}{l}\text { Lack of awareness of generally accepted accounting } \\
\text { principles or client's accounting policies }\end{array}$ \\
3. Judgment errors & $\begin{array}{l}\text { Poor or unreasonable estimates based on inadequate } \\
\text { information, e.g. uncollectable accounts }\end{array}$
\end{tabular}

4. Cut-off or accrual errors ${ }^{27}$

5. Mechanical errors

6. Inadequate control, follow-up or review procedures

7. Insufficient reflection on changed external environment
Improper posting, footing, coding, calculations etc.

Noncompliance with internal controls, failure to follow-up reconciliation differences, failure to review account collectability, etc.

Changed law and/or standards applicable, market changes etc.

Source: Questionnaire used in the current field study, based on Wright and Ashton (1989)

The descriptive results on the assessment of error causes are shown in table 5.14 and indicate that insufficient accounting knowledge, personnel problems and judgment caused $63 \%$ of all errors. The results indicate that cut-off problems

${ }^{26}$ As compared with the Wright and Ashton questionnaire, I added the category "Insufficient reflection on changed environment" in order to be able to test this variable. Due to the low response in this category, I did not analyze this category in detail further.

${ }^{n}$ This category was not explained, as it was expected to be basic knowledge for participants. 
occur more frequently in the case of small errors than in the case of larger errors. The general distribution of error causes is comparable to the error causes as reported by Wright and Ashton (1989). However, in the Wright and Ashton study, personnel problems occurred more frequently, whereas mechanical errors occur less frequently in all categories of materiality in the present study. The observed decreased influence of mechanical errors can be explained by improved data processing possibilities as compared to the 1980's and by increased attention for the human factor. The COSO report (COSO 1992) summarized the human factor as follows: "Internal control recognizes that people do not always understand, communicate or perform consistently. Each individual brings to the workplace a unique background and technical ability, and has different needs and priorities".

\section{Table 5.14: The auditor's assessment of error causes}

(Results from Wright and Ashton [1989] in parentheses)

\begin{tabular}{|c|c|c|c|c|c|c|}
\hline \multirow{6}{*}{ Canse } & \multicolumn{6}{|c|}{ Errors } \\
\hline & Total & Less than & Between 0.2 & Between I & More than & No \\
\hline & & $0.2^{\circ}$ & and $I^{*}$ & and $2 \cdot$ & $2 \cdot$ & materiality \\
\hline & & materiality & materiality & materiality & materiality & available \\
\hline & $n=600$ & $n=158$ & $n=186$ & $n=46$ & $n=82$ & $n=128$ \\
\hline & $(n=334)$ & $(n=0) *)$ & $(n=236)$ & $(n=50)$ & $(n=48)$ & $(n=0)$ \\
\hline \multirow[t]{2}{*}{ Personnel problems } & $17.5 \%$ & $15.2 \%$ & $19.4 \%$ & $28.3 \%$ & $18.3 \%$ & $13.3 \%$ \\
\hline & (6.3) & - & (7.2) & $(6.0)$ & (2.1) & - \\
\hline Insufficient accounting & 26.0 & 17.1 & 26.3 & 32.6 & 29.3 & 32.0 \\
\hline knowledge & $(28.6)$ & - & (26.8) & $(36.0)$ & $(31.2)$ & - \\
\hline \multirow[t]{2}{*}{ Judgment } & 19.5 & 21.5 & 17.7 & 13.0 & 20.7 & 21.1 \\
\hline & $(20.1)$ & - & $(22.9)$ & $(10.0)$ & (16.7) & - \\
\hline \multirow[t]{2}{*}{ Cut-off or accrual } & 11.5 & 17.1 & 15.1 & 6.5 & 1.2 & 7.8 \\
\hline & (18.6) & - & (17.8) & $(20.0)$ & (20.8) & - \\
\hline \multirow[t]{2}{*}{ Mechanical } & 6.7 & 10.8 & 5.4 & 4.3 & 3.7 & 6.3 \\
\hline & (12.9) & - & (12.7) & $(16.0)$ & (10.4) & - \\
\hline Inadequate control, & 11.3 & 13.3 & 8.6 & 10.9 & 14.6 & 10.9 \\
\hline follow-up or review & (12.6) & - & $(11,4)$ & $(12.0)$ & (18.8) & - \\
\hline Insufficient reflection & 3.0 & 1.9 & 4.3 & - & 3.7 & 3.1 \\
\hline on changed & - & - & - & - & - & - \\
\hline \multicolumn{7}{|l|}{ environment } \\
\hline \multirow[t]{2}{*}{ Other (not specified) } & 4.5 & 3.2 & 3.2 & 4.3 & 8.5 & 5.5 \\
\hline & (.9) & - & (1.2) & - & - & - \\
\hline
\end{tabular}

*) Wright and Ashton did not request for errors less than .2 times materiality 
96 CHAPTER 5

\subsection{Analytical review}

\subsubsection{Introduction}

The first primary research question in chapter 3 was defined as "How does analytical review contribute to error signaling?" and referred to the relative contribution of analytical review in error signaling. Secondary questions were developed to elaborate the primary research question.

The first secondary research question was:

\section{RQ 1.1: What is the relative contribution of analytical review in error signaling as compared to other audit procedures?}

In this section, descriptive analyses on analytical review are presented as an introduction to the univariate analyses in section 5.5 and the multivariate analyses in chapter 6 . This section consists of two parts.

The first part in section 5.4.2 addresses research question 1.1, which has a descriptive nature and is meant to give a general insight in the contribution of analytical review in error signaling. This research question focuses on factors that explain differences between errors. As a result, the analyses on research question 1.1 present the contribution of analytical review at individual error level, irrespective of the client.

The second part of this section (sections 5.4.3 and 5.4.4) contains the descriptive analyses on the effects of the contingent variables (cumulative knowledge of the client and risk assessments) on the contribution of analytical review in error signaling and are the basis for further statistical analyses for the remaining research questions. Consistent with these research questions in chapter 3 , which focuses on differences between clients, the descriptive and statistical analyses are presented on the client (audit file) level. Note that these analyses refer to all 128 audit files including one or more errors. In certain tables, the participants did not complete one or more variables. As a result, the number of included audit files may be less than 128 . 


\subsubsection{Relative contribution of analytical review in error signaling}

\subsubsection{Error size and analytical review}

Participants were requested to indicate the audit procedure that initially signaled the error. Table 5.15 contains the clarification as included in the questionnaire for each audit procedure.

\section{Table 5.15: Clarifications used in the questionnaire for each audit procedure}

\begin{tabular}{|c|c|}
\hline Audit procedure & Explanation \\
\hline 1. Analytical review & $\begin{array}{l}\text { Reasonableness tests, ratios, comparisons of balances } \\
\text { with prior years, This category includes analytical review } \\
\text { in the planning stage, substantive testing stage as well as } \\
\text { the evaluation stage. }\end{array}$ \\
\hline 2. Test of detail - analysis and review & $\begin{array}{l}\text { Account reconciliations, transaction descriptions, balance } \\
\text { 'work ups', scan etc. }\end{array}$ \\
\hline $\begin{array}{l}\text { 3. Test of detail - checks for mechanical } \\
\text { accuracy }\end{array}$ & $\begin{array}{l}\text { Recalculating totals, checks on formulas in spreadsheets } \\
\text { etc. }\end{array}$ \\
\hline 4. Test of detail - documentation & Invoices, cancelled checks, etc. \\
\hline 5. Test of detail - confirmation & Bank statements, accounts receivable confirmations etc. \\
\hline 6. Discussions with client personnel & $\begin{array}{l}\text { Including (pre-audit) meeting with the client, interviews, } \\
\text { 'field discussions' with financial department personnel } \\
\text { etc. }\end{array}$ \\
\hline 7. Expectations from the prior year & $\begin{array}{l}\text { Indications from prior engagement of a potential error or } \\
\text { risk: prior audit differences, prior working paper results, } \\
\text { etc. }\end{array}$ \\
\hline 8. General audit procedures & $\begin{array}{l}\text { Review of accounting practices, legal letters, board of } \\
\text { director's meetings etc. }\end{array}$ \\
\hline
\end{tabular}

Source: Questionnaire used in the current study, based on Wright and Ashton (1989)

The descriptive results of the contribution of analytical review in error signaling are presented in table 5.16 and indicate that analytical review signaled $20.5 \%$ of all detected errors in the sample. The contribution of analytical review in error signaling is the largest for large errors (more than twice planning materiality) with $28.0 \%$. As can be observed, the percentage of errors signaled by mathematical checks is basically inversely related to the error size. 


\section{Table 5.16: The contribution of the audit procedures to error signaling} (Results from Wright and Ashton [1989] in parentheses)

\begin{tabular}{|c|c|c|c|c|c|c|}
\hline \multirow{6}{*}{ Initial audit procedure } & \multicolumn{6}{|c|}{ Size of errors } \\
\hline & Total & Less than & Between & Between I & More than & No \\
\hline & & $0.2^{*}$ & 0.2 and $I$. & and $2^{\circ}$ & $2 \cdot$ & materiality \\
\hline & & materiality & materiality & materiality & materiality & available \\
\hline & $n=605$ & $n=159$ & $n=187$ & $n=47$ & $n=82$ & $n=|3|$ \\
\hline & $(n=362)$ & $(n=0) \bullet$ & $(n=250)$ & $(n=56)$ & $(n=56)$ & $(n=0)$ \\
\hline \multirow[t]{2}{*}{ Analytical review } & $20.5 \%$ & $19.5 \%$ & $24.1 \%$ & $12.8 \%$ & $28.0 \%$ & $15.3 \%$ \\
\hline & $(15.5)$ & $\cdot$ & $(12.8)$ & $(21.4)$ & $(21.4)$ & - \\
\hline \multirow{2}{*}{$\begin{array}{l}\text { Test of detail - analysis and } \\
\text { review }\end{array}$} & 28.8 & 29.6 & 29.4 & 19.1 & 25.6 & 32.1 \\
\hline & (28.7) & - & (32.4) & $(21.4)$ & (19.6) & - \\
\hline \multirow{2}{*}{$\begin{array}{l}\text { Test of detail - checks for } \\
\text { mathematical accuracy }\end{array}$} & 6.3 & 9.4 & 3.2 & 2.1 & 2.4 & 10.7 \\
\hline & $(9.7)$ & - & (10.4) & $(9.0)$ & $(7.2)$ & - \\
\hline \multirow{2}{*}{$\begin{array}{l}\text { Test of detail - documentation } \\
\text { and confirmation }\end{array}$} & 17.0 & 22.0 & 15.5 & 23.4 & 12.2 & 13.7 \\
\hline & $(9.1)$ & - & (8.8) & (8.9) & (10.7) & - \\
\hline \multirow[t]{2}{*}{ Client inquiry } & 13.7 & 10.1 & 15.5 & 19.1 & 15.9 & 12.2 \\
\hline & (13.3) & - & (12.8) & (17.9) & (10.7) & . \\
\hline \multirow{2}{*}{$\begin{array}{l}\text { Expectations from the prior } \\
\text { year }\end{array}$} & 5.8 & 4.4 & 2.7 & 14.9 & 11.0 & 5.3 \\
\hline & (21.5) & - & (20.4) & (21.4) & (26.8) & . \\
\hline \multirow[t]{2}{*}{ General audit procedures } & 6.6 & 4.4 & 9.1 & 2.1 & 4.9 & 8.4 \\
\hline & $(2.2)$ & - & $(2.4)$ & - & (3.6) & . \\
\hline \multirow[t]{2}{*}{ Other } & 1.3 & .6 & .5 & 6.4 & - & 2.3 \\
\hline & - & - & - & - & - & - \\
\hline
\end{tabular}

*) Wright and Ashton did not request for errors less than .2 times materiality

Note that the relative contribution of 'Expectations from the prior year' in error signaling $(5.8 \%)$ is far behind the Wright and Ashton findings $(21.5 \%)$. It is possible that the high frequency of the references to prior year findings in the Wright and Ashton study was due to explicitly asking their participants for details on last year errors (Wright and Ashton, 1989, page 722).

Surprisingly, the contribution of analytical review in error signaling in the error size range between 1 and 2 times materiality (12.8\%) lays far behind the contribution in the smaller $(24.1 \%)$ and larger $(28.0 \%)$ error size ranges. Further analysis did not reveal specific causes for these outcomes, except for the observation that the decreased contribution of analytical review in error signaling for this error size is offset by client inquiry and expectations from the 
prior year. In chapter 1, it was argued that analytical review, client inquiry and expectations from the prior year are considered to be the 'simple' audit procedures, whereas 'extensive' procedures comprise the remaining audit procedures of table 5.16, specifically the various tests of detail and general audit procedures. The contribution of the simple versus extensive audit procedures in error signaling is visualized in figure 5.1. The results show that the contribution of simple audit procedures increases with the size of the error, at the expense of extensive procedures. For example, for errors less than .2 times planning materiality, only $34 \%$ of the errors are signaled with simple procedures, increasing to $55 \%$ for errors larger than twice the materiality. The current results confirm prior findings (Wright and Ashton, 1989) that simple procedures make a significant contribution to error signaling.

Figure 5.1: The contribution of audit procedures in error signaling and error size

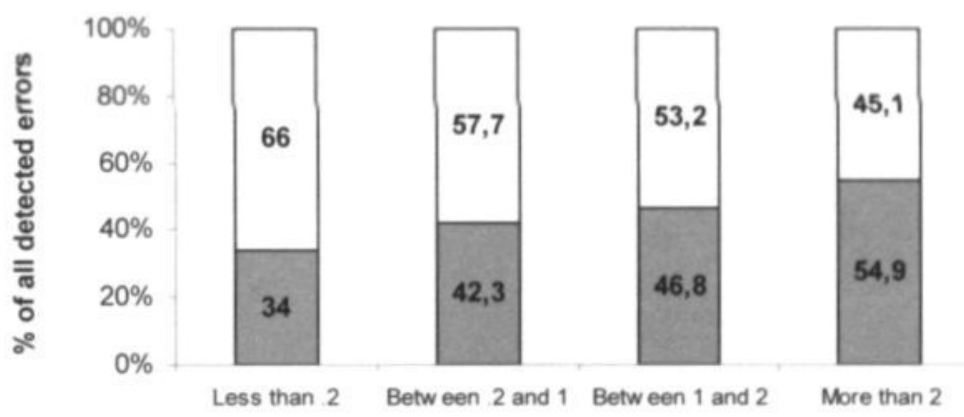

Size of errors in \% of planning materiality

"Simple" audit procedures 口"Extensive" audit procedures

\subsubsection{Specific analytical review procedure used}

Participants were asked to identify the specific analytical review procedure ${ }^{28}$ that signaled the error. Table 5.17 shows that the vast majority of errors are signaled by basic analytical review procedures such as comparison of balances with prior year $(53.2 \%)$, judgmental estimates $(20.2 \%)$ and ratio analysis $(12.1 \%)$. None of the participants used regression analysis. These findings are consistent with Wright and Ashton (1989). Note that the distinction between 'time series analysis' and 'regression analysis' is limited. The table shows that only 8 errors

\footnotetext{
${ }^{28}$ Defined as the specific procedure within the analytical review category
} 
out of 124 were not detected directly after signaling by analytical review. The detection of errors will be addressed in section 5.5.5.

A number of participants specified in the category 'other' the procedure 'coherence testing', which is specifically used in Dutch audit practice ${ }^{29}$. 'Coherence testing' can be defined as: “.... tests of plausible relationships among data. This is an analytical procedure, which is based on relationships among data of which at least one has been audited"(ISA No. 520 (Dutch addendum, par. 5A). Four participants identified this additional analytical review category. As I did not include this category in the questionnaire specifically, I have no further indication of the relative use of coherence testing as an analytical review procedure. As far as other participants also signaled errors by coherence testing, the categories 'time series analysis' and 'other' are considered to be the most appropriate categories.

${ }^{20}$ The concept of coherence testing is addressed by Blokdijk, Drieênhuizen and Wallage (1995). 


\section{Table 5.17: Breakdown of specific analytical review procedures that signaled the error \\ (Wright and Ashton (1989) in parentheses)}

\begin{tabular}{|c|c|c|c|c|}
\hline \multirow[b]{2}{*}{ Specific analytical review procedure } & \multirow[b]{2}{*}{$\begin{array}{r}\text { Percentage } \\
n=124 \\
(n=56)\end{array}$} & \multirow[b]{2}{*}{ Number } & \multicolumn{2}{|c|}{$\begin{array}{l}\text { Current procedure } \\
\text { resulted in error } \\
\text { detection }^{30}\end{array}$} \\
\hline & & & Yes & No \\
\hline Ratio analysis (e.g. current ratio, inventory ratio) & $\begin{array}{l}12.1 \\
(1.8)\end{array}$ & 15 & 12 & 3 \\
\hline Time series analysis (modeling) & $\begin{array}{r}5.6 \\
(0.0)\end{array}$ & 7 & 6 & 1 \\
\hline Comparisons of balances with prior year & $\begin{array}{r}53.2 \\
(78.6)\end{array}$ & 66 & 64 & 1 \\
\hline Comparison with industry (benchmarking) & $\begin{array}{r}3.2 \\
(0.0)\end{array}$ & 4 & 4 & - \\
\hline Regression analysis & $\begin{array}{r}0.0 \\
(0.0)\end{array}$ & $\cdot$ & - & - \\
\hline Judgmental estimates of account balances & $\begin{array}{r}20.2 \\
(17.8)\end{array}$ & 25 & 23 & 2 \\
\hline Coherence testing & $\begin{array}{r}3.2 \\
(\mathrm{~N} / \mathrm{A})\end{array}$ & 4 & 4 & - \\
\hline Other & $\begin{array}{r}2.4 \\
(1.8) \\
\end{array}$ & 3 & 1 & 1 \\
\hline Total & $\begin{array}{r}100.0 \\
(100.0)\end{array}$ & 124 & 114 & 8 \\
\hline
\end{tabular}

${ }^{30}$ The column totals do not reconcile due to missing values. 


\subsubsection{Team-member who signaled the error with analytical review}

Participants were asked to indicate which team member signaled the error. The results in table 5.18 show that managers as compared to assistants and seniors, signal far more errors with the relative simple procedures $(61.2 \%$ versus $30.0 \%$ and $38.8 \%$ ). For analytical review specifically, managers signaled more errors by analytical review $(27.1 \%)$ than assistants and seniors $(20 \%)$.

Table 5.18: The contribution of the audit procedures to error signaling related to the team member who signaled the error

Team member who signaled the error"

\begin{tabular}{|c|c|c|c|c|c|}
\hline Initial audit procedure & $\begin{array}{r}\text { Total } \\
n=606\end{array}$ & $\begin{array}{r}\text { Assistant } \\
n=150 \\
\end{array}$ & $\begin{array}{l}\text { Senior } \\
n=350\end{array}$ & $\begin{array}{r}\text { Manager } \\
n=85 \\
\end{array}$ & $\begin{array}{r}\text { Partner } \\
\quad n=2\end{array}$ \\
\hline Analytical review & $20.5 \%$ & $20.0 \%$ & $20.0 \%$ & $27.1 \%$ & $50.0 \%$ \\
\hline Test of detail - analysis and review & 28.8 & 36.0 & 30.3 & 12.9 & . \\
\hline $\begin{array}{l}\text { Test of detail - checks for mathematical } \\
\text { accuracy }\end{array}$ & 6.3 & 8.7 & 6.3 & 3.5 & . \\
\hline $\begin{array}{l}\text { Test of detail - documentation and } \\
\text { confirmation }\end{array}$ & 17.0 & 19.3 & 17.1 & 12.9 & . \\
\hline Client inquiry & 13.7 & 6.0 & 13.1 & 24.7 & 50.0 \\
\hline Expectations from the prior year & 5.8 & 4.0 & 5.7 & 9.4 & . \\
\hline General audit procedures & 6.6 & 6.0 & 6.9 & 5.9 & . \\
\hline Other & 1.3 & - & 6 & 3.6 & . \\
\hline
\end{tabular}

${ }^{31}$ The group totals do not reconcile with the total column due to missing values $(10)$ and the client who came up with the error (9). 


\subsubsection{Cumulative knowledge and analytical review}

In this section, the descriptive statistics on both elements of cumulative knowledge (client tenure and experience of the manager in charge) are presented with respect to the contribution of analytical review in error signaling. Firstly, client tenure is discussed, followed by the experience of the audit manager in charge.

Table 5.19 includes the initial audit procedure that signaled the error, stratified by client tenure. The table contains the percentage of errors signaled by analytical review as compared to the total number of errors found, related to client tenure. This ratio is referred as the 'signaling ratio' in section 5.5.3.The table shows that the contribution of analytical review in error signaling is the lowest during the first year of the engagement. In general, the contribution of analytical review in error signaling increases when client tenure increases.

\section{Table 5.19: The contribution of analytical review in error signaling and client tenure}

\section{Client Tenure (years) ${ }^{32}$}

\begin{tabular}{lrrrrrrrr}
$\begin{array}{l}\text { Initial audit procedure } \\
\text { that signaled the error }\end{array}$ & $\begin{array}{r}\text { Total } \\
n=125\end{array}$ & $\begin{array}{r}l \\
n=2\end{array}$ & $\begin{array}{r}2-5 \\
n=36\end{array}$ & $\begin{array}{r}6-10 \\
n=38\end{array}$ & $\begin{array}{r}11-15 \\
n=12\end{array}$ & $\begin{array}{r}16-20 \\
n=15\end{array}$ & $\begin{array}{r}21-25 \\
n=11\end{array}$ & $\begin{array}{r}>25 \\
n=11\end{array}$ \\
\hline Analytical review ${ }^{2}$ & $20.5 \%$ & $12.5 \%$ & $14.9 \%$ & $12.6 \%$ & $22.0 \%$ & $38.4 \%$ & $30.0 \%$ & $31.6 \%$ \\
& & & & & & & & \\
Other procedures & 79.5 & 87.5 & 85.1 & 87.4 & 78.0 & 61.6 & 70.0 & 68.4
\end{tabular}

${ }^{2} \mathrm{~F} 2.941$ at $\left.124 \mathrm{df}, \mathrm{p}=.01^{*}\right)$

$\left.{ }^{*}\right)$ significant at the .01 level (2-tailed)

Table 5.20 shows the contribution of analytical review to error signaling and the three categories of experience. The table is structured by using the median of the years of experience. The table indicates that the contribution of analytical review in error signaling is higher for the 'high' groups for all three categories of experience. Using a Mann-Whitney U test, the contribution of analytical review in error signaling significantly differs at a $\mathrm{p}=.10$ level for industry-specific experience $(p=.064)$ and client-specific experience $(p=.063)$. The current findings are consistent with the analysis in chapter 3 : the contribution of

${ }^{32}$ The sample totals do not reconcile due to missing values. 
analytical review in error signaling is expected to be positively related to the cumulative knowledge of the audit manager in charge.

The results in table 5.20 show that there is no significant difference between the two groups of general experience. These findings suggest that general experience is not a clear indicator for the contribution of analytical review in error signaling. As a consequence, general experience is not further used as an independent variable in this study.

\section{Table 5.20: The contribution of analytical review to error signaling and experience}

\begin{tabular}{rrrrrr}
\multicolumn{2}{c}{$\begin{array}{c}\text { General } \\
\text { Experience * }\end{array}$} & \multicolumn{2}{c}{$\begin{array}{c}\text { Industry-specific } \\
\text { experience }\end{array}$} & \multicolumn{2}{c}{$\begin{array}{c}\text { Client-specific } \\
\text { Experience }\end{array}$} \\
Low & High & Low & High & Low & High \\
(up to 8 & (9 years & (up to 5 & (6 years & (up to 3 & (4 years \\
years) & and & years) & and & years) & and \\
& more) & & more) & & more)
\end{tabular}

Initial audit procedure that

\begin{tabular}{lrrrrrr} 
signaled the error & $n=71$ & $n=57$ & $n=78$ & $n=49$ & $n=60$ & $n=68$ \\
\hline Analytical review & $18.1 \%$ & $23.0 \%$ & $16.9 \%$ & $25.4 \%$ & $15.6 \%$ & $24.5 \%$ \\
& & & & & & \\
Other procedures & 81.9 & 77.0 & 83.1 & 74.6 & 84.4 & 75.5 \\
\hline
\end{tabular}

${ }^{2} \mathrm{Z}$ score $-.1 .120, \mathrm{p}=.263$

${ }^{\mathrm{b}} \mathrm{Z}$ score $-1.854, \mathrm{p}=.064 *$ )

' $\mathrm{Z}$ score $-1.860, \mathrm{p}=.063 *$ )

*) significant at the .10 level (two-tailed)

Further analysis shows a high correlation $(.719, \mathrm{p}=.000$ using the Spearman rank test) between industry-specific experience and client-specific experience. This finding indicates that using both variables might cause multicollinearity problems in further statistical analyses. An additional analysis was performed on the relationship between the contribution of analytical review in error signaling versus industry-specific and client-specific experience. Using a Mann-Whitney $\mathrm{U}$ test, the contribution of analytical review in error signaling was significantly related to client-specific experience $(Z=-2.028, p=.043$ (two-tailed)). For industry-specific knowledge, the score was less significant $(Z=-1.687, p=.092$ (two-tailed)). For this reason, client-specific experience is used as domainspecific knowledge in the remaining part of this thesis. 
The arguments above for using only client-specific experience as independent variable are supported by a sensitivity analysis during the multivariate analysis of section 6.2.2.

\subsubsection{Risk assessments and analytical review}

In chapter 3, risk assessments were discussed as one of the contingent variables expected to affect the contribution of analytical review in error signaling. In this section, descriptive statistics are presented on risk assessments as compared with the contribution of analytical review in error signaling. Firstly, the control environment condition is discussed, followed by the discussion on inherent risk and control risk.

Table 5.21 contains the percentage of errors signaled by analytical review as compared to the total number of errors found, related to the control environment condition. In order to enable comparison of groups of control environment conditions, five equal groups of control environment condition were created based on the $20,40,60$ and 80 percentiles on the scores of the total number of cases. The category boundaries are 4.29, 4.75, 5.16, and 5.38 respectively. The allocation of CE scores between these five groups is arbitrary, but it was reasoned that groups should be split in a way that the weakest, moderate and strongest groups could be distinguished with a sufficient number of incidences.

\section{Table 5.21: Contribution of analytical review in error signaling related to the Control Environment condition}

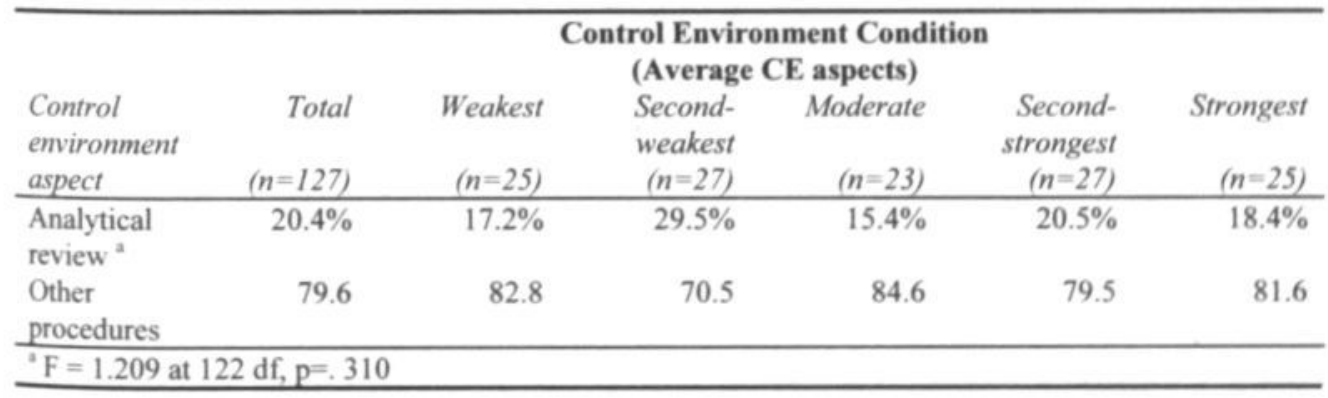

The results in table 5.21 show that the differences between the groups are not significant. Additional tests that were performed did not indicate a non-linear (for instance $\mathrm{N}$-shape) relationship between the contribution of analytical review in error signaling and the control environment condition. The suggestion in section 3.3.2.2 that the contribution of analytical review in error signaling might 
be the largest when controls are moderate as compared with strong conditions is not empirically supported by the current empirical findings. The absence of a non-linear relationship is in line with earlier studies that had difficulties in showing a relationship between risk analyses and subsequent audit procedures (see section 2.4.3.2).

The descriptive results on the inherent risk and control risk aspects are presented in table 5.22. The table contains the percentage of errors signaled by analytical review as compared to the total number of errors found, related to inherent risk and control risk assessments. For this analysis, three categories of risks are presented. The first category is 'high risk' and includes the scores of 1-3. The second category is 'medium risk' and includes the scores between 3 and 5. The last category is 'low risk' and includes the scores above 5. Table 5.22 shows consistently, but not significant, that the contribution of analytical review in error signaling decreases with the levels of inherent and control risk assessment.

\section{Table 5.22: Contribution of analytical review in error signaling related to the inherent risk and control risk assessments}

\begin{tabular}{|c|c|c|c|c|}
\hline & \multicolumn{4}{|c|}{$\begin{array}{l}\text { Inherent risk assessment } \\
(I=\text { max risk, } 7=\text { low risk })\end{array}$} \\
\hline & $\begin{array}{r}\text { Total } \\
(n=126)\end{array}$ & $\begin{array}{r}\text { High } \\
(n=25)\end{array}$ & $\begin{array}{r}\text { Medium } \\
(n=67)\end{array}$ & $\begin{array}{r}\text { Low } \\
(n=34)\end{array}$ \\
\hline Analytical review ${ }^{2}$ & $20.1 \%$ & $21.5 \%$ & $20.6 \%$ & $18.0 \%$ \\
\hline \multirow[t]{3}{*}{ Other procedures } & 79.9 & 78.5 & 79.4 & 82.0 \\
\hline & \multicolumn{4}{|c|}{$\begin{array}{l}\text { Control risk assessment } \\
(l=\max \text { risk, } 7=\text { low risk })\end{array}$} \\
\hline & $\begin{array}{r}\text { Total } \\
(n=126)\end{array}$ & $\begin{array}{r}\text { High } \\
(n=16)\end{array}$ & $\begin{array}{r}\text { Medium } \\
(n=60)\end{array}$ & $\begin{array}{r}\text { Low } \\
(n=50)\end{array}$ \\
\hline Analytical review ${ }^{b}$ & $20.1 \%$ & $22.9 \%$ & $19.8 \%$ & $19.6 \%$ \\
\hline Other procedures & 79.9 & 77.1 & 80.2 & 80.7 \\
\hline $\begin{array}{l}\text { aF. } 166 \text { at } 123 \mathrm{df}, \mathrm{p}=.847 \\
\text { bF. } 211 \text { at } 123 \mathrm{df}, \mathrm{p}=.810\end{array}$ & & & & \\
\hline
\end{tabular}

\subsubsection{Summary}

In this section, the contribution of analytical review in error signaling was analyzed. When answering research question 1.1, the contribution of analytical review in error signaling is on average $20.5 \%$ for all errors included in the sample. The contribution is contingent on error size, cumulative knowledge of 
the client, and risk assessments. In the remaining part of this chapter, the univariate analyses for the remaining research questions are presented.

\subsection{Univariate analyses of the research questions}

\subsubsection{Introduction}

In this section, univariate analyses are presented that address all research questions except for research question 1.1, which has already been addressed in the preceding section 5.4. In this section, the descriptive statistics on the signaling ratio, the non-signaling ratio and the non-detection ratio are discussed. A comprehensive discussion of the outcomes of the statistical analyses is provided in chapter 6 .

The descriptive statistics in the current chapter are introduced as a preliminary analysis for the following research questions on error signaling (section 5.5.3):

RQ 1.2: How does cumulative knowledge of the client affect the relative contribution of analytical review in error signaling?

RQ 1.3: How do risk assessments affect the relative contribution of analytical review in error signaling?

Descriptive statistics are provided on non-signaling the error by analytical review as an introduction to the following research questions (section 5.5.4):

RQ 2.1: How does cumulative knowledge of the client affect audit efficiency as measured by the non-signaling ratio?

RQ 2.2: How do risk assessments affect audit efficiency as measured by the non-signaling ratio?

Finally, this section presents the results on the following secondary research question on analytical review effectiveness (section 5.5.5):

RQ 3.1: How does starting investigating the unexpected fluctuations with client inquiry affect analytical review effectiveness? 


\subsubsection{Independent variables on the signaling ratio and the non-signaling ratio}

Following the elaboration of independent variables in the research questions, the independent variables comprise the cumulative knowledge of the client and risk assessments. As discussed in section 3.3.5 the PREFINAL variable is introduced as a control variable. Note that risk assessments do not further include the element of inherent risk. The reasons for not including this variable in the further statistical analyses are twofold. Firstly, inherent risk and control risk are highly correlated (see section 5.2.3). Secondly, sensitivity analyses including the inherent risk variable showed a decrease in explanatory power and p-values for all multivariate analyses in chapter 6 as compared to the currently used CONRISK variable. As a result, it was decided not to include the inherent risk assessment as an independent variable in the further analyses.

The independent variables are formulated as follows:

\section{Cumulative knowledge of the client}

TENURE = Duration of the audit relationship between the audit firm and the client (ratio scale, number of years, minimum $=0$ )

CLIEXP $=$ Client-specific experience (ratio scale, number of years, minimum $=0$ )

\section{Risk assessments}

CONRISK $=$ General control risk (ordinal scale, 1 to 7 (1=high risk, $7=$ low risk))

CE TOTAL = Average of $6 \mathrm{CE}$ aspects (ordinal scale, 1 to 7 (1=poor, $7=$ excellent)

\section{Control variable}

PREFINAL = Prefinal audit procedures performed $($ dichotomous, $1=y e s, 0=$ no)

Correlations of the independent variables were analyzed. Table 5.23 presents correlations for the independent variables used in the analyses on the research questions. For the PREFINAL variable, which is measured on a dichotomous scale, the Cramer coefficient $\mathrm{C}$ of association is presented. 
Table 5.23: Correlation table of independent variables (on client level)

\begin{tabular}{|c|c|c|c|c|c|c|c|c|}
\hline & TENURE & & CLIEXP & & CONRISK & & CETOTAL & PREFINAL \\
\hline TENURE & 1 & & & & & & & \\
\hline CLIEXP & .367 & $* *)$ & 1 & & & & & \\
\hline CONRISK & .023 & & .159 & *) & 1 & & & \\
\hline CETOTAL & .012 & & .105 & & .469 & $* *)$ & 1 & \\
\hline PREFINAL I & .050 & & .107 & & .039 & & .01 & 1 \\
\hline
\end{tabular}

**) significant at the .01 level (1-tailed)

*) significant at the .05 level (1-tailed)

Although TENURE versus CLIEXP and CONRISK versus CETOTAL are significantly correlated at the .01 level, the correlations are still moderately low. The highest correlation is .469 . Additional tests for multicollinearity were performed for validating the inclusion of all independent variables in the statistical analyses (see sections 6.2.2 and 6.3.2). The results of these tests do not indicate any multicollinearity problems. Consequently, all independent variables are used in the statistical analyses.

\subsubsection{Univariate analyses on the contribution of analytical review in error signaling}

\subsubsection{Dependent variable: signaling ratio}

The descriptive analysis in section 5.4.3 and 5.4.4 indicated that significant relationships exists for client tenure and client-specific experience of the manager versus error signaling by analytical review. On the other hand, both categories of risk assessments were not significantly related to analytical review. A plausible reason for finding insignificant relationships is the potential bias of the number of errors identified in an audit. For instance, if an audit file contains 8 errors, the chance of signaling at least one error by analytical review is expected to be higher than for an audit file with only one error.

The signaling ratio overcomes this potential bias. Section 3.2.3 addressed the concept of the signaling ratio. The signaling ratio is defined as the number of errors initially signaled by analytical review as compared to the total number of errors identified.

The descriptive statistics of the signaling ratio are presented in table 5.24. The total number of observations is 128 , which equals all audit files including one or more errors. The signaling ratio varies between 0 and 1 with a mean of 2027 (std .2573). A signaling ratio of 0 means that of all errors identified during 
$110 \mid$ CHAPTER 5

the audit, analytical review did not signal any error. In contrast, a signaling ratio of 1 means that all identified errors have been signaled by analytical review. The results in table 5.24 indicate that for all audit files including one or more errors, analytical review did not signal any error in $45.3 \%$ of the audit files.

\section{Table 5.24: Signaling ratio}

\section{Total}

\begin{tabular}{lrr} 
Signaling ratio & No. & $\%$ \\
\hline 0 & 58 & 45.3 \\
Above 0 and up to and including .25 & 34 & 26.6 \\
Above .25 and up to and including .50 & 24 & 18.8 \\
Above .50 and up to and including .75 & 6 & 4.7 \\
Above .75 and up to I & 1 & .08 \\
I & 5 & 3.9 \\
\hline
\end{tabular}

Table 5.25 presents the univariate results on the effect of the independent variables on the signaling ratio. The independent variable PREFINAL was tested using the Mann-Whitney U Z-score; all other scores are based on the Spearman rank correlation.

The results show that both categories of cumulative knowledge of the client are statistically significant at the $p=.05$ level. TENURE is significant, which indicates that the signaling ratio tends to increase when the client tenure is higher. The same is applicable for client-specific experience of the audit manager. For both categories of risk assessment, no significant relationship was found on univariate level. The negative correlation of PREFINAL ( $Z$ score 1.962) with the signaling ratio indicates that the existence of prefinal audit procedures has a negative effect on the contribution of analytical review in error signaling. Further analysis of the signaling ratio is continued in chapter 6 , when performing the multivariate analyses.

\section{Table 5.25: Univariate results for the signaling ratio}

\begin{tabular}{lrr}
\hline & Score & p-value \\
\hline TENURE & .179 & $.023^{\circ}$ \\
CLIEXP & .177 & $.023^{\circ}$ \\
CONRISK & -.070 & .436 \\
CETOTAL & -.001 & .899 \\
PREFINAL & -1.962 & $.050^{\circ}$ \\
\hline
\end{tabular}

*) significant at the .05 level ( 1 tailed) 


\subsubsection{Univariate analysis on audit efficiency}

\subsubsection{Dependent variable: non-signaling ratio}

In section 3.2.4 it was argued why audit efficiency is measured by the nonsignaling ratio. The non-signaling ratio was developed in order to overcome the potential relationship between the number of errors signaled by analytical review per audit file and the scores on the independent variables. The non-signaling ratio was defined as the number of errors signaled by other procedures, which could alternatively have been signaled by analytical review as a percentage of the number of total errors detected during the audit.

Participants were asked to indicate, to their best knowledge, whether analytical review could have been an alternative procedure. Possible answers were 'yes', 'no' and 'not sure'. Figure 5.2 includes the preliminary descriptive statistics on the non-signaling ratio.

As shown before in table $5.16,20.5 \%$ (124) of the 606 errors were initially signaled by analytical review. For all remaining 481 errors that were not signaled by analytical review, participants were asked to indicate whether in their opinion analytical review could alternatively have signaled this error. According to the participants, 327 errors $(74.0 \%)$ could not alternatively have been signaled by analytical review. Participants indicated that in 68 cases the error could have been signaled by analytical review. Additionally, participants were unsure in 47 cases whether analytical review could have signaled the error instead of the procedure actually used. Of these 47 cases, 38 cases referred to errors signaled by more extensive procedures, such as tests of detail.

Additional tests were performed on the characteristics of the categories 'yes' and 'not sure'. Table 5.26 includes the descriptive results. Note that the characteristics are measured on the individual error level. 


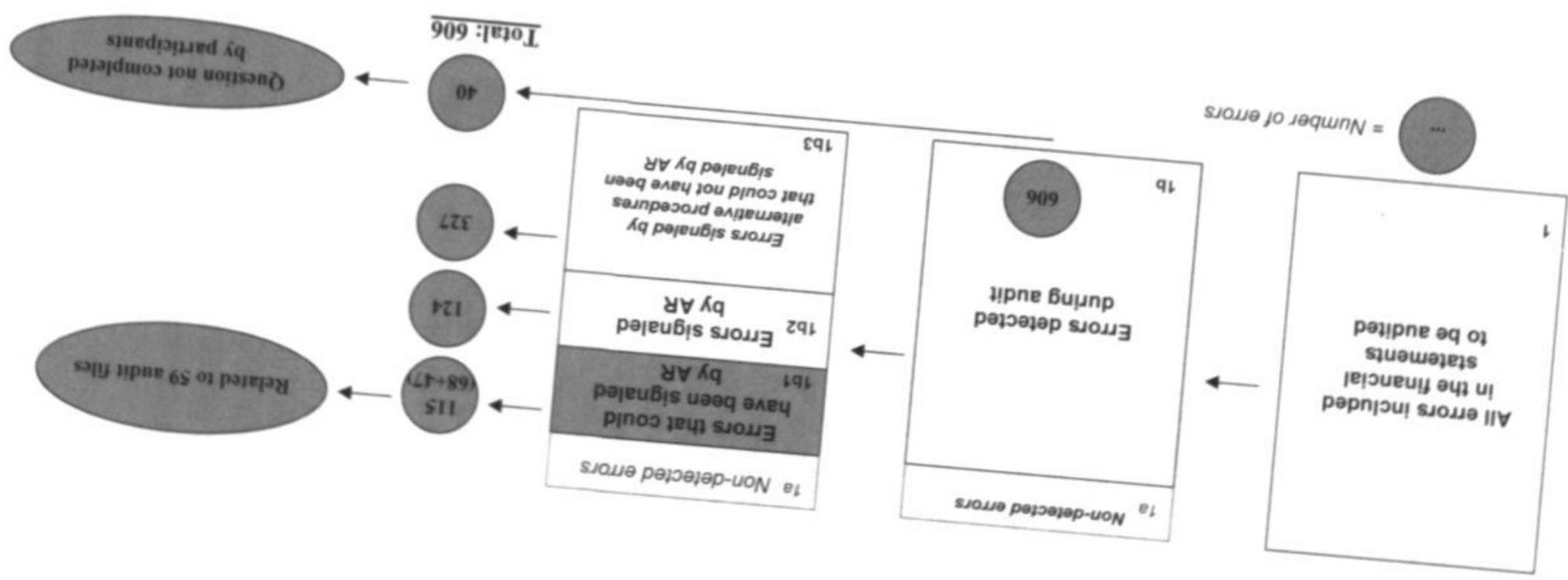

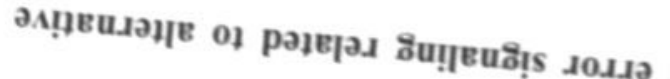

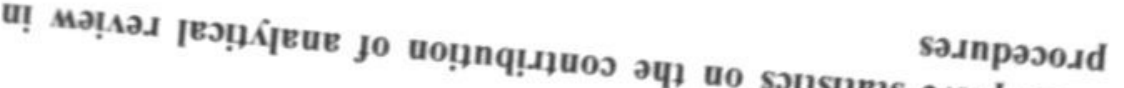




\section{Table 5.26: Descriptive results for errors that could have been signaled by analytical review for the categories 'yes' and 'not sure'}

\begin{tabular}{|c|c|c|c|c|c|}
\hline & \multicolumn{2}{|c|}{$\begin{array}{c}\text { Yes } \\
(n=68)\end{array}$} & \multicolumn{2}{|c|}{$\begin{array}{c}\text { Not sure } \\
(n=47)\end{array}$} & \multirow[t]{2}{*}{ Statistics } \\
\hline & Mean & Std & Mean & Std & \\
\hline TENURE & 11.97 & 8.85 & 11.23 & 8.23 & $\mathrm{~F}=.201,111 \mathrm{df}, \mathrm{p}=.655$ \\
\hline CLIEXP & 4.50 & 4.25 & 4.66 & 4.82 & $\mathrm{~F}=.035,111 \mathrm{df}, \mathrm{p}=.853$ \\
\hline CONRISK & 4.42 & 1.09 & 4.63 & 1.09 & $\mathrm{~F}=.953,110 \mathrm{df}, \mathrm{p}=.331$ \\
\hline CETOTAL & 4.58 & .79 & 4.80 & .75 & $\mathrm{~F}=2.319,111 \mathrm{df}, \mathrm{p}=.131$ \\
\hline $\begin{array}{l}\text { Average size of the } \\
\text { error in } \% \text { of } \\
\text { materiality }\end{array}$ & 92 & 177 & 161 & 324 & $\mathrm{~F}=1.615,89 \mathrm{df}, \mathrm{p}=.207$ \\
\hline
\end{tabular}

Based on these descriptive results that do not present significant differences between the 'yes' and 'not sure' categories, both categories ('yes' and 'not sure') are included in the definition of the non-signaling ratio. Consequently, it is considered that analytical review might be the alternative audit procedure, related to 115 errors.

It was alternatively considered to restrict the current analysis to the category 'yes' only. The advantage of this alternative is the split into certain ('yes' and 'no') and uncertain ('not sure') perceptions of the participants for analytical review as an alternative procedure. Depending on the alternative, the conclusions based on the multivariate analysis would differ from 'in the perception of the participants, analytical review is the alternative procedure' (when using the 'yes' category only) to 'in the perception of the participants, analytical review might be the alternative procedure' (when also using the 'not sure' category). For both alternatives, multivariate analyses were performed (see section 6.3).

The 115 errors that were presented in figure 5.2 concerned 59 audit files. Of these 59 files, 41 files had a non-signaling ratio larger than 0 based on the 'yes' category only. These 115 errors referred to errors that, in the perception of the participants, could have been signaled by analytical review. In the remaining 69 audit files including errors, no errors were signaled by other procedures, which in the perception of the participants, could alternatively have been signaled by analytical review. The preliminary descriptive results on the non-signaling ratio are presented in table 5.27. For all audit files containing errors, the non-signaling ratio was .1729 . This means that for $17 \%$ of the errors, analytical review could have been an alternative procedure for signaling the error. 
114 | ChAPTER 5

Table 5.27: Non-signaling ratio

Total

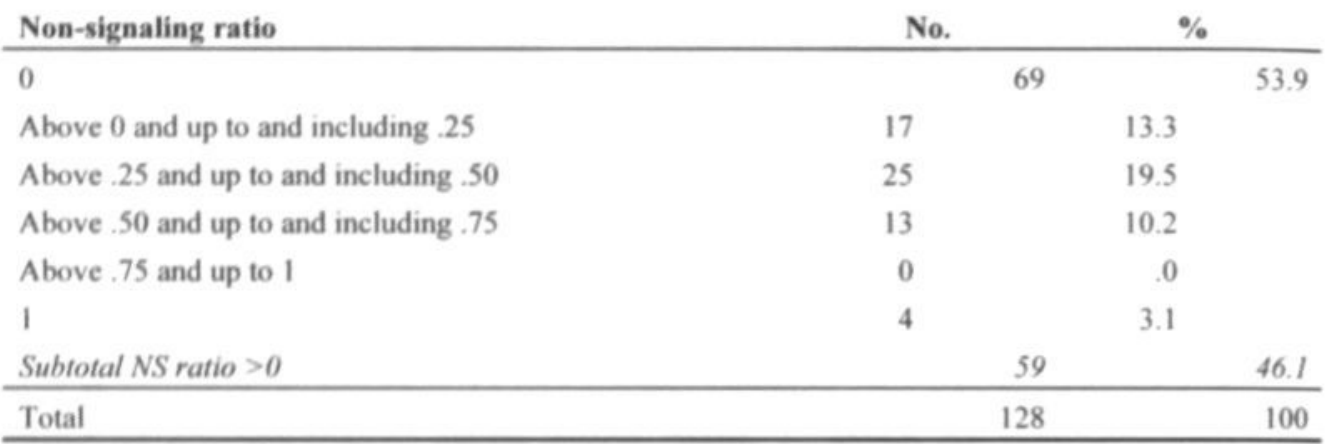

The preliminary results on the non-signaling ratio indicate that audit efficiency, as measured with the non-signaling ratio, can be improved for almost half of the audit files that were included in the sample. Specifically, in $46.1 \%$ of the files containing one or more errors in the sample, one or more errors could have been signaled by analytical review as an alternative procedure.

\subsubsection{Univariate results}

Table 5.28 presents the univariate results for the non-signaling ratio. The independent variable PREFINAL was tested using the Mann-Whitney U Zscore; all other scores are based on the Spearman rank correlation. The results show that TENURE significantly affects the non-signaling ratio, which indicates that the non-signaling ratio tends to increase when the client tenure is higher. CLIEXP is not significantly related to the non-signaling ratio. The results also show that the p-values of the non-signaling ratio with the independent variable CETOTAL is also significant at the $\mathrm{p}=.05$ level. These results indicate that the opportunity to gain audit efficiency increases when a client has a long tenure with the audit firm as well as when the control environment condition improves. A further study of the non-signaling ratio is provided in the multivariate analyses of chapter 6 . 
Table 5.28: Univariate results for the non-signaling ratio

\begin{tabular}{lccc}
\hline & Score & p-value \\
\hline TENURE & .258 & .024 & $*$ ) \\
CLIEXP & -.043 & .745 & \\
CONRISK & -.182 & .172 & \\
CETOTAL & -.244 & .032 & $*$ ) \\
PREFINAL & -1.561 & .118 & \\
\hline
\end{tabular}

*) significant a the $\mathrm{p}=.05$ level (1-tailed)

For the multivariate analysis to be used in chapter 6 , note that a distinction needs to be made for audit files with a non-signaling ratio of 0 and audit files with a non-signaling ratio $>0$ respectively. The main argument for this distinction is the different profile of both groups. The average number of errors between both groups differs significantly (NS ratio $=0$ : average 3,97; NS ratio $>0$ : average 5,$93 ; Z=-4.319, p=.000$ ), while the SIRATIO does not significantly differ $(\mathrm{Z}=-1.217, \mathrm{p}=.244)$. This means that it cannot be concluded that the audits with a NS ratio $=0$ are more efficient than the audits with a NS ratio $>0$.

Realistically, the opportunity for gaining audit efficiency for audits with a non-signaling ratio of zero is nil. I refer to the definition of the non-signaling ratio in section 3.2.4. Descriptive statistics were performed on the means of the independent variables for the three groups of the non-signaling ratio. Note that files with zero errors do not have a non-signaling ratio at all. Table 5.29 shows the means for the independent variables, which are stratified in three groups of files with 0 errors, with a non-signaling ratio of 0 and with a non-signaling ratio $>0$ respectively.

\section{Table 5.29: Descriptive results for audit files based on the non-signaling ratio}

\begin{tabular}{lcrrrrr}
\hline & $\begin{array}{c}\text { Files with 0 errors } \\
(\mathbf{n = 1 9 )}\end{array}$ & $\begin{array}{c}\text { Files with NS ratio = } \\
\text { Mean }\end{array}$ & Std & Mean & Std & $\begin{array}{c}\text { Files with NS ratio }>\mathbf{0} \\
(\mathbf{n = 6 6 )}\end{array}$ \\
& 14.43 & 13.94 & 14.0 & 9.75 & 10.60 & 8.04 \\
& 7.38 & 8.16 & 5.45 & 5.49 & 4.71 & 3.96 \\
TENURE & 4.48 & 1.13 & 4.69 & 1.11 & 4.64 & 1.09 \\
CLIEXP & 5.02 & .66 & 4.80 & .78 & 4.82 & .74 \\
CONRISK & .1 & .31 & .22 & .42 & .22 & .42 \\
CETOTAL & & & &
\end{tabular}


Additional tests that were focused on the potential sample bias were performed on 2 by 2 statistics for 2 independent samples. Between the groups NS ratio $=0$ and NS ratio $>0$, only the independent variable TENURE significantly differed $(Z=-1.852 ; p=.064)$ between both groups. No significant difference was measured between the audit files with 0 errors and both NS groups.

In conclusion, it is not expected that the multivariate analysis excluding the NS ratio $=0$ group results in a statistical bias.

\subsubsection{Univariate analysis on analytical review effectiveness}

\subsubsection{Dependent variable: non-detection ratio}

In section 3.2.5 the non-detection ratio was defined as the number of actual errors not detected as follow-up of signaling the error by analytical review relative to all errors initially signaled by analytical review. Participants were asked to indicate whether the error was detected after the directly related followup for all errors initially signaled by analytical review procedures. The descriptive results in table 5.11 showed that only 8 of the 124 errors signaled by analytical review ${ }^{33}$ had not been detected after the directly related follow-up. These 124 errors referred to 67 files. The results on the non-detection ratio are shown in table 5.30.

\section{Table 5.30: Non-detection ratio (on client level)}

\begin{tabular}{lrr}
\hline & \multicolumn{2}{c}{ Total } \\
Non-detection ratio & No. & \% \\
\hline 0 & 62 & 92.5 \\
.33 & 1 & 1.5 \\
.40 & 1 & 1.5 \\
1 & 3 & 4.5 \\
\hline
\end{tabular}

Table 5.30 shows that only in five files the non-detection ratio is $>0$. Further descriptive analyses are presented in table 5.31.

\footnotetext{
"Alternatively, these errors were detected by other procedures during the remaining part of the audit.
} 


\section{Table 5.31: Descriptive statistics for audit files based on the non-detection ratio ('ND ratio')}

\begin{tabular}{|c|c|c|c|c|}
\hline & \multicolumn{2}{|c|}{$\begin{array}{c}\text { Group ND ratio }=0 \\
(n=62)\end{array}$} & \multicolumn{2}{|c|}{$\begin{array}{c}\text { Group ND ratio }>0 \\
(n=5)\end{array}$} \\
\hline & Mean & Std & Mean & Std \\
\hline TENURE & 12.77 & 8.88 & 12.40 & 15.66 \\
\hline CLIEXP & 5.39 & 4.90 & 6.80 & 10.23 \\
\hline CONRISK & 4.60 & 1.12 & 5.28 & .50 \\
\hline CETOTAL & 4.81 & .74 & 4.82 & .75 \\
\hline PREFINAL & .18 & .39 & .00 & .00 \\
\hline
\end{tabular}

Additional non-parametric tests were performed on 2 by 2 statistics for 2 independent samples. Between the groups ND ratio $=0$ and ND ratio $>0$, no significant difference was observed between the independent variables. In fact, the p-values varied from .265 and above.

The current descriptive results indicate that no relationship was found between the non-detection ratio and the contingent variables investigated in this study. For this reason, and for the fact that the number of five observations is limited, no multivariate analyses on the non-detection ratio is investigated in the next chapter. The remaining analyses on analytical review effectiveness will be limited to the univariate analysis on the effect of client representations on analytical review effectiveness in the next subsection.

\subsubsection{Univariate results}

The third primary research question in this thesis addresses the potential for improving effectiveness: How does analytical review effectiveness contribute to audit effectiveness? The following secondary question will be addressed:

RQ 3.1: How does starting investigating the unexpected fluctuations with client inquiry affect analytical review effectiveness?

The univariate results on RQ 3.1 are presented in table 5.32. Of all 124 errors initially signaled by analytical review, 55 errors were detected by asking client representations as the first follow-up procedure after signaling. Of these 55 errors, in 48 cases client representation was the only follow-up procedure. As the participants provided information on the nature, the number and the sequence of follow-up steps, I deduce that for cases when detecting the errors and where 
client representations was the only follow-up step, the client representation was accurate.

For all errors not detected as a direct follow-up of signaling the error with analytical review, asking a client representation was the starting point ${ }^{34}$ for further investigation. Current findings suggest that, once the auditor has signaled the error with analytical review, starting further investigation by asking client representation is effective when this representation is (ex-post assessed) accurate. I observed that in 6 of the 8 cases, the error was not detected as a direct follow-up of analytical review; client representations were used as the first follow-up procedure after signaling the error. I deduced that the client representations were inaccurate, as otherwise the error would have been detected directly after signaling and would not be included in the current analysis.

\section{Table 5.32: Follow-up after signaling the error}

\begin{tabular}{|c|c|c|c|c|c|c|}
\hline & \multicolumn{2}{|c|}{$\begin{array}{c}\text { Number of } \\
\text { follow-up steps }\end{array}$} & \multicolumn{4}{|c|}{ Follow-up after signaling } \\
\hline & Range & $\begin{array}{l}\text { Average } \\
\text { (sved, , }\end{array}$ & $\begin{array}{r}\text { Started } \\
\text { with Cilim } \\
\text { represen- } \\
\text { tation } \\
\end{array}$ & $\begin{array}{r}\text { Started with } \\
\text { atler } \\
\text { investigations }\end{array}$ & $\begin{array}{r}\text { Starting } \\
\text { proceuture } \\
\text { not } \\
\text { disclosed }^{\text {s. }}\end{array}$ & Total $^{36}$ \\
\hline Number of errors & & & 61 & 13 & 48 & 122 \\
\hline $\begin{array}{l}\text { Detected after } \\
\text { follow-up }\end{array}$ & $0-3$ & $\begin{array}{l}1.37 \\
(.67)\end{array}$ & 55 & $13^{37}$ & 46 & 114 \\
\hline $\begin{array}{l}\text { Not detected after } \\
\text { follow-up }\end{array}$ & $1-3$ & $\begin{array}{l}1.75 \\
(.71)\end{array}$ & 6 & 0 & 2 & 8 \\
\hline
\end{tabular}

34 Excluding two errors of which the sequence of follow-up was not reported by the participants.

${ }^{35} 14$ respondents indicated the number and type of follow-up procedures, but not the sequence.

${ }^{36}$ Of all 124 errors initially signaled with analytical review, follow-up data were missing in 2 cases.

${ }^{37}$ The scores on other categories were: No additional follow-up as the error was clear immediately (6), recalling prior year findings (9), discussions in audit team (24), corroboration with other procedures (1) and other (5). 
DESCRIPTIVE STATISTICS | 119

\subsection{Summary}

This chapter presented the descriptive statistics on the sample and error characteristics. In section 5.2, the client characteristics were presented. Descriptive statistics on detected errors were presented in section 5.3. The 147 audit files sampled resulted in 624 financial statement errors representing 1,208 errors in the audit areas. It was observed that personnel problems caused more errors in the current study (17.5\% of all errors), as compared to previous research $(6.3 \%$ of all errors) by Wright and Ashton (1989). The number and size of errors varied significantly between various audit areas: routine-transactions based areas generated many, but relative small errors, while non-routine transactions based areas generated less, but larger errors. Of all errors in the sample, $44 \%$ would reduce earnings, whereas $35.9 \%$ would increase earnings if all errors were adjusted in the financial statements.

In section 5.4, the preliminary analysis of the contribution of analytical review in error signaling showed that for all errors, $20.5 \%$ was initially signaled by analytical review. The findings indicate that the contribution of analytical review in error signaling is positively related to the size of errors. Section 5.5 contained the univariate analyses on the signaling ratio, the non-signaling ratio and the non-detection ratio. The descriptive and univariate findings in sections 5.4 and 5.5 indicate that client tenure significantly affects the signaling ratio $(p=.023)$ and non-signaling ratio $(p=.024)$. Client-specific experience of the audit manager is significantly related with the signaling ratio $(\mathrm{p}=.023)$, but not with the non-signaling ratio $(\mathrm{p}=.745)$. Control risk assessments are insignificantly related with the signaling ratio $(p=.436)$ as well as the nonsignaling ratio $(=\mathrm{p} .172)$. Control environment is also insignificantly related with the signaling ratio $(\mathrm{p}=.899)$, but is significantly related with the non-signaling ratio $(\mathrm{p}=.032)$. Finally, the existence of prefinal audit procedures is significantly related with the signaling ratio $(\mathrm{p}=.050)$, but insignificantly related with the nonsignaling ratio $(\mathrm{p}=118)$. These preliminary findings on the signaling ratio and the non-signaling ratio will be elaborated further in the multivariate analyses in Chapter 6.

The analyses on analytical review effectiveness showed that only eight of 124 errors that were initially signaled by analytical review were not detected during direct follow-up procedures. This implies that in the vast majority of cases in this sample, analytical review was effective.

Statistical analyses also indicated that the contingent variables used in this study did not significantly differ between the two groups of the non-detection ratio $=0$ and the non-detection ratio $>0$ respectively. Consequently, the combination of the low occurrence rate of non-detected errors by analytical 
$120 \mid$ ChAPTER 5

review and the insignificant results has led to the conclusion that further multivariate analyses in chapter 6 related to analytical review effectiveness will not be performed.

Finally, the analyses on the effect of client representations on analytical review effectiveness did not indicate that starting the fluctuation analysis with client representations influences error detection as direct follow-up of error signaling by analytical review. In section 7.3.1.3 further considerations on the current outcomes are addressed.

The next chapter contains the multivariate analyses on the research questions as developed in chapter 3. Further discussion on the current findings and potential implications for practice and theory will be addressed in chapter 7 . 


\section{Multivariate QUESTIONS \\ ANALYSES OF THE RESEARCH}

\subsection{Introduction}

This chapter contains the multivariate analyses of the research questions as developed in chapter 3 . In that chapter, the research questions were categorized into research questions on the contribution of analytical review in error signaling, questions on the potential contribution of analytical review to audit efficiency and research questions related to analytical review effectiveness.

This chapter is structured as follows. Section 6.2 contains the analyses on the contribution of analytical review in error signaling. Section 6.3 addresses the research questions on audit efficiency. This chapter closes with a summary of the main findings in section 6.4, including an overview of main research findings on each research question.

\subsection{The contribution of analytical review in error signaling}

\subsubsection{Introduction}

This section investigates whether the combination of the independent variables the cumulative knowledge of the client and risk assessments - explains the contribution of analytical review in signaling errors. The main advantage of multivariate analysis over univariate analysis is that the relative contribution of each independent variable can be measured, while all other independent variables are controlled. The analysis is performed using the multiple linear regression method.

The first primary research question addresses the contribution of analytical review in a field setting: How does analytical review contribute to error signaling? In section 5.4.2, descriptive statistics were presented on the contribution of analytical review in error signaling. The descriptive results indicate that for all errors in the sample, analytical review initially signaled $20.5 \%$ of all errors. Contingent variables, such as cumulative knowledge and 
122 | CHAPTER 6

risk assessments affect the outcomes. Specifically, the contribution of analytical review in error signaling increases significantly with tenure and client-specific experience of the audit manager. The descriptive statistics did not show a significant relationship between the contribution of analytical review in error signaling and both categories of risk assessments.

Two related research questions are of interest:

RQ 1.2: How does cumulative knowledge of the client affect the relative contribution of analytical review in error signaling?

RQ 1.3: How do risk assessments affect the relative contribution of analytical review in error signaling?

A multivariate analysis using the multiple linear regression method is performed on the signaling ratio (SIRATIO) to address these research questions.

The following model is tested:
SIRATIO $=\beta 0+\beta 1$ TENURE $+\beta 2$ CLIEXP $+\beta 3$ CONRISK $+\beta 4$ CETOTAL $+B 5$ PREFINAL $+\varepsilon$

Here, the signaling ratio (SIRATIO) is defined as the total number of errors signaled by analytical review as compared with the total number of errors detected per audit.

The independent variables are defined as follows:

TENURE = Duration of the audit relationship between the audit firm and the client (ratio scale, number of years, minimum $=0$ )

CLIEXP = Client-specific experience (ratio scale, number of years, minimum $=0$ )

CONRISK $=$ General control risk (ordinal scale 1 to 7 ( $1=$ high risk, $7=$ low risk))

CETOTAL = Average of $6 \mathrm{CE}$ aspects (ordinal scale 1 to 7 (1=poor, 7 =excellent))

PREFINAL $=$ Prefinal audit procedures performed $($ dichotomous scale, $1=y e s, 0=$ no)

Based on the univariate results and the findings from previous research, it is expected that TENURE and CLIEXP are positively related with the contribution of analytical review in error signaling. For the category risk assessments (CONRISK and CETOTAL), no expectations are formulated, as previous 
research did not indicate a strong relationship between risk assessments and subsequent audit procedures.

In section 3.3.5, the prefinal audit procedures were introduced as a control variable, as these procedures may affect the timing, nature and extent of audit procedures. The preliminary findings in section 5.2.4 indicated significant differences of the contribution of analytical review in error signaling for audits including ( $11.7 \%$ of all errors) versus excluding $(22.9 \%$ of all errors) prefinal audit procedures. Consequently, the signaling ratio is expected to be negatively related with this control variable.

\subsubsection{Multivariate results}

Table 6.1 presents the results of the multiple regression. As discussed in section 5.5.2, moderate correlations were observed for a number of independent variables. Additional multicollinearity tests were conducted when performing the multiple regression. As the Variation Inflation Factors (VIF) are low (with a maximum of 1.354), it is concluded that there is no significant multicollinearity. Therefore, all of the model variables are included in the regression.

\section{Table 6.1: Multiple regression: Contribution of analytical review in error signaling}

\begin{tabular}{lcrrrrr}
\hline & $\begin{array}{c}\text { Hypothesized } \\
\text { sign }\end{array}$ & Coefficient & $\begin{array}{r}\text { Standard } \\
\text { error }\end{array}$ & t-value & Significance \\
\hline CONSTANT & & .105 & .144 & .726 & .470 & \\
TENURE & + & .169 & .003 & 1.872 & .032 & $*$ ) \\
CLIEXP & + & .315 & .005 & 3.478 & .001 & $* *$ ) \\
CONRISK & $?$ & -.120 & .022 & -1.256 & .212 & \\
CETOTAL & $?$ & .068 & .033 & .710 & .479 & \\
PREFINAL & - & -.191 & .051 & -2.305 & .012 & $*$ *)
\end{tabular}

\section{$\mathrm{N}=122$}

F Statistic $=6.188,5 \mathrm{df}, \mathrm{p}=.000$

$\mathrm{R}^{2}=.211$, Adjusted $\mathrm{R}^{2}=.177$

\footnotetext{
**) significant at the .01 level (1-tailed)

*) significant at the .05 level (1-tailed)
}

The overall explanatory power (adjusted $\mathrm{R}^{2}$ ) indicates that $17.7 \%$ of the predictors of the signaling ratio are included in the model. The multivariate results confirm the univariate results that the cumulative knowledge of the client is significantly related to the signaling ratio. Specifically, the signaling ratio is positively related to client tenure and client-specific experience of the audit 
manager in charge. This means that the contribution of analytical review in error signaling increases with the years of experience and with client tenure.

The existence of prefinal audit procedures is negatively related to the signaling ratio. This finding indicates that the existence of prefinal audit procedures decreases the contribution of analytical review in error signaling.

Finally, the multivariate analysis indicates that risk assessment variables are not significantly related to the signaling ratio. This finding indicates that the contribution of analytical review in error signaling is not statistically related to the control risk assessment and the assessed control environment condition.

In section 5.4.3, it was reasoned that general experience and industry-specific experience were not expected to contribute to the explanation of the signaling ratio. This reasoning was tested in a sensitivity analysis of the multivariate analysis of the signaling ratio. The sensitivity analysis consisted of two additional multivariate analyses (models 1 and 2 ) which add two variables generaf experience and industry-specific experience to the model used in Table 6.1. The results are presented in table 6.2. Table 6.2 shows that in all three models, the F-statistic is significant, but that general experience and industryspecific experience do not significantly contribute to the multivariate model. This finding is consistent with the expectations as discussed in section 5.4.3.

\section{Table 6.2: Sensitivity analysis on types of experience}

\begin{tabular}{|c|c|c|c|}
\hline 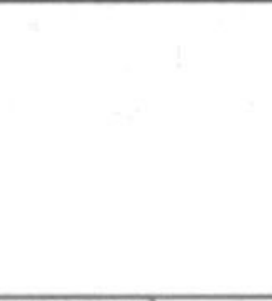 & $\begin{array}{l}\text { Model 1: } \\
\text { Multiple regression } \\
\text { including } \\
\text { - general experience } \\
\text { - industry-specific } \\
\text { experience } \\
\text { - client-specific } \\
\text { experience }\end{array}$ & $\begin{array}{l}\text { Model 2: } \\
\text { Multiple regression } \\
\text { including } \\
\text { - industry-specific } \\
\text { experience } \\
\text { - client-specific } \\
\text { experience }\end{array}$ & $\begin{array}{l}\text { Model 3: } \\
\text { Multiple regression } \\
\text { including } \\
\text { - client-specific } \\
\text { experience } \\
\text { (see table 6.1) }\end{array}$ \\
\hline Adjusted $\mathrm{R}^{2}$ & .171 & .175 & .177 \\
\hline F-statistic & $\begin{array}{r}4.532 \\
(p=.000)\end{array}$ & $\begin{array}{r}5.281 \\
(p=000)\end{array}$ & $\begin{array}{r}6.188 \\
(p=.000)\end{array}$ \\
\hline $\begin{array}{l}\text { Significance: } \\
\text { - General experience } \\
\text { - Industry-specific } \\
\text { experience }\end{array}$ & $\begin{array}{l}.135 \\
.240\end{array}$ & .186 & \\
\hline $\begin{array}{l}\text { - Client-specific } \\
\text { experience }\end{array}$ & $\left..042^{*}\right)$ & $.001 \stackrel{*}{*})$ & $.001 \bullet$ \\
\hline
\end{tabular}

**) Significant at the .01 level (1-tailed)

•) Significant at the .05 level (1-tailed) 
Further, it was tested whether omission of the control variable PREFINAL would affect the multivariate results. Table 6.3 presents this sensitivity analysis. As can be observed, model 2 including the PREFINAL variable has a higher $\mathrm{R}^{2}$, and results in greater significance measures for both risk assessments variables. Consequently, the multiple regression analysis is done including the PREFINAL variable.

Table 6.3: Sensitivity analysis on prefinal audit procedures

Model 1:

Multiple regression excluding

the PREFINAL variable

\section{Model 2:}

Multiple regression including the PREFINAL variable (see table 6.1)

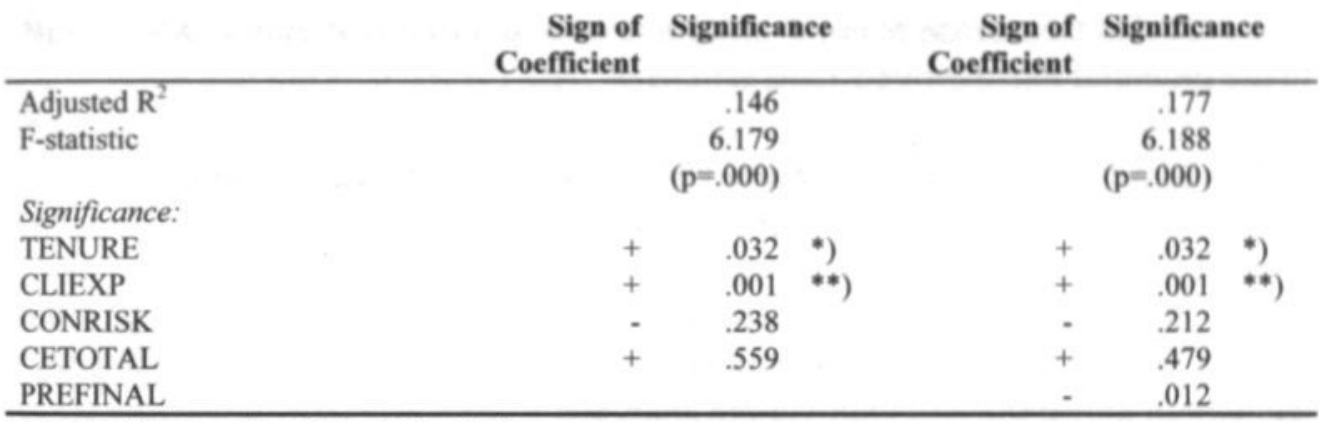

$\left.{ }^{* *}\right)$ Significant at the .01 level (1-tailed)

*) Significant at the .05 level (1-tailed)

\subsubsection{Concluding remarks}

The research findings on the contribution of analytical review in error signaling indicate three major results. Firstly, the contribution of analytical review in error signaling increases with client tenure and with the client-specific experience of the audit manager. Secondly, the contribution of analytical review in error signaling decreases in audits that include prefinal audit procedures. This finding will be considered in more detail in chapter 7 .

Finally, no significant statistical relationship exists between the signaling ratio and the risk assessment measures. This finding will also be addressed in chapter 7.

Further analysis of the cumulative knowledge and the risk assessment variables is performed in the next section. These analyses consider the potential for audit efficiency of analytical review. 
126 | CHAPTER 6

\subsection{Audit efficiency}

\subsubsection{Introduction}

The second primary research question in this thesis addresses the potential of using more analytical review on audit efficiency: How does analytical review contribute to audit efficiency? The results of the statistical analysis in section 6.2 indicated that the contribution of analytical review in error signaling is significantly related to the cumulative knowledge of the client. The statistical analysis of section 6.2 did not indicate a significant relationship between the contribution of analytical review in error signaling contingent to risk assessments. A key question is whether the (absence of) relationships as presented for the contribution of analytical review in error signaling also apply to the potential for improved audit efficiency.

In this section, tô potennai' for audit efficiency is investigated using the same independent variables as used in assessing the contribution of analytical review in error signaling where the dependent variable was the observed signaling ratio. In the following models, the dependent variable is the non-signaling ratio (NSRATIO). The following secondary research questions will be addressed using both univariate and multivariate analyses:

RQ 2.1: How does cumulative knowledge of the client affect audit efficiency as measured by the non-signaling ratio?

RQ 2.2: How do risk assessments affect audit efficiency as measured by the non-signaling ratio?

The following model is tested:

NSRATIO $=\beta 0+\beta 1$ TENURE $+\beta 2$ CLIEXP $+\beta 3$ CONRISK $+\beta 4$ CETOTAL $+B 5$ PREFINAL $+\varepsilon$

Here, the non-signaling ratio (NSRATIO) is defined as the total number of errors signaled by other procedures, which could alternatively have been signaled by analytical review, as compared with the total number of errors detected per audit. Given that these errors could have been signaled by analytical review, this represents potential areas for improved audit efficiency. 
The independent variables are defined as follows:

TENURE = Duration of the audit relationship between the audit firm and the client (ratio scale, number of years, minimum $=0$ )

CLIEXP = Client-specific experience (ratio scale, number of years, minimum $=0$ )

CONRISK = General control risk (ordinal scale, 1 to 7 (1=high risk, $7=$ low risk))

CE TOTAL $=$ Average of $6 \mathrm{CE}$ aspects (ordinal scale, 1 to 7 ( $1=$ poor, $7=$ excellent)

PREFINAL = Prefinal audit procedures performed (dichotomous, $1=y e s, 0=$ no)

Based on the univariate results and the results of previous research, it is hypothesized that TENURE and CLIEXP are positively related to the nonsignaling ratio. For the category risk assessments (CONRISK and CETOTAL), no expectations are formulated, as previous research did not indicate a strong relationship between risk assessments and subsequent audit procedures. Again, PREFINAL is expected to be negatively related with the non-signaling ratio.

Note that the analysis is based on the sample of 59 files that include a nonsignaling ratio $>0$. Section 5.5.4.2 details the arguments for not using the files with a non-signaling ratio of 0 . A sensitivity analysis on the effects of adding the files with NSRATIO $=0$ is presented in the next section.

\subsubsection{Multivariate results}

Table 6.4 presents the results of the multiple regression. Given that the independent variables are moderately correlated (see section 5.5.2), tests were performed for multicollinearity. As the VIF factors are low (maximum of 1.507), it is concluded that there is no indication of significant multicollinearity. Consequently, all independent variables are included in the analysis. 
Table 6.4: Multiple regression: Non-signaling ratio for files with NS ratio $>0$

\begin{tabular}{|c|c|c|c|c|c|c|}
\hline \multirow[b]{2}{*}{ CONSTANT } & \multirow{2}{*}{$\begin{array}{r}\text { Hypothesized } \\
\text { sign } \\
\end{array}$} & \multirow{2}{*}{$\begin{array}{r}\text { Coefficient } \\
.529\end{array}$} & \multirow{2}{*}{$\begin{array}{r}\begin{array}{r}\text { Standard } \\
\text { error }\end{array} \\
.191\end{array}$} & \multirow{2}{*}{$\begin{array}{r}\text { t-value } \\
2.770\end{array}$} & \multicolumn{2}{|c|}{ Significance } \\
\hline & & & & & .08 & \\
\hline TENURE & + & .249 & .004 & 1.923 & .030 & *) \\
\hline CLIEXP & + & .329 & .008 & 2.502 & .008 & $*)$ \\
\hline CONRISK & $?$ & -.227 & .030 & -1.636 & .108 & \\
\hline CETOTAL & $?$ & 011 & .045 & .076 & .940 & \\
\hline PREFINAL & - & -.356 & .071 & .007 & .004 & $*)$ \\
\hline
\end{tabular}

$\mathrm{N}=58$

F Statistic $=4.345,5 \mathrm{df}, \mathrm{p}=.002$

$\mathrm{R}^{2}=.295$, Adjusted $\mathrm{R}^{2}=.227$

**) significant at the .01 level (1-tailed)

*) significant at the .05 level (1-tailed)

The overall explanatory power (adjusted $\mathrm{R}^{2}$ ) is .227 , which suggests that $22.7 \%$ of the predictors of the signaling ratio are included in the current model.

The multivariate results indicate that both variables on the cumulative knowledge of the client are significantly related to the non-signaling ratio. Similar to the results on the signaling ratio, the coefficients of TENURE and CLIEXP are positive. This finding indicates that in the perception of the participants, the potential of analytical procedures for improved audit efficiency increases with the cumulative knowledge of the client.

As discussed in section 5.5.4.1, an alternative multivariate analysis was performed based on the 'yes' response category only. This question asked whether analytical review could have been an alternative procedure that would have identified the observed errors.

The outcomes of this alternative analysis based on $\mathrm{N}=41$, showed an $\mathrm{F}$ statistic of $2.342(\mathrm{p}=.062)$ and an adjusted $\mathrm{R}^{2}$ of .147 at 5 degrees of freedom. The significance levels were $\mathrm{p}=.058$ ) (TENURE), $\mathrm{p}=.13$ (CLIEXP), $\mathrm{p}=.043$ ) (CONRISK), $\mathrm{p}=.29$ (CETOTAL) and $\mathrm{p}=.071$ ) (PREFINAL) respectively with equal signs of coefficients for all variables. Based on these results, it is concluded that the decreased explanatory power of the model and the less significant model variables when using the 'yes' category only do not contradict the nature of the conclusions. 
In addition, a sensitivity analysis was performed on the statistical effect of omitting the subgroup with the NS ratio $=0$ (see section 5.5.4). The results of this analysis are presented in table 6.5. The results show that the model is not significant in a multivariate analysis including the subgroup NS ratio $=0$. This finding supports the analyses in section 5.5.4.2 when restricting the multivariate analysis to the audit files with the NS ratio $>0$.

\section{Table 6.5: Sensitivity analysis on omitting the subgroup NS ratio $=0$}

\begin{tabular}{|c|c|c|c|c|c|}
\hline & \multicolumn{2}{|c|}{$\begin{array}{c}\text { Model 1: } \\
\text { Multiple regression with } \\
-\quad \text { NS ratio }=0 \\
-\quad \text { NS ratio }>0 \\
(\mathbf{n}=121)\end{array}$} & \multicolumn{3}{|c|}{$\begin{array}{c}\text { Model 2: } \\
\text { Multiple regression with } \\
- \text { NS ratio }>0 \\
(\text { see table 6.4) } \\
(\mathbf{n}=57)\end{array}$} \\
\hline & $\begin{array}{r}\text { Sign of } \\
\text { Coefficient }\end{array}$ & Significance & $\begin{array}{r}\text { Sign of } \\
\text { Coefficient }\end{array}$ & Signif & icance \\
\hline Adjusted $\mathrm{R}^{2}$ & & .146 & & .227 & \\
\hline F-statistic & & $\begin{array}{r}.472 \\
=.796)\end{array}$ & & $\begin{array}{r}4.345 \\
=.002)\end{array}$ & \\
\hline Significance: & & & & & \\
\hline TENURE & + & .431 & + & .030 & *) \\
\hline CLIEXP & + & .445 & + & .008 & $* *)$ \\
\hline CONRISK & - & .533 & - & .108 & \\
\hline CETOTAL & + & .810 & + & .940 & \\
\hline PREFINAL & - & .350 & - & .004 & $* *)$ \\
\hline
\end{tabular}

**) Significant at the .01 level (1-tailed)

*) Significant at the .05 level (1-tailed)

\subsubsection{Concluding remarks}

The research findings on the potential of analytical review for audit efficiency show important results. Firstly, the regression model shows a positive relationship between the cumulative knowledge of the client and the potential for audit efficiency. This finding is similar to the results on the use of analytical review in error signaling in section 6.2. Both findings indicate that the higher the cumulative knowledge, the higher the actual contribution as well as the potential contribution of analytical review in error signaling.

Secondly, the multivariate model indicates that risk assessments are not significantly related to the potential use of analytical review, although the general assessment of control risk is marginally significant $(p=.108)$. When combining these results with the findings on the contribution of analytical review in error signaling (section 6.2), this implies control risk assessment is a 
stronger indicator for gaining audit efficiency than on the (actual) contribution of analytical review in error signaling.

Finally, the multivariate results indicate a significant negative relationship between the existence of prefinal audit procedures and the potential contribution of analytical review. One possible explanation for this finding is the significantly smaller size of the errors for audits including prefinal audit procedures as compared to audit without prefinal audit procedures (see table 5.8). Further discussion on this finding will be continued in chapter 7 .

\subsection{Summary}

The main findings in this chapter are reflected in table 6.6. Further analysis on these findings including the implications for future research and audit practice, are addressed in chapter 7 . 


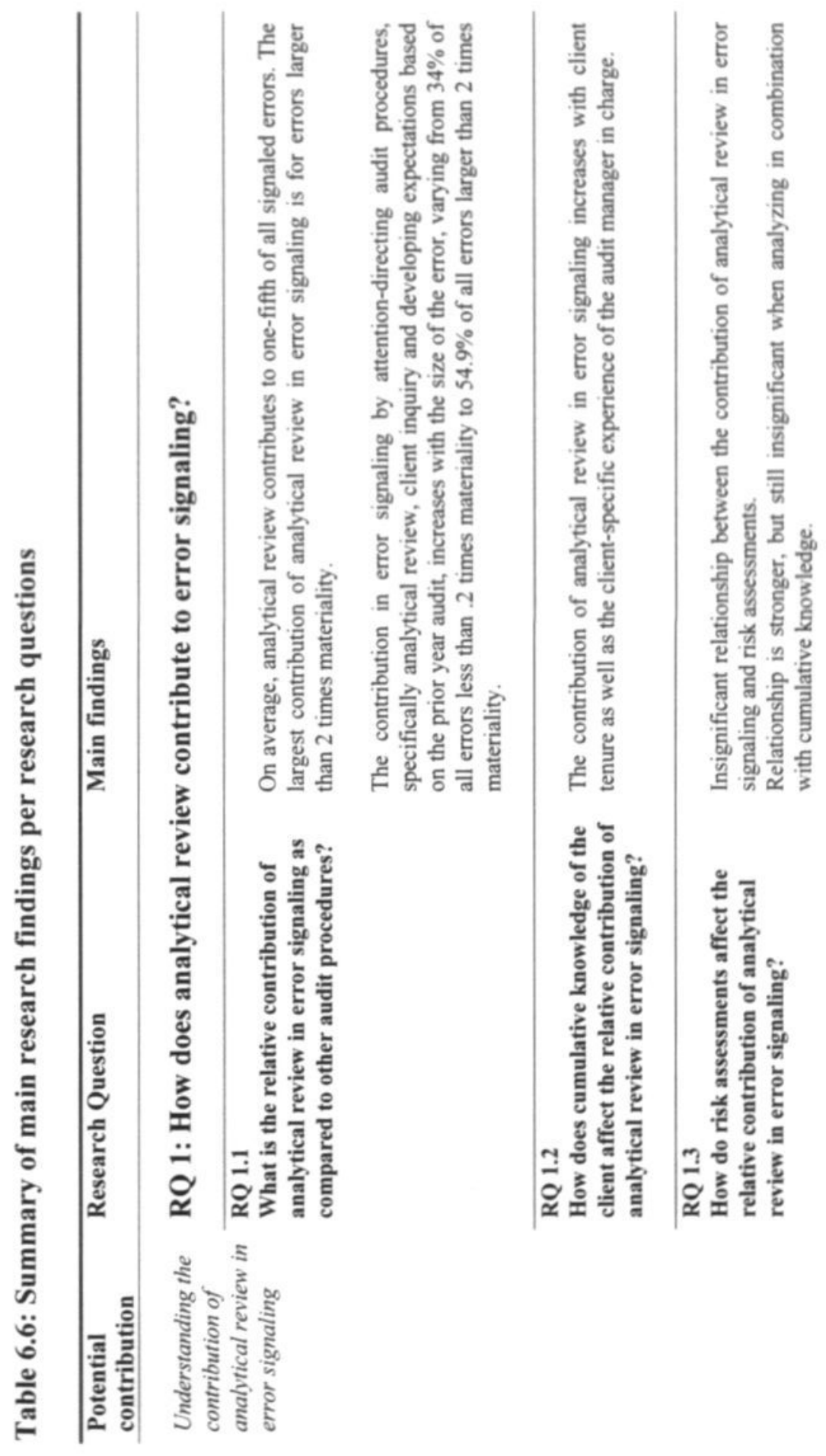




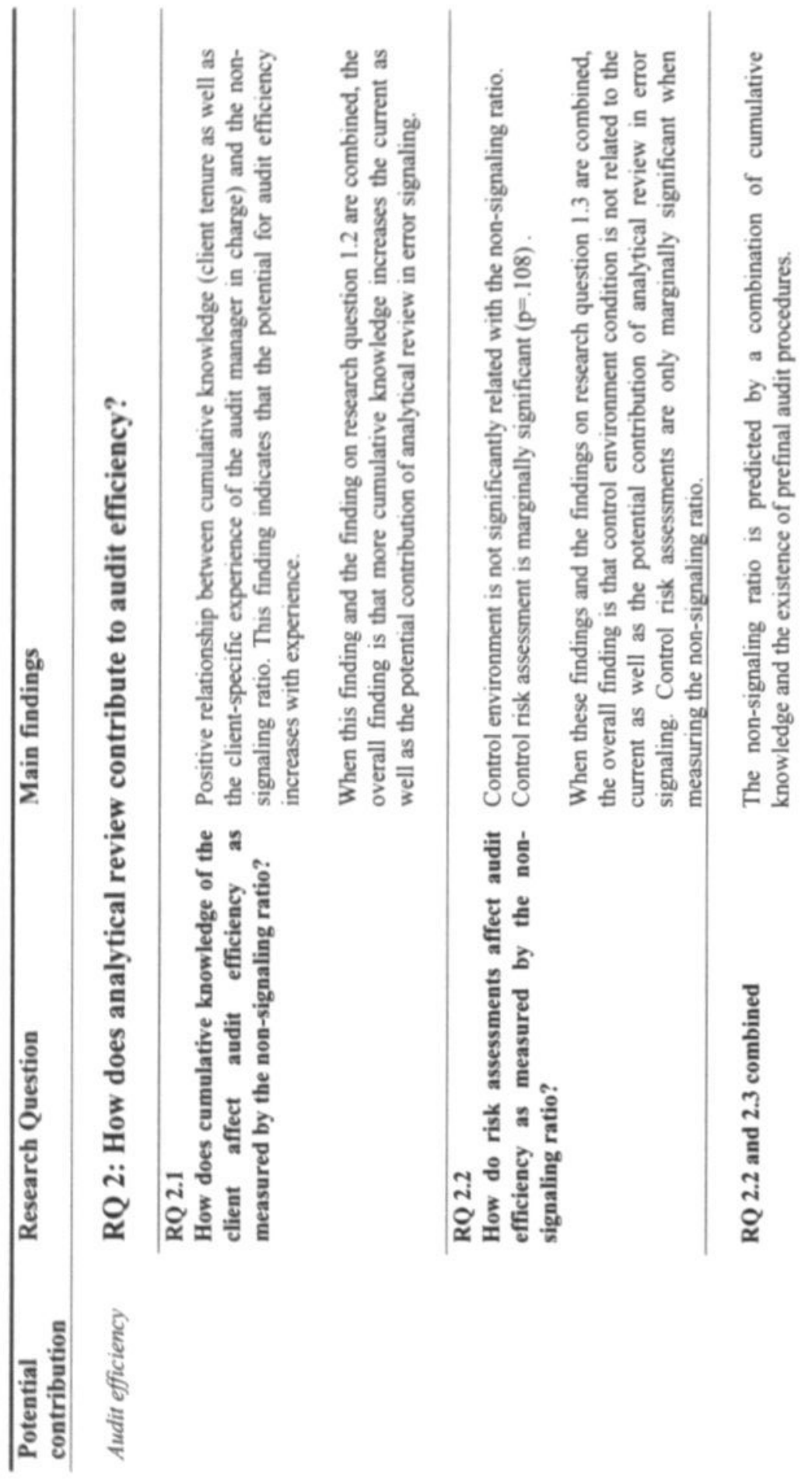




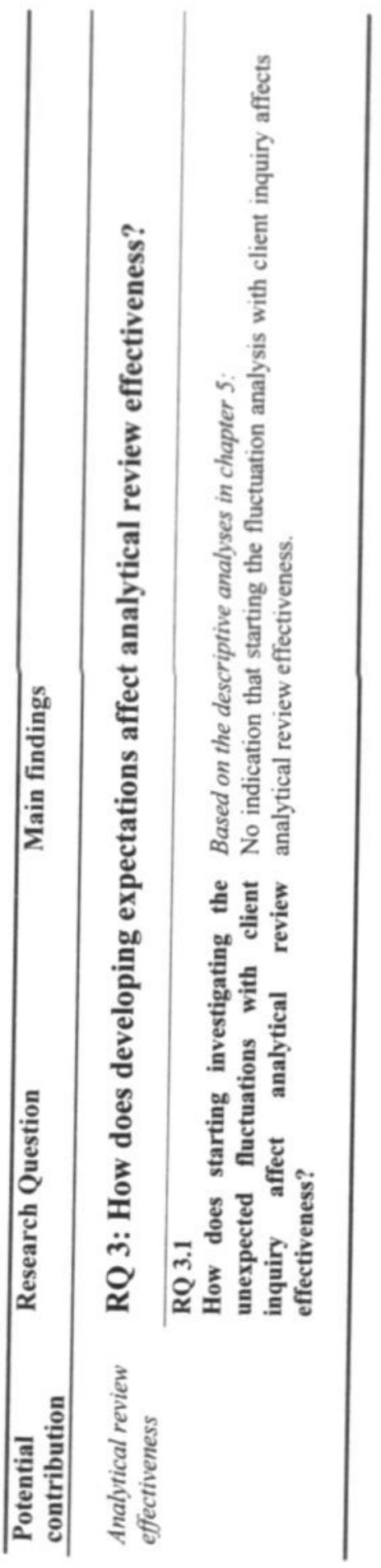




\section{SUMMARY AND CONCLUSIONS}

\subsection{Introduction}

This thesis has dealt with the contribution of analytical review to audit efficiency and analytical review effectiveness. This final chapter provides an overview of the study and a discussion of its empirical findings. This chapter is structured as follows. The next section addresses the motivation for this topic, the research design and its main empirical findings. Section 7.3 discusses the implications for practice, followed by a discussion of the strengths and weaknesses of this study. The chapter concludes with suggestions for further research.

\subsection{Summary}

The motivation for investigating analytical review is the continuing attention on analytical review by practitioners and researchers during the past decades. The attention on analytical review relates to both the opportunities for improving audit efficiency when using analytical review as well as its effectiveness. For instance, the Public Oversight Board recently underlined the significant contribution of analytical review on audit effectiveness, but stressed the need for providing guidance to auditors when performing analytical review.

Three primary research questions were introduced addressing both the actual and potential contribution of analytical review in error identification:

(a) How does analytical review contribute to error signaling?

(b) How does analytical review contribute to audit efficiency?

(c) How do developing expectations affect analytical review effectiveness?

Two main groups of contingent variables were introduced that potentially affect the contribution of analytical review in signaling and detecting errors: 'Cumulative knowledge of the client' and 'Risk assessments'. Professional standards stress the importance of both groups of variables when performing initial audit planning. 
Cumulative knowledge is the knowledge of the client developed during the current and prior years' audits by the audit team. Cumulative knowledge is considered to be important for understanding the client's business and accounting system as well as the assessment of risk and materiality. Risk assessments relate to inherent and fraud risk, the control environment and the accounting and internal control system.

Chapter 2 presented a literature review on the use and effectiveness of analytical review by auditors. It was argued that, despite the straightforward nature of many analytical review procedures, the decision making process is rather complex. Previous research on cumulative knowledge shows that the experience of the auditor, as a surrogate for expertise, is an indicator for analytical review performance (for example Biggs, Mock and Watkins, 1988; Bedard and Biggs, $1991 \mathrm{a}$ and 1991b; Bedard, Biggs and DiPietro,1998). Note that experience as investigated in previous studies has been restricted to general experience and industry-specific knowledge. No information is available from previous research on client-specific experience of the auditor as well as client tenure. These aspects of experience are investigated in the current study.

Previous research indicated a weak relationship between risk assessments and audit planning decisions (for example Bedard, 1989; Waller, 1993; Mock and Wright, 1993 and 1999). It was observed that previous research showed the auditor's sensitivity to contingent risk assessments, but still little evidence is available on the relationship between risk assessments and the contribution of analytical review in signaling errors. Due to the absence of a strong relationship between risk assessments and audit planning decisions, it is not clear whether the absence of a relationship is due to the auditor's inability to take varying risk conditions into account in the nature and extent of planned audit procedures. The current study introduced a new element of risk assessment as compared to previous risk-related research. Specifically, the control environment condition is introduced as a relevant risk indicator. The introduction of control environment as a component of risk assessments reflects the relevance of control environment as introduced in the 1992 COSO report.

Also, previous research stresses the importance of auditors developing their own expectations when performing analytical review. Specifically, experimental settings indicated the potential bias of inaccurate client representations (for example Bedard and Biggs, 1991a and 1991b; Bedard, Biggs and DiPietro, 1998; Koonce and Phillips, 1996, Anderson and Koonce, 1995), and/or inaccurate unaudited book values (for example, Kinney and Uecker, 1982; Biggs and Wild, 1985; Heintz and White,1989). As previous research findings are largely based on experimental settings, the current study 
add to this literature by exploring the effects of developing expectations in a field setting.

In chapter 3, the primary research questions were used to develop more specific questions that could be tested empirically. Three ratios were developed to test the contribution of analytical review to audit efficiency and effectiveness. The first ratio, the signaling ratio, measures the contribution of analytical review in error signaling. The second ratio, the non-signaling ratio, measures the potential contribution of analytical review in error signaling. The third ratio, the nondetection ratio, measures the contribution of analytical review in error detection after the initial identification of the error by analytical review.

The secondary research questions address the effects of cumulative knowledge and risk assessments on the actual and potential contribution of analytical review in error signaling. The secondary research questions on analytical review effectiveness address the effect of client representations on error detection.

Prefinal audit procedures are introduced as a control variable. Prefinal audit procedures are meant as an early warning procedure for multi-location audits. All local audit teams report preliminary audit findings, including errors that should be resolved before year-end in order to prevent audit adjustments at yearend. The existence of prefinal audit procedures is introduced as a variable that may have an effect on the contribution of analytical review in error signaling, as the timing and nature and extent of audit procedures in audits including prefinal audit procedures may vary from those, which have not.

Chapter 4 presents the research design. A field study was performed at a Big Four audit firm in The Netherlands using field data from 147 audit engagements for the fiscal year 1997. The data were collected in the first half of 1998. Questionnaires were distributed to 184 audit managers on randomly selected audit engagements. The questionnaire contains sections on general engagement information including control environment, inherent risk and control risk assessments. The questionnaire contains detailed questions on individual error level, including the number and size of errors, the audit area, and the audit procedure that identified the error. In total, 147 questionnaires were completed. The response rate was high $(79.9 \%)$ due to the combined effect of the support of the steering committee of the firm and the possibility of having direct contact with the participants.

Descriptive statistics are presented in chapter 5. The 147 audit files contained 624 errors, varying from 0 to 8 per file. For the whole sample, $20.5 \%$ of the errors were initially signaled by analytical review. The contribution of analytical 
review in error signaling varied with the size of the error. The contribution of 'simple' audit procedures - analytical review, client inquiry and expectations from the prior year - is positively related to the size of the error. The larger the size of the error, the higher is the likelihood that simple audit procedures signal the error.

The descriptive findings indicate that both aspects of cumulative knowledge of the client (tenure and client-specific - experience of the manager in charge) are positively related to the contribution of analytical review in error signaling. The descriptive findings also indicate that the contribution of analytical review in error signaling is not significantly contingent to control risk and the control environment condition.

The descriptive findings also indicate that performing prefinal audit procedures negatively affects the contribution of analytical review in error signaling.

In the remaining part of chapter 5 , the signaling ratio, non-signaling ratio and the non-detection ratio were explored using the independent variables cumulative knowledge, risk assessments and the control variable prefinal audit procedures. The descriptive results show that in $55 \%$ of the engagements, one or more errors were signaled by analytical review. Also, cumulative knowledge aspects were significantly related to the signaling ratio, whereas the risk assessment aspects were not.

Various other analyses of the non-signaling ratio show that the participants perceive that in $46 \%$ of the engagements where other procedures were used to identify an error, one or more errors could have been signaled by analytical review,

Only in 5 (7.5\%) engagements, errors were not detected in an audit procedure directly after the error was signaled by analytical review. Analytical review effectiveness was in these cases not affected by whether or not the auditor started with client representations.

The multivariate analyses in chapter 6 focused on the two primary research questions on audit efficiency. The absence of further multivariate analysis with respect to the research question on analytical review effectiveness was due to insignificant results on the univariate analyses in combination with the low incidence rate of non-detected errors (only at 5 engagements).

The first multivariate analysis addressed the secondary research questions 1.2 and 1.3 on effects of cumulative knowledge and risk assessments respectively on the contribution of analytical review in error signaling. The analysis was operationalized by a multiple regression model with the signaling ratio as dependent variable and cumulative knowledge and risk assessments as 
138 CHAPTER 7

independent variables, and with prefinal audit procedures as a control variable. The multivariate results show that the signaling ratio is significantly associated with tenure $(p=.032)$, client-specific experience $(p=.01)$ and prefinal audit procedures $(\mathrm{p}=.012)$, in combination with insignificant predictions by control risk assessment $(p=.212)$ and control environment condition $(p=.479)$.

The second multivariate analysis addressed the secondary research questions 2.1 and 2.2 on effects of cumulative knowledge and risk assessments on audit efficiency. The analysis was operationalized by a multiple regression model with the non-signaling ratio as dependent variable and cumulative knowledge and risk assessments as independent variables, added with prefinal audit procedures as a control variable. The multivariate results show that the non-signaling ratio is significantly associated with tenure $(p=.030)$, clientspecific experience $(\mathrm{p}=.008)$ and prefinal audit procedures $(\mathrm{p}=.004)$, in combination with a marginal prediction of control risk assessment $(\mathrm{p}=.108)$ and insignificant prediction by the control environment condition $(\mathrm{p}=.940)$.

Further discussion of the current findings including implications for practice is addressed in the section 7.3.

\subsection{Discussion of results}

\subsubsection{Implications for practice}

\subsubsection{Introduction}

This study has increased our knowledge of analytical review in several areas. Firstly, the field study provides detailed error statistics, including the number and size of errors, the audit procedures involved and the ultimate follow-up of the error. The findings address the recent call for guidance to practitioners by the Panel On Audit Effectiveness (POAE, 2000, section 1.1. of this thesis), specifically with respect to developing expectations, backgrounds on the characteristics and reliability of data, the effects of risk assessment on analytical review procedures, including identifying, investigating and evaluating the results of analytical review. Secondly, the findings increase our understanding of the contingent variables affecting the actual contribution of analytical review in error signaling and the opportunities for improving audit efficiency. Thirdly, the findings improve our understanding of the influence of client representations on analytical review effectiveness. These findings are elaborated on in the following section. 


\subsubsection{Audit efficiency}

The main results can be summarized into two groups: cumulative knowledge and risk assessments. The results show that cumulative knowledge of the client significantly affects both the actual and potential contribution of analytical review in error signaling. The field study goes beyond previous research by using client tenure and client-specific experience of the manager in charge as surrogates for expertise. The results are consistent with previous experimental audit research. Specifically, that expertise has a positive effect on task performance.

The observation that cumulative knowledge affects the contribution of analytical review in error signaling indicates that more client-specific experience enables the auditor to select a more appropriate procedure for signaling errors. The findings show that more cumulative knowledge of the client results in a larger contribution of analytical review in error signaling. Assuming that analytical review is cost-effective, the results indicate that more experienced auditors are at the best to gain audit efficiency.

Even more interesting is the potential efficiency gain for continuous engagements with substantial cumulative knowledge. Participants acting on engagements with substantial cumulative knowledge indicate that still more errors could have been signaled by analytical review. Again assuming that analytical review is cost-effective, more cumulative knowledge evidently provides an opportunity to gain audit efficiency.

The results suggest a number of recommendations for audit practice. Firstly, audit efficiency is gained when the audit team has more cumulative knowledge. Audit firms are recommended to take advantage of the cumulative knowledge developed by the current team (especially the client-specific knowledge of the manager in charge) and also from previous team members (measured by client tenure). Secondly, audit firms are encouraged to evaluate the nature and extent of audit procedures used for engagements with high client tenure and/or an audit manager with high client-specific experience. The ultimate outcome of this evaluation might be a reduction of actual hours spent on the engagement.

The findings with respect to the effects of risk assessments on error signaling by analytical review confirm previous archival research results (for example Bedard, 1989; Waller, 1993; Mock and Wright, 1993 and 1999). These studies have found no significant relationship between risk assessments and the subsequent nature and extent of audit procedures. The current study goes beyond previous research concerning data on the control environment condition, resulting in two observations for practitioners. Firstly, the number of errors 
identified during the audit is significantly related to the control environment condition. This implies that the control environment condition is an explanatory variable of the number of errors in an audit file.

Secondly, the findings confirm the need for improvement for risk assessment and subsequent response by practitioners as expressed by the Panel On Audit Effectiveness (see section 1.1). With respect to both implications for practitioners, auditors are encouraged to explicitly evaluate the control environment condition before starting the audit in order to improve the fit between risks and audit response on the extent and nature of audit procedures to be used.

\subsubsection{Analytical review effectiveness}

The research findings do not indicate that starting the fluctuation analysis with client representations has a negative effect on error detection. Note however that the analyses of analytical review effectiveness were exploratory. Further analysis is required to assess the potential positive and negative effects of using client representations. In the meantime, practitioners are encouraged to remain skeptical on the evidential power of client representations and always corroborate client representations with other audit evidence. Documentation of the evaluation of audit evidence may improve the cumulative knowledge of current and future audit team members.

\subsubsection{Strengths and weaknesses}

In this section, the strengths and weaknesses of the study are discussed. The discussion is organized in the categories 'sample', 'definitions' and 'contingent variables'.

\subsubsection{Sample}

A major strength of the current study is the use of recent archival data as compared to the previous archival studies of the 1980's. Audit approaches have evolved in the last decade with currently more focus on the control environment since the COSO report (COSO, 1992). This study investigates the relationship between control environment and analytical review. Further, the findings indicate a shift in the error causes. Specifically, the percentage of errors caused by mechanical and cut-off/accrual errors have decreased, whereas errors caused 
by personnel problems have significantly increased as compared with Wright and Ashton (1989).

The current field setting studies audit engagements in The Netherlands, whereas previous analytical review research was in the United States. Selecting data in only one country is a potential weakness. In section 4.2.1, it was hypothesized that the various audit approaches would not generate substantially different audit findings between globally organized audit firms due to the widely implemented IFAC-GAAS in all globally organized audit firms. In general, this is the case, as "the objective of an audit of financial statements is to enable the auditor to express an opinion whether the financial statements are prepared, in all material respects, in accordance with an identified financial reporting framework" (ISA No. 200, par.2). In other words, the audit objective is the same for all audits, but the ways to reach these objectives, including the nature, timing and extent of the audit procedures to be used, may differ between firms and between geographic regions.

A potential weakness of the current study is the restriction of data collection to only one audit firm. As a result, the engagement base of the audit firm might bias the sample. This potential weakness was considered before starting the data collection. It was observed that audit firms are very hesitant to cooperate based on individual (confidential) engagements. As a consequence, the potential weakness of restricting the data collection to only one firm is acknowledged.

The sample of PwC files encompassed audit engagements performed in 1998 on the audit of 1997 financial statements. Importantly, the audit engagements were based on the pre-merger legacy Coopers \& Lybrand. Since the merger with Price Waterhouse in 1998, a new audit approach and new documentation standards have been implemented. One consequence of the new documentation standards is that posted errors are no longer documented.

\subsubsection{Definitions}

The definitions in the questionnaire as detailed in section 4.6.3 encompass a number of inherent limitations. Firstly, the definition of errors focuses on errors actually signaled during the audit. One inherent limitation of using this definition is the absence of data on errors not signaled during the audit (type I error, see section 3.2.2). As a consequence, this study does not present all errors in the sample. It is evident that this type I error cannot be revealed in a fieldstudy.

Secondly, this thesis focuses on the contribution of analytical review in error signaling rather than the use of analytical review in general. The usefulness of 
analytical review goes beyond the contribution in error signaling. For instance, analytical review can also be used in the planning stage of the audit as a tool to improve the auditor's understanding of the business (section 2.2). Due to the chosen definition of errors, no information is available on efforts put in the identification of unexpected fluctuations that in the end have a non-error nature (type II error, see section 3.2.2). Type II errors potentially decrease audit efficiency when analytical review is not used as a corroborative audit procedure.

In chapter 2, the literature review addressed the potential effects of developing expectations (use of unaudited book values and client representations) on analytical review effectiveness. In chapter 3 onwards, the research questions and further analyses on analytical review effectiveness only included the potential effect of client representations and not the use of unaudited book values as a starting point for fluctuation analyses.

The limitation of analyzing only the effects of client representations and ignoring the effects of unaudited book values is motivated by the fact that the current study focused on analytical review effectiveness once the error has been signaled. The starting point is thus the error already signaled, whereas the potential bias effects of unaudited book values is in place before performing the preliminary analytical review procedures. As the research design was based on indirect observation, ex-post information on the role of unaudited book values was not available. It is possible that using unaudited book values as a starting point for fluctuation analyses might affect the findings.

Participants were asked to indicate, to the best of their knowledge, whether analytical review could have been an alternative procedure (see section 5.5.4.1) in discovering errors identified by other audit procedures. It is possible that the participants biased their replies to this question. Specifically, the interpretation whether an error could have been signaled by analytical review may depend on a number of variables, for instance the experience of the participant and his knowledge of the client, but also the time lag between the execution of the audit procedures and completing the questionnaire. During the data analysis phase of the study, no effects of this potential bias were observed. Nevertheless, it is possible that this possible bias has affected some results.

Also in section 5.5.4.1, it was mentioned that the responses of the participants were 'yes', 'not sure' or 'no' for the question whether analytical review could have been an effective alternative procedure. The 'yes' and 'not sure' categories were further considered as one homogenous group based on the group characteristics in terms of the independent variables. Additional tests were performed on the non-signaling ratio including and excluding the 'not sure' 
category. However, it is possible that the non-signaling ratio analyses were affected by excluding the 'not sure' category.

\subsubsection{Contingent variables}

This thesis focuses on two groups of contingent variables: cumulative knowledge and risk assessments. Selecting these variables was based on the professional standards that stress the importance of using the cumulative knowledge of the client and risk assessments during the planning stage of the audit.

Additional categories of contingent variables were considered such as client-specific or auditor-related aspects, industry-effects, financial position, economic situation or educational background of the audit team members. It was concluded that the contingent variables studied do cope with important aspects stressed in the professional standards. Nevertheless, it might be that omitted variables affect the findings.

In section 5.2.3.2 the control environment condition was discussed. The assessment of the control environment condition is split into a number of aspects as described in table 5.4. Before deciding to use the average of the six aspects of control environment, detailed analyses were performed per aspect on the effects on the number and size of errors and the effects on analytical review contribution in error signaling. Although the results showed a number of significant and insignificant results per aspect, the control environment aspects are used during the analyses in order to have one single control environment measure.

Using an average inherently results in the smoothing of outcomes per control environment aspect. Using the average of the six aspects is somewhat arbitrary. A weighted average might have been a sound alternative. However, no previous research is available to provide appropriate weighing factors. Therefore, it was decided to restrict the analyses to the average of the six aspects. Nevertheless, it is possible that including additional contingent variables or different weighting might affect the findings. 


\subsubsection{Suggestions for further research}

When evaluating the research findings, its implications for practice and the strengths and weaknesses of this study, a number of suggestions for future research are evident.

\subsubsection{Analytical review}

A major part of this thesis focused on the contribution of analytical review in error signaling and detection. As noted before, the use of analytical review in the audit process goes beyond error identification when using analytical review as a 'red flag' or as a confirmation that no unexpected fluctuations exist. Future research should focus on the role of analytical review in the whole audit process.

Further, no data were available on the distinction between intentional versus unintentional errors and analytical review. Future research could address the effects of intentional versus unintentional errors in combination with the contingent variables used in this study on the contribution of analytical review in error signaling and analytical review effectiveness.

\subsubsection{Cumulative knowledge}

The currently used aspects of cumulative knowledge of the client, client tenure and client-specific experience of the manager in charge were innovations related to the research on auditor's expertise. The significant results should encourage researchers to corroborate the current findings in experimental and alternative field settings.

\subsubsection{Risk assessments}

The insignificant results on risk assessments are somewhat disappointing, despite the consistency with previous research findings on the effects of risk assessments on subsequent audit steps. The absence of a significant relationship could be due to inadequate risk response scales used by practitioners. Future research should focus on improving our understanding of risk assessments and decisions on subsequent audit steps by auditors. 


\subsubsection{Error characteristics}

The analyses of error characteristics were limited to those analyzed that contributed to the scope of this thesis. However, the collected data may further address the call for guidance to practitioners on the characteristics of errors in specific audit engagements. Specifically, further analyses on the effects of the six investigated aspects of the control environment condition on the number, size and nature of errors is a potential area for further investigation.

An additional area for further research is the effect of errors on earnings. Table 5.12 in section 5.3 .3 showed that $44 \%$ of the errors found reduced earnings with an average effect of $28 \%$, whereas $36 \%$ increased earnings with only an average effect of $.5 \%$. Further investigations should focus on the variables that affect earnings management.

\subsubsection{Developing guidance}

The call for developing practical guidance to auditors (see chapter 1) on performing analytical review stresses the importance of analytical review for the audit process. Improving the performance of analytical review is an important step to improving audit effectiveness. It was stressed in this thesis that analytical review is a complex "diagnostic process of identifying, investigating and resolving unexpected fluctuations" (Koonce, 1993).

Future research should be focused on transferring the cumulative knowledge of experienced auditors to subordinates. Part of this transfer of cumulative knowledge will always be done by coaching-on-the-job, but researchers can play an important instructive role by developing training tools including providing information on the contingent variables that are relevant when performing analytical review. For instance, educational software including simulation of the decision making process of analytical review could be developed in order to accelerate the learning curve of the younger staff.

\subsection{Closing remarks}

This thesis dealt with the contribution of analytical review on audit efficiency and analytical review effectiveness. The research design, which was based on an archival setting, provided further insight in the process of analytical review and its place in the contribution in signaling and detection of errors. 
The results show the significant effects of cumulative knowledge on the actual and potential contribution of analytical review in error signaling. The effects of risk assessments on the actual and potential contribution of analytical review in errors signaling were only partly significant.

The results on analytical review effectiveness did not indicate that client representations actually negatively influenced the process of analytical review in the sample. The findings suggest that client representations may have positive effects on the analytical review process when the client representation is accurate.

The field of auditing is currently subject to severe criticism. Main criticism deals with (perceived) independence and the effectiveness of the audit process. Audit firms and standard setters have been reconsidering the effectiveness of the audit process. Without doubt, analytical review as a powerful and cost-effective audit procedure will play an important role in the audit process in the future. This should encourage future research in this aspect of auditing. 


\title{
APPENDIX A: ASSESSMENT OF CONTROL ENVIRONMENT ASPECTS
}

\author{
Source: PwC audit approach (1997 version C\&L legacy)
}

\begin{tabular}{ll}
\hline Control environment aspect & Required assessment \\
\hline $\begin{array}{l}\text { The role of the Board of } \\
\text { Directors }\end{array}$ & $\begin{array}{l}\text { Assess whether the composition, activities and attitudes of members of the } \\
\text { board of directors and the information provided to it set an appropriate tone } \\
\text { at the top; are conducive to effective decision-making and control; and } \\
\text { motivate management to act properly in the interest of shareholders. }\end{array}$ \\
\hline $\begin{array}{l}\text { Effectiveness of the organization } \\
\text { and key management }\end{array}$ & $\begin{array}{l}\text { Assess whether: } \\
\text { The organizational structure, management responsibilities and attitudes are } \\
\text { effective in controlling the business; and } \\
\text { Directors and senior management (particularly those with direct financial } \\
\text { responsibility) possess the requisite skills and experience to implement } \\
\text { board decisions and deal with changing business conditions. }\end{array}$ \\
\hline $\begin{array}{l}\text { Reasonableness of management } \\
\text { plans and budgetary controls }\end{array}$ & $\begin{array}{l}\text { Assess whether: } \\
\text { Management develops plans and budgets to direct and monitor the activities } \\
\text { of the business. Assess whether they are realistic, based on valid } \\
\text { assumptions, developed by knowledgeable individuals and at an appropriate } \\
\text { level of detail; and } \\
\text { Information produced is sufficient, timely and reliable enough to review, } \\
\text { evaluate and if necessary take executive action affecting the business' } \\
\text { operations and financial position. }\end{array}$ \\
\hline $\begin{array}{l}\text { Thess whether: } \\
\text { There are regular financial reporting routines designed to produce summary } \\
\text { lans and regulations }\end{array}$ \\
$\begin{array}{l}\text { Thanagement information; } \\
\text { Reviews by management of the information would identify control } \\
\text { breakdowns or possible material misstatements in the information; and } \\
\text { Appropriate follow-up action is taken. }\end{array}$ \\
$\begin{array}{l}\text { Assess whether management is aware of laws and regulations applicable to } \\
\text { its activities, and whether significant risk of non-compliance is identified } \\
\text { and appropriate action taken. }\end{array}$ \\
\hline
\end{tabular}

\begin{tabular}{ll}
\hline $\begin{array}{l}\text { Human resource policies and } \\
\text { procedures }\end{array}$ & $\begin{array}{l}\text { Assess whether policies and procedures ensure that sufficient competent } \\
\text { people are recruited, developed and retained to enable business plans to be } \\
\text { carried out and to guard against control breakdown or undue loss. }\end{array}$ \\
\hline The role of the audit committee & $\begin{array}{l}\text { Assess whether the composition, activities and attitudes of the board's audit } \\
\text { committee and the information provided to it: result in effective monitoring } \\
\text { and review of the business' accounting, internal control and financial } \\
\text { reporting policies and practices; help set the 'tone at the top'; and help } \\
\text { maintain constructive lines of communication with external and internal } \\
\text { auditors. }\end{array}$ \\
\hline The role of internal audit & $\begin{array}{l}\text { Assess whether internal audit is a valuable part of the control environment, } \\
\text { helping assess business risk and providing assurance on the continuing } \\
\text { operation of internal control established to meet the business' objectives. }\end{array}$ \\
\hline
\end{tabular}




\title{
APPENDIX B: QUESTIONNAIRE
}

\section{Note that not all questions have been used in subsequent data analyses of the research due to limited relevance.}

\section{Analytical Procedures Questionnaire}

\author{
Regarding the 1997 audit findings
}

\section{Summer 1998}

\section{All data will be used confidentially}

\section{Analytical. Procedures Questionnaire}

\subsection{Introduction}

The purpose of this questionnaire is to investigate the use and role of Analytical Procedures during the audit. This inquiry is focused on errors identified during the audit of the financial statements, their causes, team members involved and client environment involved. You are requested to look through your 1997 audit file issues and report us the key data on main errors signaled and detected.

We suggest you to start looking at the critical matter and/or SUD issues identified during the audit and/or discussion items during the clearance meeting. Of course, you may decide to start the way you like as you know the best the specific engagement settings. Mind however the comments in the next paragraphs.

\subsection{Definition of Error}

During the audit one or more audit differences may appear. An audit difference is defined as an unexpected deviation in the unaudited figures between actual outcomes and outcomes as expected by the auditor (whether or not explicitly stated). A number of audit differences are solved during the audit and have a non-error nature. On the other hand, a number of audit differences have an error or fraud nature. The term error refers to 'unintentional mistakes in financial statements'. The term fraud refers 
to 'an intentional act by one or more individuals among management, employees, or third parties, which results in a misrepresentation of financial statements' (ISA 240).

In this questionnaire, an error is defined as an unintentionally or intentionally mistake in the financial statements (=error and fraud according to ISA 240). This questionnaire is only focused on audit differences with an error nature. Non-error nature differences are not relevant.

\section{Examples:}

1. Gross margin unexpectedly decreased as compared to prior year (audit difference). Further investigation during the audit led to the conclusion that a new competitor caused a $10 \%$ decrease in sales price level (=non-error nature)

2. The provision for obsolete stock as a percentage of gross stock value is far below prior year (audit difference). Further investigation during the audit revealed that a mechanical error in the formula of the client's spreadsheet had caused this error (=error-nature).

\subsection{Materiality}

Errors found during the audit may not be material individually, but may be material if combined with other errors. If individual (non-material) errors were relevant for your audit, these are relevant for in this questionnaire too.

\subsection{The effect of discussions with the client during the audit}

In this questionnaire, all errors found are relevant, independent from their follow up. Therefore, posted, adjusted, unadjusted and waived errors should be written down. For instance, you may have found an error, which adjustment has been accepted by the client during the field work. This posted error may not be discussed at the end of the audit, but is still relevant for purposes of this questionnaire!

\subsection{The effect of timing and evaluating of audit findings}

For a number of audits we perform a hard close on $3^{\text {rid }}$ quarter figures or Oct 31 figures (etc.). Audit findings discussed at that time may be adopted by the client before year-end. Therefore, during the final audit this error will not occur. For purposes of this questionnaire, these pre-closing errors are still relevant!

\subsection{Signaling and detecting the error}

In the questionnaire a distinction is made between signaling and detecting the error. The first identification of an error is referred as 'signaling the error'. After signaling, the auditor has to assess whether the unexpected fluctuation has a non-error or an error nature. Improper follow up might prevent the auditor to conclude that the fluctuation has an error nature. 'Detecting the error' is defined as the final assessment that the unexpected fluctuation has an error nature. 
$150 \mid$ APPENDIX B

\section{Examples:}

1. During Preliminary Analytical Procedures an unexpected fluctuation was signaled in the December gross margin of main product group (=signaling). Further investigation as a direct follow up to this finding revealed that the internal cut off procedure on purchase invoices was insufficient (detecting). In this case signaling as well as detecting is based on the audit procedure 'analytical procedures'.

2. During Preliminary Analytical Procedures an unexpected fluctuation was signaled in the December gross margin of main product group (=signaling). The senior interviewed the administrator and the latter had a plausible explanation. No further action was taken. However. during later cut off testing the error was revealed (=detecting). In this case, Analytical Procedures did signal, but did not detect the error.

\subsection{Analytical procedures}

Analytical procedures is defined (ISA 520) as the analysis of significant ratios and trends including the resulting investigation of fluctuations and relationships that are inconsistent with other relevant information or which deviate from predicted amounts.

Analytical procedures include the consideration of comparisons of the entity's financial information with, for example:

- comparable information for prior periods;

- anticipated results of the entity, such as budgets or forecasts, or expectations of the auditor, such as an estimation of depreciation;

- similar industry information, such as a comparison of the entity's ratio of sales to accounts receivable with industry averages or with other entities of comparable size in the same industry.

Analytical procedures also include consideration of relationships:

- among elements of financial information that would be expected to conform to a predictable pattern based on the entity's experience;

- between financial information and relevant non-financial information.

In the questionnaire a mumber of questions refer to analytical procedures. Mind that analytical procedures can be used during various stages of the audit and therefore do not only include the preliminary analytical procedures during the planning stage, but also as substantive procedures and as an overall review during the final stage of the audit. 


\section{QUESTIONNAIRE $\mid 151$}

\section{GLOSSARY/VERKLARENDE WOORDENLIJST}

Adjusted error

Clearance meeting

Client representation

Posted error

Waived error
Een fout die naar aanleiding van en na afloop van de controle (bijv. in de eindbespreking) alsnog in de jaarrekening wordt gecorrigeerd.

Eindbespreking met de client waarin de belangrijkste controlebevindingen worden besproken en de geconstateerde fouten ter sprake komen.

Een (mondelinge of schriftelijke) verklaring van de client (directeur, controller, administratief medewerker etc), bijvoorbeeld een toelichting op de cijfers in de periodieke rapportage of een ad-hoc reactie op vragen van de accountant.

Een fout die na ontdekking door de accountant door de client is gecorrigeerd tijdens de audit.

Een fout die niet wordt gecorrigeerd. 
152 APPENDIX B

\section{SECtion 1: GENERAL Engagement INFORMATION}

\subsection{Client name and participant's name}

For confidentiality reasons the client name above is shown as a number. During the selection procedures of the engagements, the QA partners only handed the client name and type of industry. The link between client name and number is only available for Peter Eimers and only during this project.

1.2 Is the person who filled this inquiry form the same as above-mentioned person?

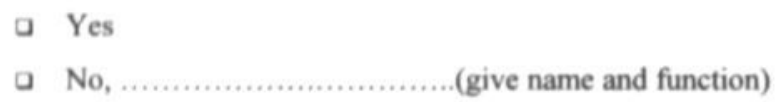

1.3 Client history with C\&L:

a ............years (including current year)

1.4 Fiscal year:

a as per December 31

a other,....

THE FOLLOWING QUESTIONS REFER TO THE PARTICIPANT

Please indicate (current season $=$ one year):

1.5 Your experience in audit practice

a ....... years

1.6 Your experience in current function

a ....... years

1.7 Your experience in this specific industry

a ....... years

1.8 Your experience at this client

a ....... years

1.9 Did you render an unqualified audit opinion ('goedkeurende verklaring') in this particular engagement?

a Yes

a No, main reason:

For some audits a pre-final audit and or an hard close on interim figures is performed in order to identify audit issues and discuss them with management on an early basis. 
1.10 Did you perform a pre-final/interim hard close?

a Yes, on the figures (e.g. Q3, Oct31, Nov30, etc.)

a No

In this questionnaire, errors found during the pre-final/interim hard close should be considered like the errors during the final audit.

\subsection{Please indicate the following financial data}

The figures should be taken from the financial statements before and after current year audit.

\begin{tabular}{|l|c|c|c|}
\cline { 2 - 4 } \multicolumn{1}{c|}{} & $\begin{array}{c}\text { Prior Year } \\
\text { (audited) } \\
\text { NLG '000 }\end{array}$ & $\begin{array}{c}\text { Current Year } \\
\text { (before audit) } \\
\text { NLG '000 }\end{array}$ & $\begin{array}{c}\text { Current Year } \\
\text { (audited) } \\
\text { NLG 000 }\end{array}$ \\
\hline Inventory & & & \\
\hline Equity & & & \\
\hline Total turnover & & & \\
\hline $\begin{array}{l}\text { Cost of goods } \\
\text { sold }\end{array}$ & & & \\
\hline $\begin{array}{l}\text { Gross profit } \\
\text { Net profit } \\
\text { (before taxes) }\end{array}$ & & & \\
\hline
\end{tabular}

1.12 The monetary precision ('controletolerantie') used in the audit is:

a not calculated

Working paper reference: (section and WP number) 
154 APPENDIX B

SECTION 2: CONTROL ENVIRONMENT/ENGAGEMENT SPECIFIC FACTORS

THE FOLLOWING QUESTIONS REFER TO THE PLANNING STAGE OF THE AUDIT

2.1 Did you review prior year audit findings before starting the (interim) field work?

a Yes, by:

a Recall prior year management letter

a Recall issues in prior year file

a Other

Working paper reference

a No, because

2.2 Did you review potential changes in the industry?

a Yes, by:

a Reading newspapers

a Industry magazines

a Discussions with client management

Other,

Working paper reference

a No, because

2.3 Did you discuss potential current year changes in industry with client management?

a Yes, before performing preliminary Analytical Procedures

a Yes, after performing preliminary Analytical Procedures

Working paper reference

a No 
2.4 What is the assessment of inherent and control risk on the engagement as a whole and per cycle?

Note that the terms used refer to the Coopers \& Lybrand Audit Approach (CLAA), which was appropriate during the 1997 audit.

Max $=$ Maximum risk

$\mathrm{BM}=$ Risk below maximum, but more than low

Low $=$ Low risk

$\mathrm{N} / \mathrm{A}=$ Not applicable

Please mark $X$ in the appropriate cells of the table

Working paper reference:

\begin{tabular}{|c|c|c|c|c|c|c|c|c|c|c|c|c|}
\hline & \multicolumn{4}{|c|}{$\begin{array}{c}\text { Assessment of inherent } \\
\text { risk }\end{array}$} & \multicolumn{4}{|c|}{ Assessment of control risk } & \multicolumn{4}{|c|}{ Remaining risk } \\
\hline & $\operatorname{Max}$ & BM & Low & N/A & $\operatorname{Max}$ & BM & Low & N/A & $\operatorname{Max}$ & BM & Low & N/A \\
\hline General & & & & & & & & & & & & \\
\hline Purchase- $t$ & & & & & & & & & & & & \\
\hline Revenue- $f$ & & & & & & & & & & & & \\
\hline Inventory & & & & & & & & & & & & \\
\hline Payroll cy & & & & & & & & & & & & \\
\hline Fixed asse & & & & & & & & & & & & \\
\hline Provisions & & & & & & & & & & & & \\
\hline Treasury & & & & & & & & & & & & \\
\hline
\end{tabular}

The C\&L audit approach uses a 3-point scale between max risk and low risk for the assessment of inherent and control risk. Unfortunately, the 'below max' category contains a large area within this contimum. We ask you to re-assess your risk assessment on a 7-point scale on the next page. 
156 | APPENDIX B

2.5 Assume you had to assess inherent risk and control risk on a 7-point scale instead of above 3-point scale.

Please assess inherent and control risk again.

(Please mark $X$ in the appropriate location on the scale)

GENERAL

Assessment of inherent risk

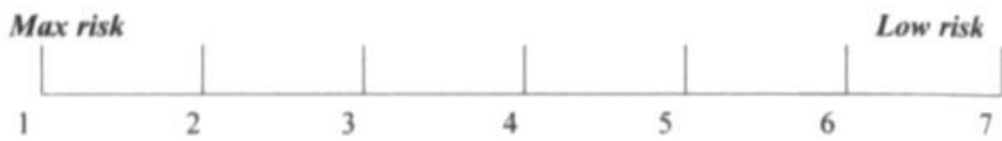

Assessment of control risk

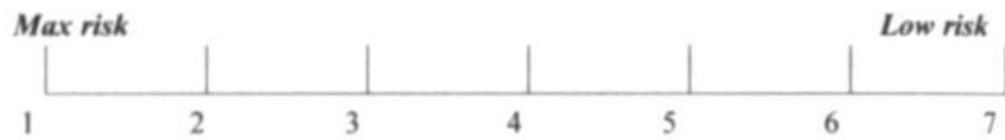

PURCHASE- AP CYCLE

Assessment of inherent risk

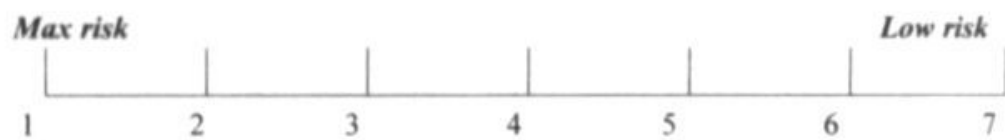

Assessment of control risk

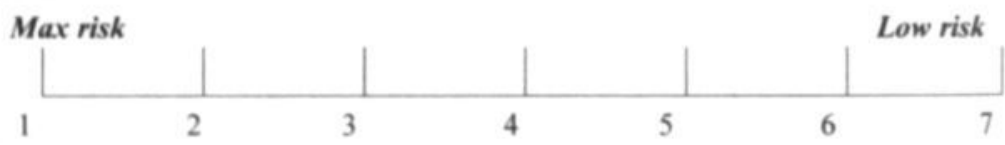

REVENUE-A/R CYCLA

Assessment of inherent risk

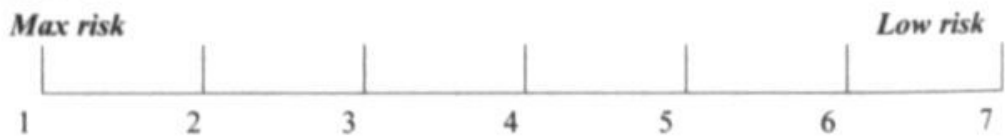

Assessment of control risk

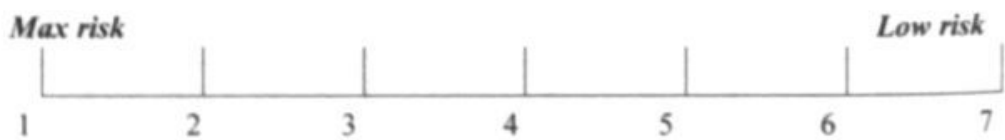

INVENTORY CYCLE

Assessment of inherent risk

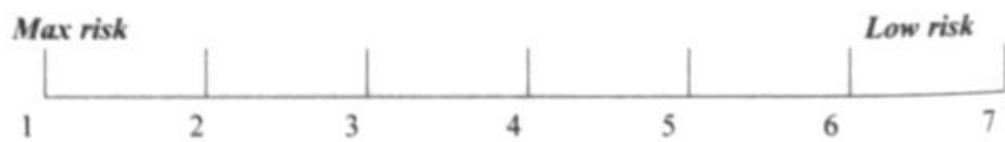

Assessment of control risk

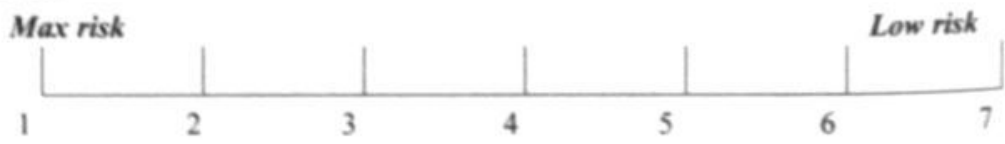




\section{PAYROLL CYCLE}

\section{Assessment of inherent risk}

Max risk

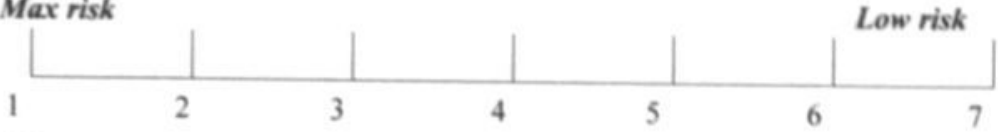

Assessment of control risk

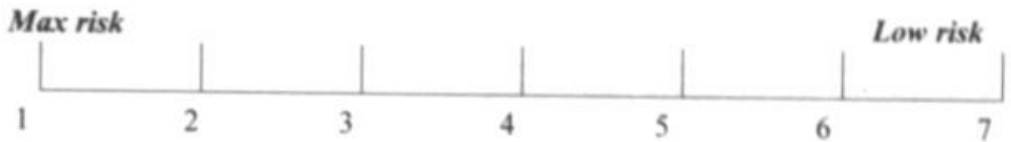

FLXED ASSETS CYCLE

\section{Assessment of inherent risk}

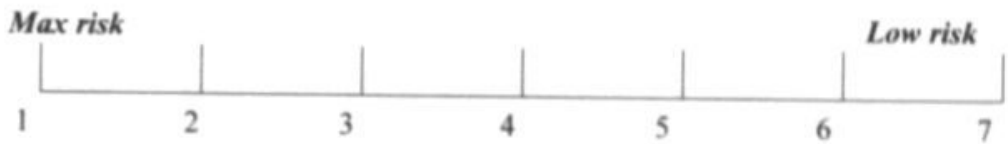

Assessment of control risk

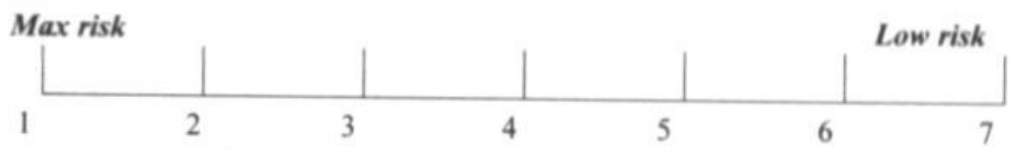

PROVISIONS

\section{Assessment of inherent risk}

\section{Max risk}

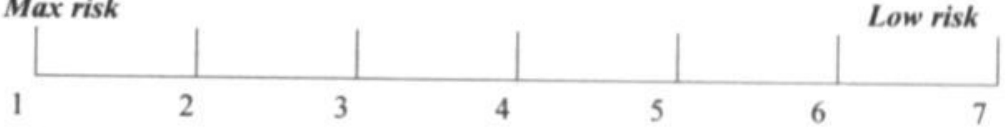

Assessment of control risk

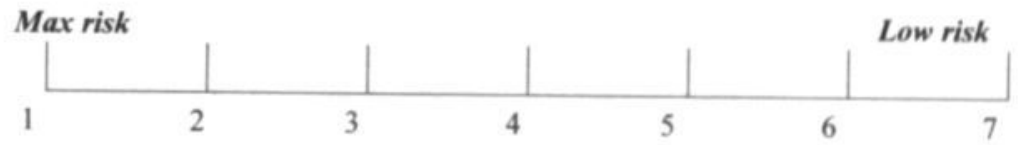

TREASUR

Assessment of inherent risk

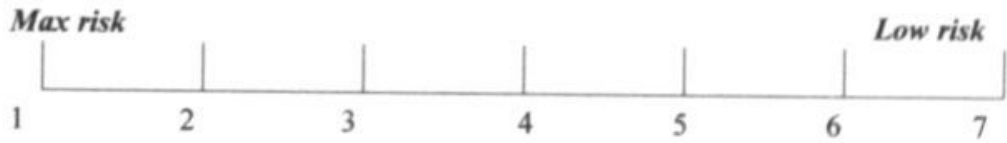

Assessment of control risk

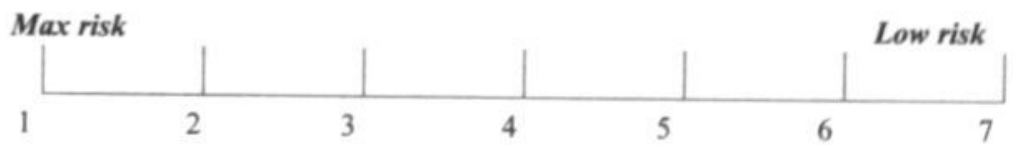


158 APPENDIX B

\subsection{What is your assessment on the control environment quality?}

In the planning stage of the audit, you have to assess the client's control environment. Please indicate, based on your working papers of section 2000 preferably, the quality of the following control environment aspects. You are asked to measure the quality on a 7-point scale as stated below:

(Please mark X on the appropriate location on the scale)

\section{THE ROLE OF THE BOARD OF DIRECTORS}

Poor quality

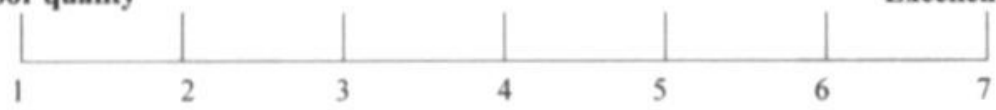

\section{EFFECTIVENESS OF THE ORGANIZATION AND KEY MANAGEMENT]}

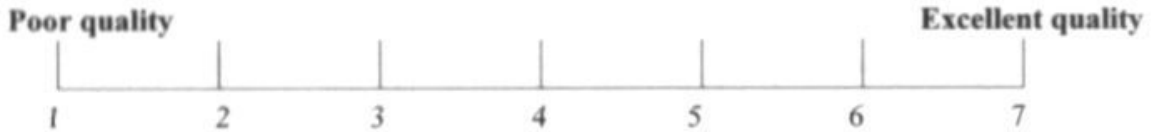

HUMAN RESOURCE POLICIES AND PROCEDURES

Poor quality

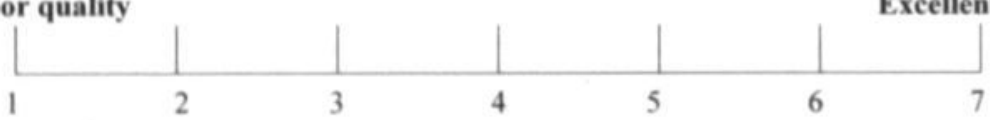

AWARENESS OF COMPLIANCE WITH LAWS AND REGULATIONS

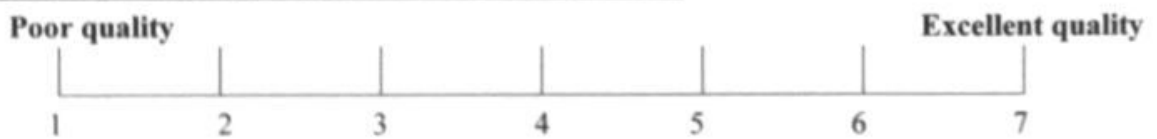

REASONABLENESS OF MANAGEMENT PLANS AND BUDGETARY CONTROLS

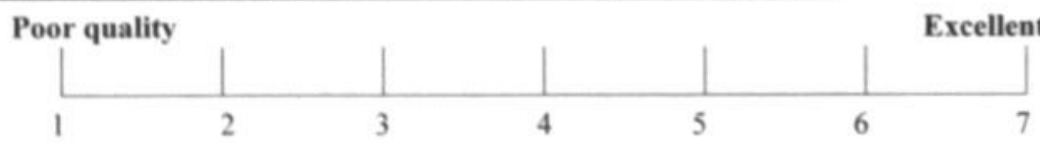

RELIABILITY OF OVERALL. FINANCIAL REPORTING

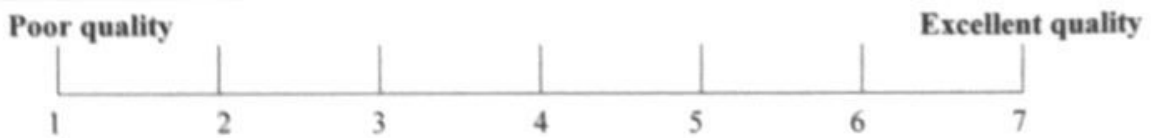




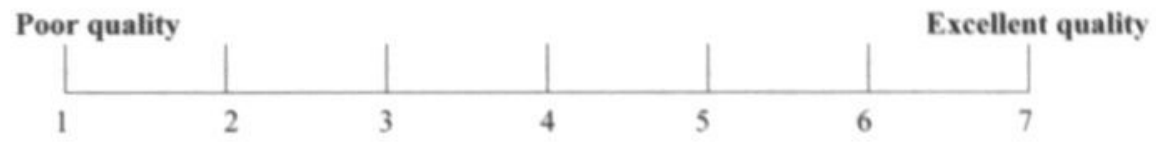

THE ROLE OF INTERNAL AUDIT (mark onby if appropriate)

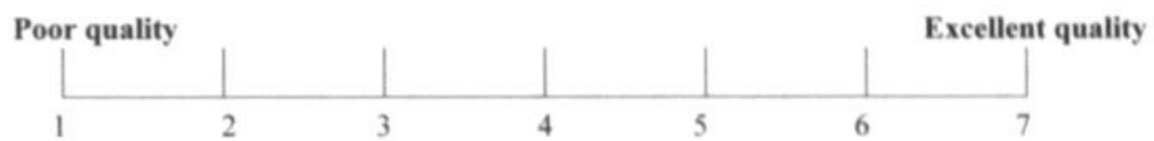

\section{SECTION 3: AUDIT FINDINGS}

THE FOLLOWING QUESTIONS ARE AIMED TO OBTAIN KEY CHARACTERISTICS OF ERRORS FOUND DURING THE AUDIT YOU PERFORMED. MIND THAT THE ERRORS INCLUDE RECLASSIFICATIONS, POSTED, ADJUSTED AND WAIVED ERRORS

\subsection{Overview of errors}

Please specify the details of the errors found during the audit

Errors found during the audit may not be material individually, but may be material if combined with other errors. If individual (non-material) errors were relevant for your audit, these are relevant for in this questionnaire too.

The table on the next page has capacity for a maximum of 8 errors. If you have observed more than 8 errors, please write down the 8 errors with the largest monetary impact.

Example:

A cut off error in December resulted in an understatement of purchases and accrued liabilities of NLG 100.000.To be noticed in the table:

\begin{tabular}{|l|c|}
\hline & Amount \\
& Debit (Credit) \\
& NLG \\
& '000 \\
\hline Other liabilities & $\mathbf{( 1 0 0 )}$ \\
\hline Purchases & 100 \\
\hline
\end{tabular}


160 APPENDIX B

\begin{tabular}{|c|c|c|c|c|c|c|c|c|}
\hline & Error 1 & Error 2 & Error 3 & Error 4 & Error 5 & Error 6 & Error 7 & Error 8 \\
\hline & $\begin{array}{c}\text { Amount } \\
\text { Debit } \\
\text { (Credit) } \\
\text { NLG } \\
' 000 \\
\end{array}$ & $\begin{array}{c}\text { Amount } \\
\text { Debit } \\
\text { (Credit) } \\
\text { NLG } \\
' 000 \\
\end{array}$ & $\begin{array}{c}\text { Amount } \\
\text { Debit } \\
\text { (Credit) } \\
\text { NLG } \\
{ }^{0} 00 \\
\end{array}$ & $\begin{array}{c}\text { Amount } \\
\text { Debit } \\
\text { (Credit) } \\
\text { NLG } \\
' 000 \\
\end{array}$ & $\begin{array}{c}\text { Amount } \\
\text { Debit } \\
\text { (Credit) } \\
\text { NLG } \\
000 \\
\end{array}$ & $\begin{array}{c}\text { Amount } \\
\text { Debit } \\
\text { (Credit) } \\
\text { NLG } \\
\text { '000 } \\
\end{array}$ & $\begin{array}{c}\text { Amount } \\
\text { Debit } \\
\text { (Credit) } \\
\text { NLG } \\
' 000 \\
\end{array}$ & $\begin{array}{c}\text { Amount } \\
\text { Debit } \\
\text { (Credit) } \\
\text { NLG } \\
.000 \\
\end{array}$ \\
\hline Fixed Assets & & & & & & & & \\
\hline Inventory & & & & & & & & \\
\hline Current assets & & & & & & & & \\
\hline Equity & & & & & & & & \\
\hline $\begin{array}{l}\text { Provisions/ accrued } \\
\text { taxes }\end{array}$ & & & & & & & & \\
\hline Long term liabilities & & & & & & & & \\
\hline Current liabilities & & & & & & & & \\
\hline Revenues & & & & & & & & \\
\hline Purchases & & & & & & & & \\
\hline Salary expenses & & & & & & & & \\
\hline $\begin{array}{l}\text { Depreciation and } \\
\text { amortization }\end{array}$ & & & & & & & & \\
\hline $\begin{array}{l}\text { Other operating } \\
\text { expenses }\end{array}$ & & & & & & & & \\
\hline Interest & & & & & & & & \\
\hline Income tax expense & & & & & & & & \\
\hline $\begin{array}{l}\text { Other accounts (please } \\
\text { specify): }\end{array}$ & & & & & & & & \\
\hline
\end{tabular}


3.2 What was the ultimate follow up of the error?

\begin{tabular}{|c|c|c|c|c|c|c|c|c|}
\hline & $\begin{array}{c}\text { Error } \\
1 \\
\end{array}$ & $\begin{array}{c}\text { Error } \\
2 \\
\end{array}$ & $\begin{array}{c}\text { Error } \\
3 \\
\end{array}$ & $\begin{array}{c}\text { Error } \\
4 \\
\end{array}$ & $\begin{array}{c}\text { Error } \\
5 \\
\end{array}$ & $\begin{array}{c}\text { Error } \\
6 \\
\end{array}$ & $\begin{array}{c}\text { Error } \\
7 \\
\end{array}$ & $\begin{array}{c}\text { Error } \\
8 \\
\end{array}$ \\
\hline $\begin{array}{l}\text { Posted by client ( } \mathrm{d} \\
\text { audit) }\end{array}$ & & & & & & & & \\
\hline $\begin{array}{l}\text { Adjusted by client } \\
\text { clearance meeting }\end{array}$ & & & & & & & & \\
\hline Waived by partner & 8 & & & & & & & \\
\hline Waived by client & & & & & & & & \\
\hline
\end{tabular}

3.3 What was the initial audit procedure that signaled the error? Check one of the following categories

\begin{tabular}{|c|c|c|c|c|c|c|c|c|}
\hline & $\begin{array}{c}\text { Error } \\
1 \\
\end{array}$ & $\begin{array}{c}\text { Error } \\
2 \\
\end{array}$ & $\begin{array}{c}\text { Error } \\
3 \\
\end{array}$ & $\begin{array}{c}\text { Error } \\
4 \\
\end{array}$ & $\begin{array}{c}\text { Error } \\
5 \\
\end{array}$ & $\begin{array}{c}\text { Error } \\
6 \\
\end{array}$ & $\begin{array}{c}\text { Error } \\
7 \\
\end{array}$ & $\begin{array}{c}\text { Error } \\
8 \\
\end{array}$ \\
\hline Analytical procedures & & & & & & & & \\
\hline $\begin{array}{l}\text { Test of detail -analysis } \\
\text { review }\end{array}$ & & & & & & & & \\
\hline $\begin{array}{l}\text { Test of detail - checks } \\
\text { mathematical accuracy }\end{array}$ & & & & & & & & \\
\hline $\begin{array}{l}\text { Test of detail - } \\
\text { documentation }\end{array}$ & & & & & & & & \\
\hline $\begin{array}{l}\text { Test of detail - } \\
\text { confirmation }\end{array}$ & & & & & & & & \\
\hline $\begin{array}{l}\text { Discussions with client } \\
\text { Personnel }\end{array}$ & & & & & & & & \\
\hline $\begin{array}{l}\text { Expectations from prio } \\
\text { year }\end{array}$ & & & & & & & & \\
\hline General audit procedur & & & & & & & & \\
\hline Other (please specify) & & & & & & & & \\
\hline
\end{tabular}


Explanation of the categories:

\begin{tabular}{|l|l|}
\hline Audit procedure category & Explanation \\
\hline Analytical procedures & $\begin{array}{l}\text { Reasonableness tests, ratios, comparisons of balances with } \\
\text { prior years, This category includes analytical procedures in the } \\
\text { planning stage, substantive testing stage as well as the } \\
\text { evaluation stage. }\end{array}$ \\
\hline Test of detail (analysis and review) & $\begin{array}{l}\text { Account reconciliations, transaction descriptions, balance } \\
\text { "work ups", scan etc. }\end{array}$ \\
\hline Test of detail - checks for & Recalculating totals, checks on formulas in spreadsheets etc. \\
\hline Test of detail - documentation & Invoices, cancelled checks, etc. \\
\hline Test of detail - confirmation & Bank statements, accounts receivable confirmations etc. \\
\hline Discussions with client personnel & $\begin{array}{l}\text { Including (pre-audit) meeting with the client, interviews, 'field } \\
\text { discussions' with financial department personnel etc. }\end{array}$ \\
\hline Expectations from the prior year & $\begin{array}{l}\text { Indications from prior engagement of a potential error or risk: } \\
\text { prior audit differences, prior working paper results, etc. }\end{array}$ \\
\hline General audit procedures & Review of accounting practices, legal letters, board of \\
\hline
\end{tabular}


3.4 During which audit phase was the error signaled (check one)?

\begin{tabular}{|c|c|c|c|c|c|c|c|c|}
\hline & $\begin{array}{c}\text { Error } \\
1\end{array}$ & $\begin{array}{c}\text { Error } \\
2\end{array}$ & $\begin{array}{c}\text { Error } \\
3\end{array}$ & $\begin{array}{c}\text { Error } \\
4\end{array}$ & $\begin{array}{c}\text { Error } \\
5\end{array}$ & $\begin{array}{c}\text { Error } \\
6\end{array}$ & $\begin{array}{c}\text { Error } \\
7\end{array}$ & $\begin{array}{c}\text { Error } \\
8\end{array}$ \\
\hline $\begin{array}{l}\text { During initial planning } \\
\text { (outlining the general scope } \\
\text { of the engagement; } \\
\text { identifying critical audit } \\
\text { areas) }\end{array}$ & & & & & & & & \\
\hline
\end{tabular}

Field work planning (including interim work)

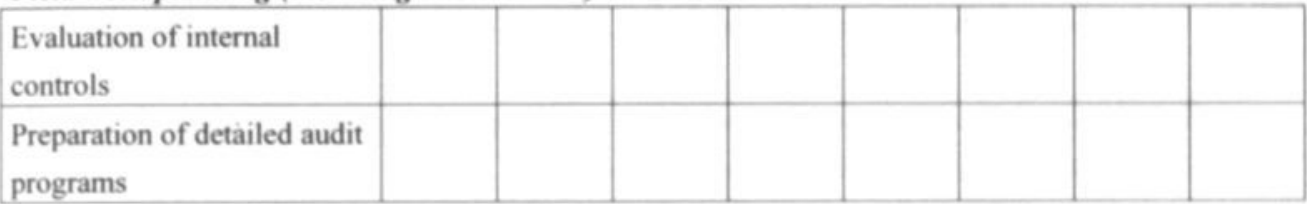

During field work (prefinalinterim hard close)

\begin{tabular}{|l|l|l|l|l|l|l|l|l|}
\hline Performing audit procedures & & & & & & & & \\
\hline $\begin{array}{l}\text { Evaluation of results of audit } \\
\text { procedures }\end{array}$ & & & & & & & & \\
\hline
\end{tabular}

\begin{tabular}{|l|l|l|l|l|l|l|}
\hline $\begin{array}{l}\text { Review of field work } \\
\text { (prefinal/interim hard } \\
\text { close) }\end{array}$ & & & & & & \\
\hline
\end{tabular}

\section{During field work (final)}

\begin{tabular}{|l|l|l|l|l|l|l|l|l|}
\hline Performing audit procedures & & & & & & & & \\
\hline $\begin{array}{l}\text { Evaluation of results of audit } \\
\text { procedures }\end{array}$ & & & & & & & & \\
\hline
\end{tabular}

\section{Review of field work}

(final) 
164 APPENDIX B

3.5 Who signaled the error?

\begin{tabular}{|l|c|c|c|c|c|c|c|c|}
\cline { 2 - 9 } \multicolumn{1}{l|}{} & Error & Error & Error & Error & Error & Error & Error & Error \\
\hline Assistant & & 2 & $\mathbf{3}$ & $\mathbf{4}$ & $\mathbf{5}$ & $\mathbf{6}$ & $\mathbf{7}$ & $\mathbf{8}$ \\
\hline Senior/supervising senior & & & & & & & & \\
\hline Manager/senior manager & & & & & & & & \\
\hline Partner & & & & & & & & \\
\hline
\end{tabular}

3.6 In your best judgment, what was the cause of the error?

Please check one or more of the following categories for each error identified

\begin{tabular}{|l|c|c|c|c|c|c|c|c|}
\cline { 2 - 8 } & Error & Error & Error & Error & Error & Error & Error & Error \\
\hline Personnel problems & & 2 & $\mathbf{3}$ & $\mathbf{4}$ & $\mathbf{5}$ & $\mathbf{6}$ & $\mathbf{7}$ & $\mathbf{8}$ \\
\hline $\begin{array}{l}\text { Insufficient accounting } \\
\text { knowledge }\end{array}$ & & & & & & & & \\
\hline Judgment errors & & & & & & & & \\
\hline Cut off or accrual errors & & & & & & & & \\
\hline $\begin{array}{l}\text { Mechanical errors } \\
\text { Inadequate control, follow } \\
\text { up or review procedures }\end{array}$ & & & & & & & & \\
\hline $\begin{array}{l}\text { Insufficient reflection on } \\
\text { changed external } \\
\text { environment }\end{array}$ & & & & & & & & \\
\hline \begin{tabular}{l} 
Other (please specify): \\
\hline
\end{tabular} & & & & & & & & \\
\hline
\end{tabular}


Explanation of the categories (as far as necessary):

\begin{tabular}{|l|l|}
\hline Error category & Explanation \\
\hline Personnel problems & $\begin{array}{l}\text { Turnover, new/inexperienced employees, } \\
\text { carelessness, time pressures, incompetence etc. }\end{array}$ \\
\hline Insufficient accounting knowledge & $\begin{array}{l}\text { Lack of awareness of generally accepted } \\
\text { accounting principles or client's accounting } \\
\text { policies }\end{array}$ \\
\hline Judgment errors & $\begin{array}{l}\text { Poor or unreasonable estimates based on } \\
\text { adequate information, e.g. uncollectible accounts }\end{array}$ \\
\hline Cut off or accrual errors & $\begin{array}{l}\text { Improper posting, footing, coding, calculations } \\
\text { Mechanical errors }\end{array}$ \\
\hline Inadequate control, follow up or review \\
procedures & $\begin{array}{l}\text { Noncompliance with internal controls, failure to } \\
\text { follow up reconciliation differences, failure to }\end{array}$ \\
\hline Insufficient reflection on changed external & $\begin{array}{l}\text { Changed law and/or standards applicable, market } \\
\text { changes etc. }\end{array}$ \\
\hline environment
\end{tabular}

THE FOLLOWING QUESTIONS REFER ONLY TO ERRORS SIGNALED BY ANALYTICAL. PROCEDURES

3.7 What specific analytical procedure signaled the error?

\begin{tabular}{|c|c|c|c|c|c|c|c|c|}
\hline & $\begin{array}{c}\text { Error } \\
1 \\
\end{array}$ & $\begin{array}{c}\text { Error } \\
2 \\
\end{array}$ & $\begin{array}{c}\text { Error } \\
3 \\
\end{array}$ & $\begin{array}{c}\text { Error } \\
4 \\
\end{array}$ & $\begin{array}{c}\text { Error } \\
5 \\
\end{array}$ & $\begin{array}{c}\text { Error } \\
6\end{array}$ & $\begin{array}{c}\text { Error } \\
7 \\
\end{array}$ & $\begin{array}{c}\text { Error } \\
8 \\
\end{array}$ \\
\hline $\begin{array}{l}\text { Ratio analysis (e.g. curre } \\
\text { ratio, inventory turnover) }\end{array}$ & & & & & & & & \\
\hline $\begin{array}{l}\text { Time series analysis } \\
\text { (modeling) }\end{array}$ & & & & & & & & \\
\hline $\begin{array}{l}\text { Comparisons of balances } \\
\text { with prior year }\end{array}$ & & & & & & & & \\
\hline $\begin{array}{l}\text { Comparisons to industry } \\
\text { averages/standards } \\
\text { (benchmarking) }\end{array}$ & & & & & & & & \\
\hline Regression analysis & & & & & & & & \\
\hline $\begin{array}{l}\text { Judgmental estimates of } \\
\text { account balances }\end{array}$ & & & & & & & & \\
\hline Other (describe below): & & & & & & & & \\
\hline
\end{tabular}


3.8 What was the follow up as a direct result of signaling the unexpected fluctuation during analytical procedures?

(check one or more, with subsequent numbering 1-2-3 etc.)

\begin{tabular}{|c|c|c|c|c|c|c|c|c|}
\hline & $\begin{array}{c}\text { Error } \\
1\end{array}$ & $\begin{array}{c}\text { Error } \\
2\end{array}$ & $\begin{array}{c}\text { Error } \\
3 \\
\end{array}$ & $\begin{array}{c}\text { Error } \\
4 \\
\end{array}$ & $\begin{array}{c}\text { Error } \\
5\end{array}$ & $\begin{array}{c}\text { Error } \\
6\end{array}$ & $\begin{array}{c}\text { Error } \\
7\end{array}$ & $\begin{array}{c}\text { Error } \\
8 \\
\end{array}$ \\
\hline No further investigation & & & & & & & & \\
\hline Recall prior year findings & & & & & & & & \\
\hline $\begin{array}{l}\text { Asking for a client } \\
\text { representation }\end{array}$ & & & & & & & & \\
\hline $\begin{array}{l}\text { Discussion within the audit } \\
\text { team }\end{array}$ & & & & & & & & \\
\hline $\begin{array}{l}\text { Corroboration by an other } \\
\text { audit procedure (please } \\
\text { describe) }\end{array}$ & & & & & & & & \\
\hline Other (describe below): & & & & & & & & \\
\hline
\end{tabular}

3.9 Was the error detected after these directly related follow up procedures?

\begin{tabular}{|l|c|c|c|c|c|c|c|c|}
\cline { 2 - 8 } \multicolumn{1}{l|}{} & \begin{tabular}{c} 
Error \\
\multicolumn{1}{l|}{}
\end{tabular} & Error & Error & Error & Error & Error & Error & Error \\
\hline $\begin{array}{l}\text { Yes, it was clear that the } \\
\text { error existed }\end{array}$ & & & 3 & 4 & $\mathbf{5}$ & $\mathbf{6}$ & $\mathbf{7}$ & $\mathbf{8}$ \\
\hline $\begin{array}{l}\text { No, subsequent audit } \\
\text { procedures revealed that the } \\
\text { earlier assessment of the } \\
\text { 'non-error' nature was } \\
\text { incorrect }\end{array}$ & & & & & & & & \\
\hline
\end{tabular}


THE FOLLOWING QUESTION REFERS TO ERRORS SIGNALED BY ANY AUDIT PROCEDURE EXCEPT FOR ERRORS SIGNALED BY ANALYTICAL. PROCEDURES.

3.10 In your opinion, could this error alternatively have been signaled by Analytical Procedures?

\begin{tabular}{|l|l|l|l|}
\hline $\begin{array}{l}\text { Error } \\
\text { No. }\end{array}$ & No & $\begin{array}{l}\text { Not } \\
\text { sure }\end{array}$ & Yes, with the following considerations: \\
\hline 1 & & & \\
\hline 2 & & & \\
\hline 3 & & & \\
\hline 4 & & & \\
\hline 5 & & & \\
\hline 6 & & & \\
\hline 7 & & & \\
\hline 8 & & & \\
\hline
\end{tabular}

This was the last question regarding the audit findings. Please complete the debriefing questions on the next page. 
168 APPENDIX B

SECTION 4: DEBRIEFING QUESTIONS

4.1 Did you perceive the contents of the questionnaire as interesting?

a Yes

a Moderate

a No

4.2 Give an indication of the instructions

๑ Very clear

a Moderate clear

a Not clear

If not or moderate, please explain:

व

4.3 Did you need assistance from other team members?

a Yes, reason

a No

4.4 How much time did you spend on completion of the questionnaire?

a Appr....... minutes

4.5 Did you perceive the English wording (instead of Dutch) of the questionnaire as inconvenient?

- Yes

a No

4.6 If you have any remarks, please write them down concisely

Thank you for your cooperation! 


\section{REFERENCES}

Ameen, E.C., Strawser, J.R., 1994, Investigating the Use of Analytical Procedures: An Update and Extension, Auditing: A Journal of Practice and Theory, Vol. 13 No. 2, 69-76

American Institute of Public Accountants (AICPA), 1998, The Auditor's Use of Analytical Procedures, in: Practice Alert, 98-1

Anderson, U., Koonce, L., 1995, Explanation as a Method for Evaluating ClientSuggested Causes in Analytical Procedures, Auditing: A Journal of Practice and Theory, Vol. 14 No. 2, 124-132

Anderson, U., Koonce, L., Marchant. G., 1994, The Effects of SourceCompetence Information and its Timing on Auditors' Performance of Analytical Procedures, Auditing: A Journal of Practice and Theory, Vol. 13 No. 1, 137-147

Asare, S.K., Davidson, R.A., 1995, Expectation of Errors in Unaudited Book Values: The Effect of Control Procedures and Financial Condition, Auditing: A Journal of Practice and Theory, Vol. 14 No. 1, 1-18

Asare, S., Wright, A., 1997, Evaluation of Competing Hypotheses In Auditing, Auditing: A Journal of Practice and Theory, Vol. 16 No. 1, 1-13

Ashton, R.H., Ashton, A.H., 1995, Perspectives on judgment and decisionmaking research in accounting and auditing, in: Ashton R.H and A.H. Ashton, 1995, Judgment and decision-making research in accounting and auditing, Cambridge University Press, 1-25

Bédard, J., 1989, Expertise in Auditing, Myth or Reality?, Accounting, Organizations and Society, Vol. 14 No.1, 113-131

Bedard, J.C., 1989, An Archival Investigation of Audit Program Planning. Auditing: A Journal of Practice and Theory, Vol. 9 No. 1, 57-71 
Bedard, J.C., Biggs, S.F., 1991a, Pattern Recognition, Hypotheses Generation and Auditor Performance in an Analytical Task, The Accounting Review, Vol. 66 No. 3, 622-642

Bedard, J.C., Biggs, S.F., 1991b, The Effect of Domain-Specific Experience on Evaluation of Management Representations in Analytical Procedures, Auditing: A Journal of Practice and Theory, Vol. 10 Supplement, 77-90

Bedard, J.C., Biggs, S.F. DiPietro, J.D., 1998, The Effects Of Hypothesis Quality, Client Management Explanations, and Industry Experience On Audit Planning Decisions, Advances in Accounting, Vol. 16, 49-73

Bell, T.B., Wright, A.M., eds., 1995, Auditing Practice, Research, and Education: A Productive Collaboration, AICPA, New York

Bierstaker, J.L., Bedard, J.C., Biggs, S.F., 1999, The Role of Problem Representation Shifts on Auditor Decision Processes in Analytical Procedures, Auditing: A Journal of Practice and Theory, Vol. 18 No. 1, 1836

Biggs, S.F., Knechel, W.R., Walker, N.R., Wallace, W.A., Willingham, J.J., 1995, Analytical procedures, in: Bell and Wright (1995), Auditing Practice, Research, and Education: A Productive Collaboration, AICPA, New York

Biggs, S.F., Mock, T.J., Watkins, P.R., 1988, Auditor's use of Analytical Review in Audit Program Design, The Accounting Review, Vol. 63 No. 1, 148-161

Biggs, S.F., Mock, T.J., Watkins, P.R., 1989, Analytical Review Procedures and Processes in Auditing, The Canadian Certified General Accountant's Research Foundation

Biggs, S.F., Mock, T.J., Watkins, P.R., 1995, Auditor Judgment Research in Analytical Procedures: Implications for Practice, MARC Working Paper Universiteit Maastricht

Biggs, S.F., Wild, J.J., 1985, An Investigation of Auditor Judgment in Analytical Review, The Accounting Review, Vol. 60 No. 4, 607-633

Blokdijk, J.H., Drieënhuizen, F., Wallage, P. 1995, Reflections on Auditing Theory: A contribution from the Netherlands, Kluwer Bedrijfswetenschappen, Deventer/Limperg Instituut, Amsterdam 
Bonner, S., 1990, Experience Effects in Auditing: The role of task-specific Knowledge, The Accounting Review, Vol. 55 No. 1, 72-92

Bonner, S.E., Lewis, B.L., 1990, Determinants of Auditor Expertise, Journal of Accounting Research, Vol. 28 (Supplement), 1-20

Burns, T., Stalker, G.M., 1961, The Management of Innovation, Tavistock, London

Chandler, A.D., 1962, Strategy and Structure: Chapters in the History of the American Industrial Enterprise, M.I.T. Press, Cambridge, MA

Cohen, J., Kida, T., 1989, The Impact of Analytical Review Results, Internal Control Reliability and Experience on Auditor's Use of Analytical Review, Journal of Accounting Research, Vol. 27 No. 2, 263-276

Committee of Sponsoring Organizations (COSO), 1992, Internal ControlIntegrated Framework, New York

Cooper, D.E., Emory, C.W., 1995, Business Research Methods, Richard D. Irwin Inc., Chicago, $5^{\text {th }}$ edition,

Eimers, P.W.A., Biggs, S.F., Mock, T.J., 1997, Oordeelsvorming bij cijferanalyse: conclusies uit cognitief onderzoek, Maandblad voor Accountancy en Bedrijfseconomie, 171-180

Emmanuel, C., Otley, D., Merchant, K., 1990, Accounting for management control, Chapman and Hall, London, second edition

Hair, J., F. jr, Anderson, R.E., Tatham, E.L., Black, W.C., 1998, Multivariate data analysis, $5^{\text {th }}$ edition, Prentice Hall Inc., New Jersey

Heiman, V.B., 1990, Auditors' Assessments of the Likelihood of Error Explanations in Analytical Review, The Accounting Review, Vol. 65 No. 4, 875-890

Heintz, J.A., White, G.B., 1989, Auditor Judgment in Analytical Review: Some Further Evidence, Auditing: A Journal of Practice and Theory, Vol. 8 No. 2, 22-39 
$172 \mid$ REFERENCES

Heintz, J.A., White, G.B., Bedard J.C., 1999, The effect of data reliability on the influence of unaudited values in audit analytical procedures, International Journal of Auditing, Vol. 3, 135-146.

Hirst, D.E., 1994, Auditors' Sensitivity to Source Reliability, Journal of Accounting Research, Vol. 32 No. 1, 113-126

Hirst, E., Koonce, L., 1996, Audit Analytical Procedures: A Field Investigation, Contemporary Audit Research, Vol. 13 No. 2, 457-486

Houghton, C.W., Fogarty, J.A., 1991, Inherent Risk, Auditing: A Journal of Practice and Theory, Vol. 10 No. 1, 1-21

Hylas, R.E., Ashton, R.H., 1982, Audit Detection of Financial Statement Errors, The Accounting Review, Vol. 57 No. 2, 751-765

International Federation of Accountants (2000), International Standards on Auditing (ISA), New York

Kinney, W.R., 1987, Attention directing analytical review using accounting ratios: A case study, Auditing: A Journal of Practice and Theory, Vol. 6 No. 2, 59-73

Kinney, W.R., Uecker, W.C., 1982, Mitigating the Consequences of Anchoring in Auditor Judgments, The Accounting Review, Vol. 57 No. 1, 55-69

Koninklijk Nederlands Instituut voor Registeraccountants (NIvRA), 2000, Richtlijnen voor de Accountantscontrole, Amsterdam

Koonce, L. 1993, A Cognitive Characterization of Audit Analytical Review: Some Further Evidence, Auditing: A Journal of Practice and Theory, Vol. 12 (Supplement), 57-76

Koonce, L., Phillips, F., 1996, Auditors' Comprehension and Evaluation of Client-Suggested Causes in Analytical Procedures, Behavioral Research in Accounting, Vol. 8, 33-48

Kreutzfeldt, R., Wallace, W., 1986, Error characteristics in audit populations: Their profile and relationship to environmental factors, Auditing: A Journal of Practice and Theory, Vol. 6 No. 2, 20-43 
Lawrence, P.R., Lorsch, J.W., 1967, Differentiation and Integration in Complex Organizations, Administrative Science Quarterly, Vol. 12, 1-47

Libby, R., 1985, Availability and the Generation of Hypotheses in Analytical Review, Journal of Accounting Research, Vol. 23 No.2, 649-667

Libby, R., Frederick, D., 1990, Experience and the ability to explain audit findings, Journal of Accounting Research, Vol. 28 No. 2, 348-367

Maletta, M., Wright, A., 1996, Audit Evidence Planning: An Examination of Industry Error Characteristics, Auditing: A Journal of Practice and Theory, Vol. 15 No. 1, 71-86

Marden, R.E., Holstrum, G.L, Schneider, S.L., 1997, Control Environment Condition and the Interaction Between Control Risk, Account Type and Management's Assertions, Auditing: A Journal of Practice and Theory, Vol. 16 No. 1, 51-68

Mock, T.J., Wright, A.M., 1993, An Exploratory Study of Auditors' Evidential Planning Judgments, Auditing: A Journal of Practice and Theory, Vol. 12 No. 2, 39-61

Mock, T.J., Wright, A.M., 1999, Are Audit Program Plans Risk-Adjusted?, Auditing: A Journal of Practice and Theory, Vol. 18 No. 1, 55-74

Otley, D.T., 1980, The Contingency Theory of Management Accounting: Achievement and Prognosis, Accounting Organizations and Society, 194-208

Public Oversight Board (POB), 2000, The Panel On Audit Effectiveness, report and recommendations, exposure draft

Quadackers, L., Mock, T.J., Maijoor, S.J., 1996, Audit Risk and Audit Programmes: Archival Evidence from Four Dutch Audit Firms, The European Accounting Review, Vol. 5 No. 2, 217-237

Siegel, S., Castellan, N.J. jr, 1988, Nonparametric Statistics for the Behavioral Sciences, second edition, McGraw-Hill, Singapore

Tversky, A., Kahnemann, D, 1974, Judgment under Uncertainty: Heuristics and Biases, Science, Vol. 185, 1124-1131 
174 | REFERENCES

Waller, W.S., 1993, Auditors' Assessments of Inherent and Control Risk in Field Settings, The Accounting Review, Vol. 68 No. 4, 783-803

Webster's Third New International Dictionary of the English language, unabridged, 1986, Encyclopaedia Britannica

Wild, J.J., Biggs, S.F., 1990, Strategic Considerations for Unaudited Account Values in Analytical Review, The Accounting Review, Vol. 65 No. 1, 27-241

Wright, A., Ashton, R., 1989, Identifying audit adjustments with attention directing procedures, The Accounting Review, Vol. 64 No. 3, 710-728

Wright, A., Mock, T.J., 1985, Toward a contingency view of audit evidence, Auditing: A Journal of Practice and Theory, Vol. 5 No. 2, 91-100 


\section{SuMMARY IN DUTCH (NEDERLANDSE SAMENVATTING)}

Dit proefschrift beschrijft de bijdrage die cijferanalyse ('analytical review') levert tot de efficiency van het controleproces alsmede de effectiviteit van cijferanalyse. In hoofdstuk 1 wordt het begrip cijferanalyse geïntroduceerd:

Cijferanalyse is het analyseren van kenmerkende verhoudingscijfers en trends, inclusief het daarop aansluitende onderzoek van fluctuaties en verbanden, die niet overeenstemmen met andere relevante gegevens of afwijken van verwachte bedragen/hoeveelheden (ISA 520, par. 3).

De motivatie om een onderzoek uit te voeren naar cijferanalyse komt voort uit de voortdurende aandacht in de afgelopen decennia van zowel accountants als onderzoekers voor dit controlemiddel. Zo publiceerde de Public Oversight Board in 2000 een rapport, waarin de belangrijke bijdrage van cijferanalyse tot de effectiviteit van het controleproces werd benadrukt. In dat rapport werd aanbevolen dat accountants meer getraind moeten worden bij het uitvoeren van cijferanalyse om zo de effectiviteit ervan te verbeteren.

De drie primaire onderzoeksvragen die in hoofdstuk 1 worden geïntroduceerd, zijn:

(a) Op welke wijze draagt cijferanalyse bij tot het signaleren van fouten in de jaarrekening?

(b) Op welke wijze draagt cijferanalyse bij tot de efficiency van het controleproces?

(c) Hoe beïnvloedt het ontwikkelen van verwachtingen de effectiviteit van cijferanalyse?

In deze studie wordt onderscheid gemaakt tussen het signaleren en detecteren van fouten. Onder signaleren wordt verstaan het initieel identificeren van een onverwachte fluctuatie waarvan de accountant het vermoeden heeft dat het een fout kan bevatten. Onder detecteren wordt verstaan de definitieve vaststelling dat een onverwachte fluctuatie wordt veroorzaakt door een fout.

Er zijn in dit proefschrift twee belangrijke groepen van contingente variabelen gehanteerd die de bijdrage van cijferanalyse tot het signaleren en detecteren van fouten mogelijk beïnvloeden: opgebouwde kennis ('cumulative knowledge') van de cliënt en risico analyse ('risk assessment'). Professionele 
standaarden benadrukken het belang van deze beide groepen in de planningsfase van de jaarrekeningcontrole ('audit').

De opgebouwde kennis over de cliënt is opgebouwd gedurende de huidige audit en audits uit voorafgaande jaren door het (huidige en voormalige) controleteam. De opgebouwde kennis is van belang voor het doorgronden van de business en het financiële systeem van de cliënt alsmede voor het inschatten van risico's en materialiteit in de jaarekening.

Risico analyse heeft betrekking op de inschatting van inherente en fraude risico's en op het financiële en interne beheersingssysteem, waaronder de controleomgeving ('control environment').

In hoofdstuk 2 wordt een literatuuroverzicht gepresenteerd waarin het gebruik en effectiviteit van cijferanalyse door accountants wordt beschreven. Ondanks de relatief eenvoudige techniek van cijferanalyse, is het uiteindelijk een ingewikkeld beslissingsproces. Eerder uitgevoerde studies hebben aangetoond dat de opgebouwde ervaring van de accountant, als surrogaat voor expertise, een indicatie is van de kwaliteit van de toegepaste cijferanalyse. Hierbij wordt opgemerkt dat ervaring in eerdere studies zich heeft beperkt tot generieke ervaring en branchespecifieke ervaring van de betreffende accountant. In de eerdere studies was er geen informatie beschikbaar over cliëntspecifieke ervaring en het aantal jaren dat het accountantskantoor de cliënt kent. Deze twee laatste aspecten van ervaring worden nader onderzocht in deze studie.

Uit eerdere studies is tevens gebleken dat er slechts een beperkte relatie zichtbaar is tussen risico analyse en keuzes in de controleplanning. Er bleek wel dat accountants gevoelig zijn voor veranderingen in risico profielen, maar dat er slechts beperkte documentatie beschikbaar is over de in dit proefschrift onderzochte relatie tussen de risico analyse en de bijdrage van cijferanalyse in het signaleren van fouten. In deze studie wordt een nieuw element van risicoinschatting gehanteerd: de controleomgeving. De introductie van controleomgeving als element van risico analyse reflecteert de relevantie van controleomgeving zoals dat is geïntroduceerd in het COSO rapport.

Daarnaast is in eerdere studies het belang van het ontwikkelen van verwachtingen benadrukt ('toetsen aan de norm') bij het uitvoeren van cijferanalyse. Experimenteel onderzoek toont aan dat accountants het risico lopen te worden beïnvloed ('biased') door onjuiste representaties van de cliënt en door fouten in de te controleren cijfers. Aangezien voorgaand onderzoek met name was gebaseerd op experimentele situaties, is de huidige studie vernieuwend omdat het de effecten van het ontwikkelen van verwachtingen in een praktijksituatie onderzoekt. 
In hoofdstuk 3 zijn de primaire onderzoeksvragen nader uitgewerkt in secundaire onderzoeksvragen. Drie ratio's zijn ontwikkeld om de bijdrage van cijferanalyse voor de efficiency van het controleproces en de effectiviteit van cijferanalyse te meten. De eerste ratio, de 'signaling ratio' meet de bijdrage van cijferanalyse tot het signaleren van fouten. De tweede ratio, de 'non-signaling ratio' meet de potentiële bijdrage van cijferanalyse tot de efficiency van het controleproces. De derde ratio, de 'non-detection ratio' meet het detecteren van fouten nadat de fout is gesignaleerd door cijferanalyse.

Hoofdstuk 4 beschrijft de opzet van het uitgevoerde onderzoek. Het onderzoek betreft een archiefstudie bij een van de 'Big Four' accountantskantoren in Nederland. In dit onderzoek zijn 147 controleopdrachten betrokken met betrekking tot het jaar 1997. De gegevens zijn verzameld in de eerste helft van 1998. Vragenlijsten werden verspreid onder 184 audit managers op willekeurig geselecteerde opdrachten. De vragenlijst bevatte algemene vragen over de opdracht, zoals de controleomgeving en de inschatting van inherente risico's en interne controle risico's. Daarnaast bevatte de vragenlijst gedetailleerde vragen met betrekking tot individuele fouten, zoals het aantal en omvang van de fouten, de betreffende posten in de jaarrekening en het controlemiddel dat de fout identificeerde. De response rate was hoog $(79,9 \%)$. Dit werd positief beïnvloed door het gecombineerde effect van betrokkenheid van het beroepsgroepbestuur van het accountantskantoor alsmede de mogelijkheid om direct contact te hebben met de participanten.

De beschrijvende statistieken worden gepresenteerd in hoofdstuk 5. In de 147 controleopdrachten hebben de participanten 624 fouten ontdekt, variërend van 0 tot een maximum van 8 per dossier. Van alle fouten werd $20,5 \%$ gesignaleerd door cijferanalyse. De bijdrage van cijferanalyse in het signaleren van fouten varieerde met de grootte van de geconstateerde fout. De bijdrage van relatief eenvoudig uit te voeren controlemiddelen -hiertoe behoren cijferanalyse, discussies met de cliënt en opgebouwde verwachtingen uit voorgaand jaar- is positief gerelateerd aan de grootte van de fout. Hoe groter de fout, hoe groter de kans dat eenvoudige controlestappen de fout signaleren.

'Prefinal audit procedures' zijn geïntroduceerd als een controlevariabele in de statistische analyses. Zij hebben de functie van een 'early warning' systeem en worden vaak gebruikt bij controles die op verschillende locaties wordt uitgevoerd, zoals bij multinationals. Alle lokale audit teams rapporteren de voorlopige controlebevindingen aan de cliënt en het centrale audit team. Deze rapportage bevat onder andere de geconstateerde fouten in de tussentijdse cijfers die moeten worden opgelost voor het einde van het boekjaar om zo te 
voorkomen dat er aanpassingen in de jaarcijfers moeten plaatsvinden. 'Prefinal audit procedures' worden in dit onderzoek gebruikt als variabele omdat het uitvoeren van prefinal audit procedures van invloed kan zijn op de bijdrage van cijferanalyse tot het signaleren van fouten. De timing, aard en omvang van gebruikte controleprocedures kan namelijk variëren tussen audits waar wel of geen prefinal audit procedures worden toegepast.

De beschrijvende statistieken geven aan dat de eerder genoemde aspecten van opgebouwde kennis (namelijk het aantal jaren van de audit-relatie en de cliëntspecifieke ervaring van de audit manager) positief gerelateerd zijn aan de bijdrage van cijferanalyse in het signaleren van fouten.

De beschrijvende statistieken geven ook aan dat de bijdrage van cijferanalyse in het signaleren van de fouten niet significant is gerelateerd aan de risico-inschatting, namelijk van de controleomgeving en het interne controle risico. Deze laatste bevinding is consistent met eerder uitgevoerde studies die de relatie tussen risico analyse en opvolgende controlewerkzaamheden onderzochten. De beschrijvende statistieken geven ook aan dat het uitvoeren van prefinal audit procedures de bijdrage van cijferanalyse tot het signaleren van fouten negatief beïnvloedt.

In het resterende deel van hoofdstuk 5 zijn de signaling ratio, de non-signaling ratio en de non-detection ratio uitgewerkt in relatie tot de onafhankelijke variabelen van opgebouwde kennis en risico-inschattingen. De beschrijvende statistieken geven aan dat in $55 \%$ van de onderzochte opdrachten, één of meer fouten met cijferanalyse zijn gesignaleerd. Daarnaast blijken de aspecten van opgebouwde kennis significant te zijn gerelateerd aan de signaling ratio, terwijl dit verband tussen de risico-inschattingen en de signaling ratio niet zichtbaar is.

Verdere analyses inzake de non-signaling ratio tonen aan dat in $46 \%$ van de opdrachten de audit manager aangaf dat één of meerdere fouten die thans door een andere controlemiddelen waren ontdekt, ontdekt hadden kunnen worden met cijferanalyse.

In slechts 5 gevallen werd de met cijferanalyse ontdekte fluctuatie niet direct als een fout onderkend, terwijl deze wel aanwezig was. Deze fout werd in een latere fase van de controle met een ander controlemiddel alsnog ontdekt. Op basis van dit onderzoek blijkt niet dat het starten met representaties van de cliënt een positief dan wel negatief effect heeft op de effectiviteit van cijferanalyse.

De multivariate analyses in hoofdstuk 6 richten zich op de twee primaire onderzoeksvragen met betrekking tot de efficiency van het controleproces. De multivariate analyses zijn uitgevoerd met een multiple regressiemodel waarbij de signaling ratio respectievelijk de non-signaling ratio als afhankelijke 
variabelen zijn gebruikt. De opgebouwde kennis en de risico-inschattingen zijn als onafhankelijke variabelen gebruikt. Prefinal audit procedures zijn gebruikt als controle variabele.

De resultaten uit de multivariate analyses met betrekking tot de signaling ratio tonen aan dat deze ratio significant is gerelateerd aan het aantal jaren dat het accountantskantoor de cliënt kent, aan de cliëntspecifieke ervaring van de manager en aan de aanwezigheid van prefinal audit procedures. $\mathrm{Er}$ is een nietsignificante relatie met het interne controle risico en de kwaliteit van de controleomgeving.

De resultaten uit de multivariate analyses met betrekking tot de nonsignaling ratio tonen aan dat deze ratio significant is gerelateerd aan het aantal jaren dat het accountantskantoor de cliënt kent, aan de cliëntspecifieke ervaring van de manager en aan de aanwezigheid van prefinal audit procedures. Er is een marginaal significante relatie met het interne controle risico en een nietsignificante relatie met de kwaliteit van de controleomgeving.

In hoofdstuk 7 worden de resultaten nader bediscussieerd en zijn mogelijke implicaties voor de accountantspraktijk en audit research geschetst. Ten eerste kan worden gesteld dat de efficiency van het controleproces kan worden bevorderd als het audit team meer opgebouwde kennis heeft en deze kan gebruiken in het controleproces. Snelle teamwisselingen kunnen een negatief effect hebben op de kracht van cijferanalyse. Ten tweede geven de onderzoeksresultaten aan dat bij opdrachten waarbij de manager lang betrokken is, er nog steeds mogelijkheden zijn om meer fouten te signaleren met cijferanalyse. Dit duidt erop dat audit teams er verstandig aan doen om bij de jaarlijkse evaluatie van de opdracht na te gaan of de aard en omvang van controlestappen in de opvolgende audit moeten worden aangepast aan de nieuw opgedane kennis.

Uit eerdere veldstudies bleek dat er geen significante relatie was gevonden tussen risico-inschattingen en de aard en omvang van controleprocedures. De huidige onderzoeksresultaten met betrekking tot de effecten van risicoinschattingen op het signaleren van fouten door cijferanalyse bevestigen de uitkomsten van voorgaand onderzoek.

Het in de huidige studie toegevoegde element van de kwaliteit van de controleomgeving geeft, ondanks de niet-significante resultaten in de multivariate analyses, enkele relevante observaties voor de accountants in de praktijk. Ten eerste blijkt dat de kwaliteit van de controleomgeving een verklarende factor is voor het aantal ontdekte fouten in een jaarrekening. Ten tweede bevestigen de huidige empirische resultaten de moeilijkheid van het vertalen van risico-inschattingen naar de aard en omvang van uit te voeren controlewerkzaamheden. Accountants wordt daarom aanbevolen de kwaliteit 
van de controleomgeving expliciet te evalueren voordat de verdere controlewerkzaamheden worden uitgevoerd.

De bevindingen inzake de effectiviteit van cijferanalyse geven niet aan dat representaties van de cliënt een negatief effect hebben op het detecteren van fouten. Hierbij zij opgemerkt dat de in het huidige onderzoek opgenomen analyses een verkennend karakter hebben als gevolg van het ontbreken van voorgaand veldonderzoek met betrekking tot de effecten van representaties van de cliënt op de effectiviteit van cijferanalyses. Verdere onderzoeksinspanningen zijn noodzakelijk om mogelijke positieve en negatieve effecten van het gebruik van representaties van de cliënt op de effectiviteit van cijferanalyses te meten. Accountants wordt aangemoedigd een sceptische houding te (blijven) houden inzake de bewijskracht en plausibiliteit van de door de cliënt verstrekte documentatie en verklaringen. Een adequate documentatie en evaluatie van deze 'evidence' kan tevens de opgebouwde kennis van huidige en toekomstige leden van het audit team bevorderen. 


\section{Curriculum Vitae}

Peter W.A. Eimers (1968) studied Business Administration at Universiteit Maastricht (1992) and Fiscal Economics at Katholieke Universiteit Brabant, Tilburg (1993). During 1992-1993 he followed the post-graduate auditing program at Universiteit Maastricht, and qualified as a registered accountant. He has been working for PricewaterhouseCoopers since 1992 in several offices in The Netherlands. Currently he is a senior manager in the Assurance and Business Advisory Services business unit of the Utrecht office. 
